$10.42 x y=0$

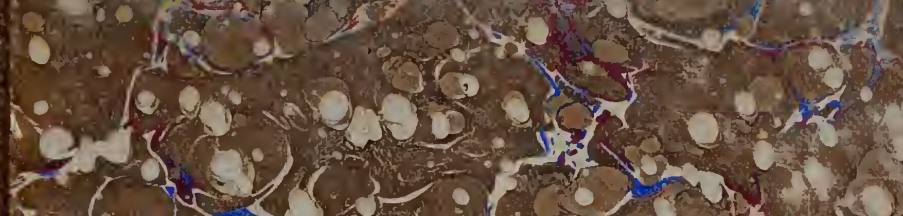

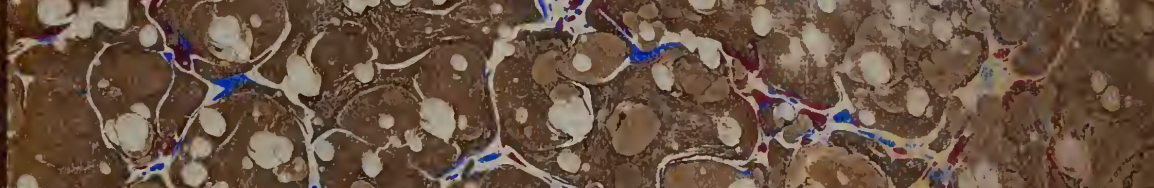

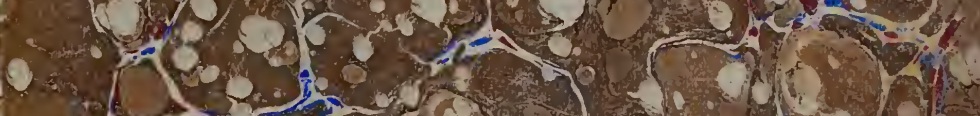

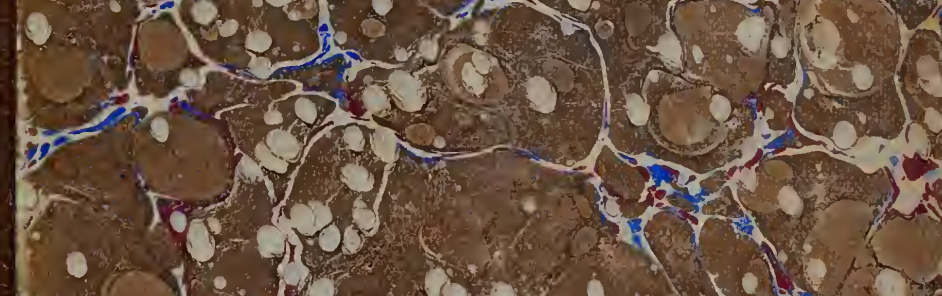
10.

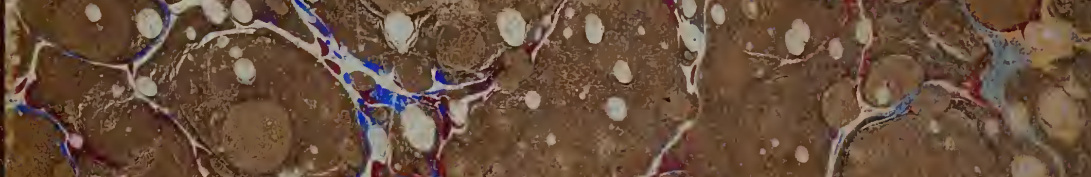

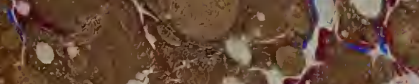

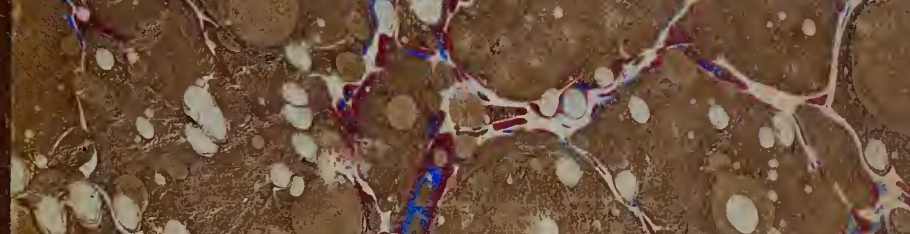
1)

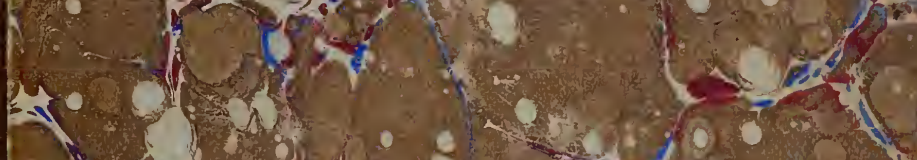

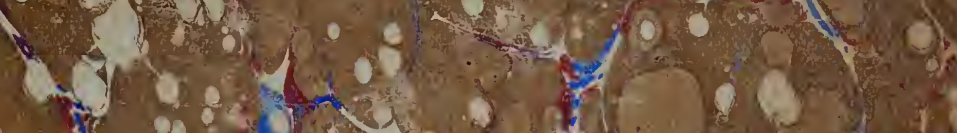

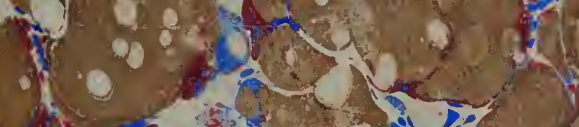

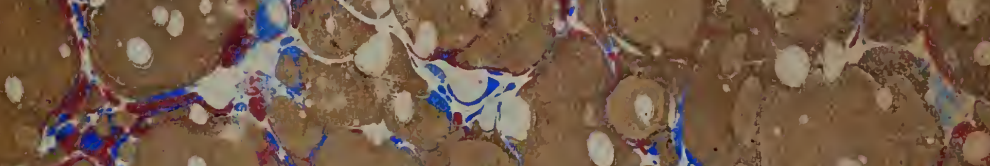
$600^{\circ}+10$ Tom: $x+1$ 


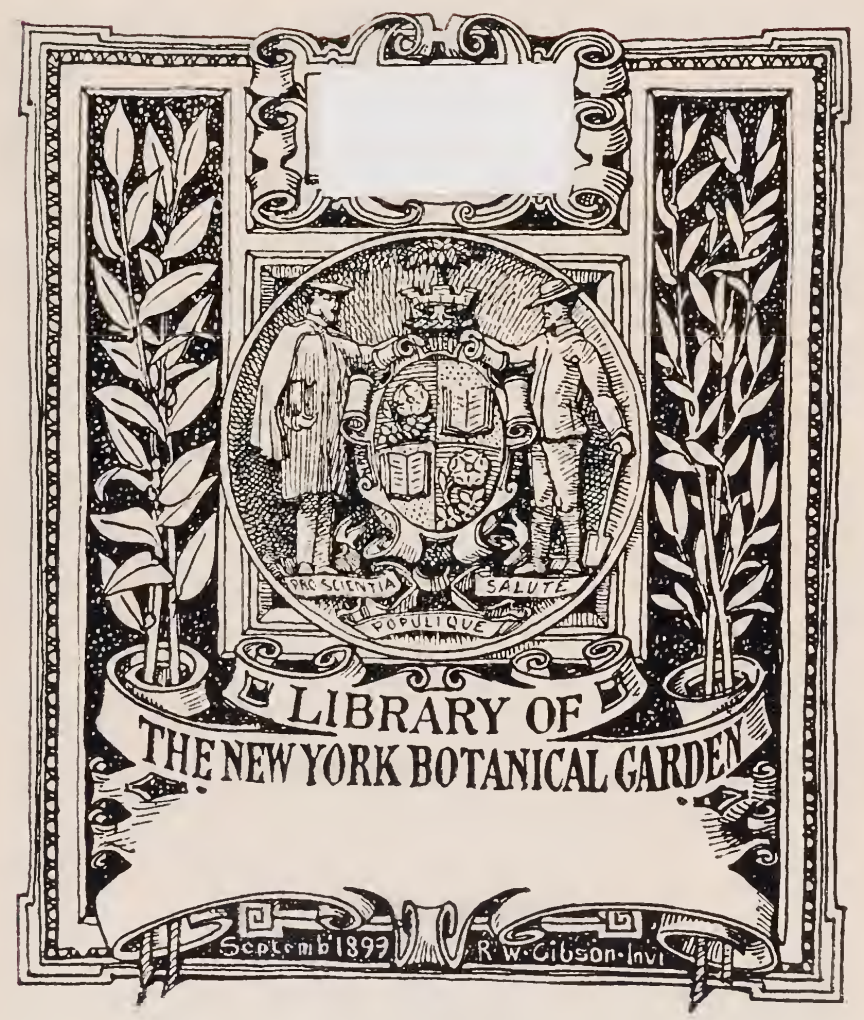






\section{DIE STELÄR-THEORIE.}

Von

DR. J, G. Sohoute,

AS:INTENT AM BOTANISCHEN INSTITUT DER REICHSUNIVERSITÄT GRONINGEN

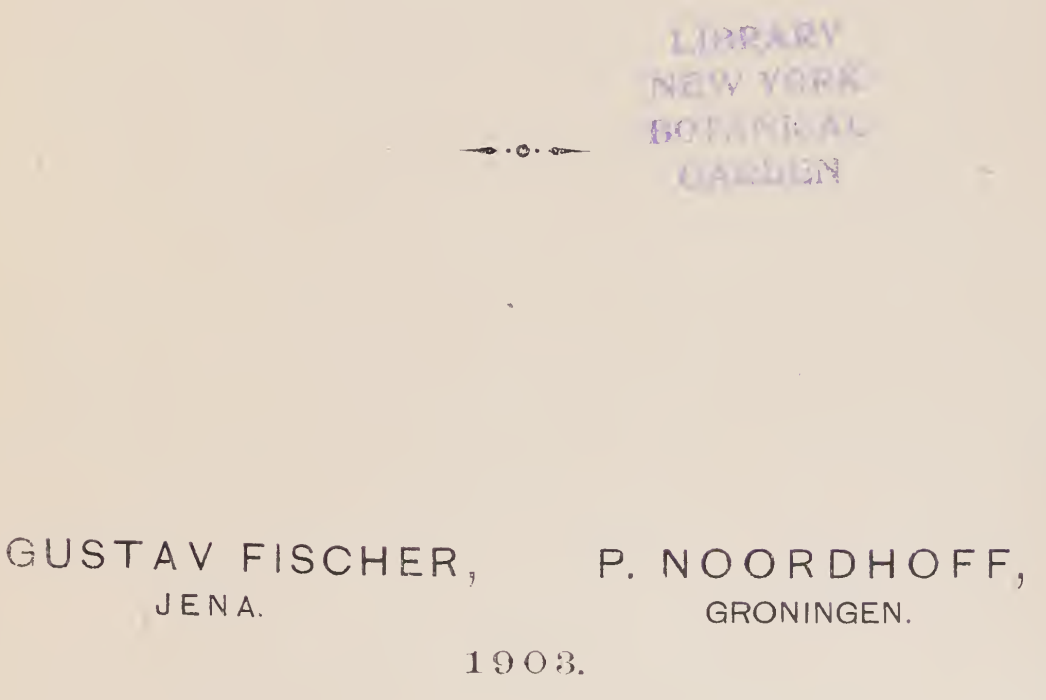

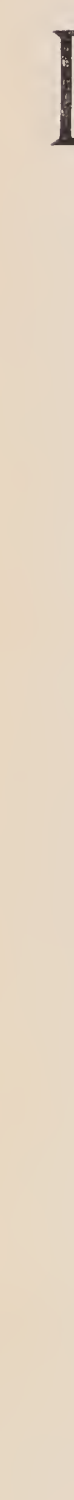

A 


$$
\begin{aligned}
& Q K \\
& 646 \\
& .534 \\
& 1903
\end{aligned}
$$




\section{INHALTSÜBERSICHT.}

\section{LIBRARY}

WEW YORIC

GARLBN

Seite.

Einleitung, zugleich Übersicht über die Stelär-Theorie 1.

\section{ERSTER TEIL.}

\section{DIE STELÄR-THEORIE UND DIE ENTWICKLUNGSGESCHICHTE.}

I. Kapitel. Tatsächliches über die Gewebesonderung in Dermatogen, Periblem und Plerom. Kritische Literaturbesprechung . . . . . . . . . . .

9.

$\S 1$. Die Entwicklung des Embryos aus der Eizelle und die ersten morphologischen Differenzierungen

$\S 2$. Die Entwicklung der Gewebe von Stengel und Wurzel aus dem Vegetationskegel . . . . . 14.

I. Gefässkryptogamen . . . . . . . 14.

II. Phanerogamen . . . . . . . . . . 16.

1. Das Spitzenwachstum der Wurzel . . . 17.

2. Das Spitzenwachstum des Stengels . . 20.

§ 3. Die Anlage seitlicher Organe . . . . . . 30.

§ 4. Zusammenfassung der in diesem Kapitel be sprochenen Tatsachen . . . . . . . . . 33.

II. Kapitel. Die Übereinstimming zwischen den primären Geweben Hansteins und denjenigen VAN Tieghams .

$\S 1$. Literaturgeschichte

34.

$\S 2$. Eigene Untersuchung. . . . . . . . . . 45.

A. Untersuchungen an Wurzeln. . . . . . . 45.

1. Methodisches . . . . . . . . . . 45.

2. Hyacinthus orientalis . . . . . . . 52.

3. Helianthus annuus . . . . . . . . 55.

4. Linum usitatissimum . . . . . . . 62.

5. Ficaria ranunculoides . . . . . . . 62. 
Seite.

B. Untersuchungen an Stengeln . . . . . . 64.

1. Methodisches . . . . . . . . . . 64.

2. Hippuris vulgaris . . . . . . . . 68.

3. Aesculus Hippocastanum . . . . . . 84.

4. Lysimachia Ephemerum . . . . . . . . 86.

5. Evonymus europaeus . . . . . . . . . 86.

6. Ajuga reptans . . . . . . . . . 86.

7. Elodea canadensis . . . . . . . . 86.

§ 3. Zusammenfassung und Diskussion der Ergebnisse der Untersuchungen über das Spitzenwachstum. . 90.

\section{ZWEITER TEIL.}

. OIE STELÄr-THEORIE URD DIE VERGLEICHENDE ANATOMIE.

III. Kapitel. Die Grenze zwischen Rinde und Centralcylinder . . . . . . . . . . . . . 94.

1. Gymnospermen . . . . . . . . . 99

2. Monokotyledonen . . . . . . . . 101.

3. Dikotyledonen . . . . . . . . . . 108.

IV. Kapitel. Vergleichende Anatomie des Stengels der junge Planze . . . . . . . . . . . 132

$\mathrm{V}$. Kapitel. Allgemeine Betrachtungen und Folgerungen

Zusammenfassung der Ergebnisse und Folgerungen . . 163.

Verzeichnis der benutzten Literatur . . . . . . 164

ERRATA:

S. 25, Zeile 9 von unten ist zwischen den Klammern zu setzen: 8 .

S. 43 , Zeile 2 und 9 von oben: 150 lies: 153. 


\section{DIE STELÄR-THEORIE.}

EINLEITUNG, ZUGLEICH ÜBERSICHT ÜBER DIE STELÄR-THEORIE.

Von den französischen Anatomen wird nach dem Vorgang VAN TIEghems jetzt allgemein die Einteilung der primären Gewebe der Phanerogamen und der Gefässkryptogamen in Wurzel, Stengel und Blatt in drei gleichwertige Unterteile angenommen, nämlich in Epidermis, Rinde und Centralcylinder oder Stele. Auch ausserhalb Frankreichs kommt diese Einteilung mehr und mehr in Gebrauch, und die ältere Auffassung von SAcHS, welche die Gewebe in Hautgewebe, Grundgewebe und Fibrovasalstränge teilte, wird immer mehr durch die VAN Treaneusche verdrängt. Das allein weist schon auf die grosse Bedeutung dieser Einteilung hin; und tatsächlich hat sie sich sowohl wissenschaftlich wie praktisch als zutreffend bewährt. Die praktische Bedeutung derselben erfährt ein jeder, sobald er sie bei anatomischen Arbeiten den Beschreibungen mikroskopischer Strukturen zu Grunde legt; sie wird dabei zu einem bald unentbehrlichen Hilfsmittel.

Über die wissenschaftliche Bedeutung dieser Einteilung haben die verschiedenen Forscher bis jetzt noch nicht einig werden können. Namentlich in England und in Amerika, wo in letzter Zeit zahlreiche Abhandlungen über die Stelär-Theorie, wie 
die Ansicht Van Tieghems dort genannt wird, erschienen sind, hat man verschiedene Ergänzungen und Abänderungen zu diesen Auffassungen vorgeschlagen. Wohl lässt sich heute schon feststellen, dass diese Ansichten theoretisch jedenfalls wichtig sein müssen. Weil ihre Begründung aber noch nicht in jeder Hinsicht gelungen ist, so sind weitere Untersuchungen über dieselbe noch sehr erwünscht.

Aus diesem Grunde habe ich auch die folgenden Untersuchungen unternommen; aus ihnen wird sich, wie ich hoffe, aufs neue ergeben, dass Van Tieghem in der Begründung seiner Theorie eine sehr wertvolle Arbeit geliefert hat.

Betrachten wir zuerst die Einteilung etwas näher, unủ zwar in der Form, wie Van Tregrem sie vorträgt. (101) ${ }^{1}$ ) Auf die kritische Beurteilung derselben komme ich unten noch zurück.

Wir haben also bei Gefäss-Kryptogamen und bei Phanerogamen, in Blatt, Stengel und Wurzel, Epidermis, Rinde und Centralcylinder zu unterscheiden.

Die Epidermis überzieht alle Organe der Pflanze mit einer einfachen Zellschicht. Nur in wenigen Fällen wird sie zusammengesetzt, mehrechichtig, z. B. in Blatt und Stengel von vielen Arten der Gattungen Begonia, Peperomia, Ficus.

Auch kann nach Van Tieghem die Epidermis ganz fehlen, wie bei den Gefässkryptogamen und in den Wurzeln der Monokotylen und der Nymphateaceen. Die äussere Rindenschicht übernimmt dann in den Wurzeln ihre Funktion als „assise pilifère", (wurzelhasitreibende Schicht), in den Stengeln als schützende Hülle; sie wird der gewöhnlichen Epidermis ganz ähnlich. Dass sie aber dennoch die äussere Rindenschicht ist, schliesst Van Tieghem auf Grund der Entwicklungsgeschichte.

1) Diese Zahlen beziehen sich auf das Literaturverzeichnis. 
Die Rinde besteht aus mehreren Zelllagen, welche gewöhnlich parenchymatisch sind. Die äusserste Rindenschicht ist oft noch besonders ausgebildet, in Blatt, Stengel und Wurzel. Daher hat Vuillemin (69) vorgeschlagen, diese Schicht mit dem besonderen Namen Exodermis (exoderme) zu bezeichnen.

Noch mehr aber als die Exodermis trägt die innerste Rindenschicht einen besonderen Charakter, die Endodermis, wie Van Treghem sie nennt. Diese Endodermis ist in den Wurzeln als Schutzscheide ausgebildet, in den Stengeln entweder als Schutzscheide oder als Stärkescheide, als Zuckerscheide oder als Parenchymscheide.

Gewöhnlich führt die Rinde keine eigenen Gefässbündel. In den Stengeln durchziehen aber die "Blattspuren” die Rinde, diese durchlaufen bisweilen mehrere Internodien in der Rinde, bevor sie in den Centralcylinder eintreten.

Der Centralcylinder bildet den dritten und meist komplizierten Teil des Pflanzenkörpers. An seinem Aussenrande befindet sich der Pericykel, (44) eine ein- bis mehrschichtige Gewebezone, welche meist parenchymatisch ist, öfters auch, zumal im Stengel, Sklerenchym führt. Sie ist die Bildungsstätte mancher Neubildungen (Kork, Nebenwurzeln, Adventivknospen). Nach der Beschaffenheit des Pericykels unterscheidet Мовот (52 S. 229, 231, 233), der den Pericykel zuerst genau untersucht hat, die Formen des Péricycle homogène, Péricycle hétérogène und Péricycle incomplet. Der homogene Pericykel ist von einem einzigen Gewebe gebildet, der heterogene aus mehreren, der unvollständige ist an einzelnen Stellen unterbrochen.

Innerhalb des Pericykels finden sich die Gefässbündel oder in den Wurzeln die Gefässstränge, in einem Kreise oder in mehreren (Monokictylen). Zwischen diesen Bündeln 
finden sich parenchymatische Gewebestreifen, die sogenannten Markverbindungen, während der innere parenchymatische Teil des Centralcylinders das Mark bildet. Pericykel, Markverbindungen und Mark stellen zusammen das Konjonktiv des Centralcylinders dar. Von L. FLOT ist noch vorgeschlagen worden, den äusseren Teil des Míarkes im Stengel als „Zone périmédullaire" dem Pericykel gegenüberzustellen. (109).

Das hier gegebene allgemeine Schema des Centralcylinders erleidet inzwischen bei verschiedenen Pflanzen nicht unerhebliche Abänderungen.

Erstens fehlt der Pericykel in einigen Fällen ganz: Wurzel der Equiseten, dünne Stengel einiger Wasserpflanzen (Salvinia, Azolla, Ceratophyllum); dagegen in der Wurzel der Gramineen und einiger anderen Familien (VAN Tieghem 75 S. 315) an bestimmten Stellen, nämlich gegenüber den Xylemteilen. Das Mark fehlt häufiger, im Stengel sowie in der Wurzel.

Weitaus die wichtigsten Abänderungen, welche den Centralcylinder betreffen, sind aber diejenigen Fälle welche von VAN Tieghem als A stelie und Poly stelie (67) bezeichnet werden.

Bei der Astelie ist der Centralcylinder "zerrissen”, wie VAN Tieghem es nennt. Die Gefässbündel sind je von einer besonderen Endodermis und einem pericykelartigen Gewebe umgeben. Dieses Gewebe bekommt hier aber den Namen Peri(ies m, weil "Pericykel” immer einen Teil des Centralcylinders bezeichnet (87 S. 434). Markverbindungen und Mark sind nicht mehr zu unterscheiden.

Diese Anordnung der Elemente findet sich in einigen Stengeln (Nuphar und einige andere Nymphaeaceen, Hydrocleis Humboldtii, viele Ranunculaceen) in den meisten Blattstielen und in allen Blattscheiben (ausgenommen die der Koniferen). 
Die Polystelie dagegen ist derjenige Fall, wo statt eines Centralcylinders viele im Stengel vorhanden sind. Jede Stele hat dann seine eigene Endodermis und seinen Pericykel. Der Unterschied zwischen diesem und dem vorhergehenden Fall liegt in der Anordnung der Gefässelemente, welche hier in jeder Stele konzentrisch ist; um ein zentrales Xylem sind mehrere Phloembündel in einem Kreise gelagert. Bisweilen ist sogar ein Mark in jeder Stele anwesend. Die Polystelie findet sich nach VAN TIEghem in Stengeln bei Gunnera, Auricula und den Farnen, im Blattstiele bei Gunnera, und in einigen Wurzeln [Leguminosen- (71) und Cycadeenwurzelknollen].

Von diesen Verhältnissen der Polystelie und Astelie gibt es noch wieder einige Komplikationen. In beiden Fällen können nämlich die einzelnen Stelen oder Gefässbündel, welche immer mit einander anastomosieren, mehr oder weniger zusammenfliessen. Wenn ein solches Verwachsen sehr weit geht, gibt Van Tieghem dieser Struktur den Namen Gamostelie (68) oder Gamodesmie (87); ersteren wenn Stelen verwachsen, letzteren wenn Gefässbündel ( $\delta \varepsilon \sigma \mu \eta=$ Bündel) verwachsen. Diejenigen Fälle, bei denen ein Verwachsen nicht stattfindet, werden dagegen zur Unterscheidung Dialystelie und Dialydesmie genannt. So weit VAN Tieghem.

Von STRASBURGFR sind in seinen Leitungsbahnen (98 S. 310) einige andere Bezeichnungen vorgeschlagen. Statt des Namens Endodermis wählt er für die innerste Rindenschicht die Bezeichnung Phloe oterma, während er den Namen Endodermis nur auf die Schutzscheide Casparys anwenden will. Auf diese Weise wird der Name Endodermis wieder in demselben Sinne gebraucht, wie es schon von DE BARY in seiner Vergleichenden Anatomie geschah. Im folgenden werde ich mich dieser Strasburgerschen Nomenklatur nicht bedienen. Das Wort 
Endodermis bezeichnet bei VAx TIEGHem genau dasselbe, was bei Strasburger Phloeoterma heisst: die innerste Rindenschicht. Das Wort aus historischen Gründen wieder auf die Schutzscheide anzuwenden hätte keinen Zweck, und wäre dazu noch inkonsequent; denn wenn man historisch verfahren wollte, sollte man das Wort Endodermis auf die Exodermis in den Orchideenwurzeln anwenden, wio es von Oudemans, von dem dieses Wort herstammt, geschah (2 S. 9).

Ich werde also stets unter Endodermis nur die innere Rindenschicht verstehen, deren besondere Formen aber mit Stärkescheice, Schutzscheide u. s. w. bezeichnen. Weiter will Strasburger den Namen Astelie ändern in Schizostelie. (98 S. 312). Hierauf komme ich später noch zurück.

Für denjenigen, der diese Einteilung der pflanzlichen Gewebe annimmt, taucht alsbald die Frage auf: Wie steht es mit der Entwicklung dieser Gewebe aus den verschiedenen Meristemen des Embryos und des Vegetationkegels?

Wenn dieser morphologischen Einteilung eine hohe phylogenetische Bedeutung zukommt, wie es nach dem vorhergehenden wohl wahrscheinlich ist, wird sich dasselbe dann auch aus der Embryologie ergeben? Denn in vielen Fällen ist diese ja noch immer ein sehr wichtiges Hilfsuittel, um die morphologische Bedeutung eines gegebenen Gebildes zu erklären. Mag das "biogenetische Grundgesetz" in seiner Bedeutung: manchmal auch überschätzt werden, so gibt es doch viele Fälle, in denen nur die Entwicklungsgeschichte die richtige Deutung zu geben vermag.

Es fragt sich also in concreto: Muss die Stelär-Theorie auch entwicklungsgeschichtlich geprüft werden? Diese Frage muss meines Erachtens entschieden bejaht werden. Wenn wirklich der gegebenen Gewebeeinteilung eine phylngenetische Bedeutung 
zukommt, so ist es von vornherein nicht ausgeschlossen, dass in den pflanzlichen Bildungsgeweben dieselbe Sonderung schon früh zu Tage tritt, bevor noch andere Differenzierungen stattfinden. Nun findet sich aber ja tatsächlich in den pflanzlichen Meristemen öfters eine Gewebesonderung, die von Hanstein zuerst beschrieben worden ist, diejenige in Dermatogen, Periblem und Plerom. Wir finden diese sowohl in den Vegetationspunkten als in den Embryonen der Pflanzen teilweise oder vollständig durchgeführt. Es liegt also nahe die Beziehungen zwischen diesen beiden Einteilungen etwas genauer zu untersuchen.

Dass diese Frage eine sehr berechtigte ist, geht schon aus der grossen Zahl von Forschern hervor, welche sie tatsächlich schon gestellt hat. Die Hansteinsche Einteilung, welche stets viel Widerspruch gefunden hat, aber vielleicht noch mehr Anerkennung, hat jedenfalls die Aufmerksamkeit der Forscher von jeher sehr in Anspruch genommen, und wiederholt hat man es versucht, die Frage zu lösen, in welcher Beziehung diese Sonderung zu der späteren Verteilung der Gewebe von Stengel und Wurzel stand. Zu einer endgültigen Lösung ist man dabei jedoch nicht gelangt: und zwar deshalb nicht, weil in dieser Hinsicht eine genaue Untersuchung niemals unternommen wurde; die meisten Forscher haben sich, wie wir unten sehen werden, auf die Fragestellung und auf Behauptungen, denen nur wenige fragmentarische Beobachtungen zu Grunde lagen, beschränkt. Die Zahl der Forscher, welche die Hansteinsche mit der Van Tieghemschen Einteilung identifizieren, hält sich darum auch so ziemlich das Gleichgewicht mit der Zahl derjenigen, welche die Behauptung geäussert haben, dass diese zwei Sonderungen durchaus unabhängig seien und oft nicht korrespondieren. 
Es war nach dem Gesagten also für die Stelär-Theorie von grundlegender Bedeutung, eine möglichst eingehende Untersuchung nach der Beziehung zwischen der Hansteinschen und der Van Tieghemschen Einteilung anzustellen. Als Resultat dieser Untersuchung hat sich zweierlei ergeben. Erstens, dass bei denjenigen untersuchten Wurzeln, wo eine Differenzierung in Periblem und Plerom tatsächlich vorhanden war, die Grenze zwischen diesen beiden die nämliche war wie die spätere zwischen Rinde und Centralcylinder. Bei denjenigen Stengeln aber, wo eine Differenzierung in der Spitze auftrat, stimmte diese gewiss nicht mit der späteren überein.

Dieser Unterschied lässt sich meines Erachtens, wie man sehen wird, nur erklären durch die Annahme, dass der Hansteinschen Einteilung ein besonderes Gewicht nicht beizumessen ist.

Dagegen werden wir weiter sehen, dass der Van Tieghemschen Einteilung, ungeachtet dieses Ergebnisses, dennoch eine hohe phylogenetische Bedeutung unbedingt zugesprochen werden muss. 


\section{ERSTER TEIL.}

DIE STELÄR-THEORIE UND DIE ENTWICKLUNGSGESCHICHTE.

\section{KAPITEL.}

Tatsächliches über die Gewebesonderung der Meristeme in Dermatogen, Periblem und Plerom. Kritische Literaturbesprechung.

Die Einteilung in Dermatogen, Periblem und Plerom in den pflanzlichen Meristemen ist in den 30 Jahren, die seit ihrer Begründung von Hanstein verflossen sind, den verschiedensten Beurteilungen anheim gefallen. Während ihr Wert von einigen Autoren sehr übertrieben ist, haben andere ihr tatsächliches Bestehen sogar geleugnet. Wenn wir also den Wert dieser Einteilung als Basis für die Stelärtheorie untersuchen wollen, müssen wir uns zuerst bemühen, die tatsächlichen Verhältnisse, auf denen sie begründet ist, aus der Literatur genau kennen zu lernen. Diese Literaturbesprechung zerfällt naturgemäss in drei Abschnitte, in denen wir das Auftreten der Gewebesonderung im Embryo, in den Vegetationskegeln und in den neugebildeten Seitenorganen betrachten werden. 
\$1. Die Entwicklung des Embryos aus der Eizelle und die ERSten MORPhologischen Differenzierungen.

In diesem Kapitel werde ich untersuchen, in wieweit im Embryo in den ersten Jugendstadien eine Sonderung in Dermatogen, Periblem und Plerom anzugeben ist, hauptsächlich vor dem Auftreten der äusseren Differenzierung. Denn wenn einmal Wurzel, Stengel und Blatt gebildet sind, so wachsen die ersteren in den Vegetationskegeln weiter, und neue Blätter werden dort gebildet, ganz in derselben Weise, wie es später in der älteren Pflanze auch immer der Fall sein wird; diese Verhältnisse werden im zweiten und dritten Paragraphen Berücksichtigung finden. Das Auftreten von Gewebesonderungen vor der äusseren Differenzierung ist aber etwas ganz besonderes, das auch von Hanstein sehr in den Vordergrund gestellt worden ist. Eine gesonderte Besprechung ist daher hier wohl berechtigt.

Die Gefässkryptogamen können wir dabei unberücksichtigt lassen. Hier findet sich nämlich anfangs im Embryo keine Sonderung der Gewebe in verschiedene Schichten, die innere Differenzierung tritt erst in den gebildeten Stengeln, Blättern und Wurzeln auf. Nach der Zusammenstellung Van Treghems in seinem Traité (101 S. 1383, 1419, 1427, 1433, 1440) können wir die Farne als Typus betrachten, der bei den andern Gefässkryptogamen einige Abänderungen erleidet. Bei den Farnen teilt sich die Eizelle durch drei successiven Teilungen in acht Oktantenzellen, von denen zwei den „Fuss” bilden, zwei das erste Blatt, eine den Stammscheitel und eine die Wurzel. Die zwei übrigen abortieren. Von einem Dermatogen usw. kann hier also nicht die Rede sein.

Wir haben hier nur die Phanerogamen zu berücksichtigen, von 
denen die Angiospermen wohl am besten untersucht worden sind. Grundlegend ist dabei die eingehende Arbeit Hansteins über „Die Entwicklung des Keimes der Monokotylen und Dikotylen" (8).

Hanstein gelangt darin zu dem Ergebnis, dass einige Zellen des Vorkeimes (zwei bei den Dikotylen, drei bei den Monokotylen) das Embryo bilden. Diese Zellen scheiden nach einigen anderen Teilungen schon früh ein Dermatogen ab, das sich von nun an nur senkrecht zur Oberfläche teilen wird. Die Trennung von Periblem und Plerom findet zumal im späteren Wurzelende auch schon früh statt, zuweilen schon vor dem Auftreten der äusseren Differenzierung. Diese Vorgänge vollziehen sich alle am regelmässigsten bei den Dikotylen, weniger regelmässig bei den Monokotylen.

Ähnliche Untersuchungen führte Strasburger einige Jahre später für die Koniferen und Gnetaceen aus (10); hier ergaben sich schon manche Abweichungen. Die Bildung des Embryos aus dem Vorrieime findet hier in der mannigfaltigsten Weise statt; es bilden sich sogar mehrmals viele Embryonen aus ein und derselben Eizelle. Auch das weitere Wachstum weicht sehr ab; anfangs wächst der Embryo mit einer Scheitelzelle, während die Abgrenzung von Dermatogen, Periblem und Plerom nicht sehr scharf und verhältnismässig spät auftritt.

Von den späteren Autoren ist auch für die Angiospermen festgestellt worden, dass das Schema Hansteins lange nicht überall zutraf.

So fand Guigarard (40) bei den Loguminosen, dass dort die Embryobildung aus dem Vorkeim ebenfalls auf die verschiedenste Weise stattfindet, mit fast ebensovielen Verschiedenheiten als bei den Gymnospermen. Auch die Trennung 
der drei Hansteinschen Gewebeschichten ist sehr wechselnd. Hegeldraier gab in der Zusammenfassung seiner genauen und eingehenden „Vergleichenden Untersuchungen über Entwickelung dikotyledoner Keime" (37 S. 188) folgende Verhältnisse an: "Nochmalige perikline Spaltungen von anscheinend als Angehörige des Dermatogens constituirten Zellen können, wenn sie vereinzelt vorkommen (Fumaria) als unwesentlich gelten, scheinen aber doch in gewissen Fällen in grösserer Verbreitung einzutreten, wie bei Cuscuta (L. KocH, a. a. O. T. II. Fig. 9-11, p. 48) und können, wie bei Geranium und Tropaeolum, so zur Regel werden, dass eine längere Fortdauer eines schwankenden Verhältnisses zwischen Epidermis und Rinde daraus resultiren kann auch dann, wenn, wie hier, durch frühzeitige und regelmässige Theilungen eine Aussenschicht von Zellen gebildet worden ist, also nicht blos in solchen Fällen, wo überhaupt längere Zeit hindurch Mängel an einer festen Regel im Zellenaufbau herrscht und ein ziemlich zusammengesetzter Zellenkörper entsteht, bevor eine durch eine zusammenhängende Flucht von Zellwänden begrenzte Aussenschicht hervortritt, wie zweifellos bei manchen Monokotyledonen."

Etwas höher heisst es: „Sehr grossen Schwankungen ist jedenfalls der Zeitpunkt und der nähere Verlauf der Pleromausscheidung unterworfen; denn obwohl die Erforschung gerade dieses Punktes in den meisten Fällen mit besonderen Schwierigkeiten verbunden ist und oft nicht in befriedigender Weise ausführbar ist, so zeigen doch die darüber vorliegenden Erfahrungen, dass diese Differenzirung bald mit frühzeitigen und regelmässigen Theilungsschritten erfolgt (Cruciferen, Ranunculus, und wie ich noch hinzufügen kann, Callitriche) bald durch eine kleinere oder grössere Zahl von Zellenvermehrungen verzögert wird .... auch in solchen Fällen, wo, wie bei Helleborus, 
der Keim ganz ansehnlich heranwächst und es sicher einmal zu Ausscheidung eines centralen Cylinders kommt, da man in dem ruhenden Keim dieselbe immerhin eingeleitet findet, scheint es geschehen zu können, dass dieselbe zur Zeit der Samenruhe wenigstens nicht vollendet und um diese Zeit noch keine feste Abgrenzung getroffen ist" (37 S. 187, 188).

Diese Verhältnisse, welche auf ein Schwanken der Differenzierungen in den Embryonen hinweisen, stehen gar nicht vereinzelt dar.

So hat NöRner bei seiner Untersuchung über die Gramineen (41) auch dort gefunden, dass die Dermatogenbildung spät auftritt, nach vielen anderen Teilungen, so dass sie schwer zu unterscheiden ist. Eine Trennung von Periblem und Plerom hat NöRNER gar nicht beobachten können.

Am meisten abweichend sind wohl die Verhältnisse bei den Orchideen (Fleischer 15 S. 441). Die Eizelle bildet nach einigen Teilungen eine unregelmässige Zellmasse, die sich bei der Keimung in ein assimilierendes Knöllchen verwandelt. Aus der äussersten Schicht desselben werden Wurzelhaare getrieben. Diese Knolle bringt nun eine oder mehrere exogene Knospen hervor, welche sich zu beblätterten Sprossen entwickeln. Bisweilen auch bildet die Knolle zuerst neue Knöllchen, welche dann ebenfalls Sprossen entwickeln.

Alle diese verschiedenen Ergebnisse stehen in völligem Einklang mit denjenigen, welche wir im folgenden Kapitel über das Spitzenwachstum antreffen werden. Auch dort ist die Trennung der drei Gewebesysteme sehr ungleich entwickelt, es kann also nicht befremden, dass solches im Embryo der Fall ist.

In diesem Paragraphen hat sich somit ergeben, dass die Einteilung Hansteins in den Embryonen oft nicht scharf und 
deutlich hervortritt; ihr Auftreten geht sehr unregelmässig vor sich, und bei einigen Pflanzen fehlt sie fast ganz.

\section{§ 2. DIE ENTWICKLUNG DER GEWEBE VON STENGEL UND WURZEL AUS DEM VEGELATIONSEEGEL.}

Wenn wir von der Gewebesonderung in einem terminalem Neristem sprechen, so müssen wir immer zweierlei auseinander halten, das nicht immer scharf unterschieden wird; ich meine die Selbständigkeit der Initialen der verschiedenen Histogene und das Vorkommen einer Sonderung in den etwas älteren Teilen, wo dennoch alles meristematisch ist. Es kann vorkommen, dass sich ein Periblem und ein Plerom sehr gut. bis hoch in die Spitze hinein verfolgen lassen, denen aber dennoch gemeinsame Initialen zukommen. Zur leichteren Bezeichnung dieser Verhältnisse werde ich im folgenden die Termini Vegetationspunkt, und Vegetationskegel nur in dem Sinne gebrauchen, dass mit Vegetationspunkt derjenige Teil der Spitze bezeichnet wird, an dem sich die Scheitelzelle oder die Initialen befinden; unter Vegetationskegel oder einfach Spitze werde ich dagegen den ganzen meristematischen Teil des Stengels oder der Wurzel verstehen. Die Sonderung der Initialen bezieht sich also nur auf den Vegetationspunkt, die von Dermatogen, Periblem und Plerom auf die ganze Spitze. Mit dieser Terminologie schliesse ich mich ganz an Warming an (22 S. 7-11, Resumé S. I.).

\section{Gefässkryptogamen.}

Obwohl wir bei den Gefässkryptogamen, bis auf einige wenige Ausnahmen, in Stengel und Wurzel stets eine einzige Schei-- 
telzelle im Vegetationspunkt finden, ist hier doch alsbald im Vegetationskegel von einer Gewebesonderung die Rede, sodass wir diese Pflanzen hier auch in Betracht ziehen müssen.

Die ersten Teilungen, welche sich in den von der Scheitelzelle abgegebenen Segmenten vollziehen, haben nach VAN Treahem schon für die Gewebesonderung eine grundlegende Bedeutung (76).

Die Segmente werden nämlich durch zwei tangentiale Wände in drei Zellen geteilt. Die innere dieser drei Zellen soll nun bei den monostelen Organen den Centralcylinder liefern, während die mittlere die Endodermis und einen Teil der Rinde, die äussere die übrige Rinde bildet. Eine Epidermis spricht Van Tizghem den Gefässkryptogamen ab (101 S. 773 ff.): in der Wurzel, weil die Epidermis hier im Vegetationspunkt zur Kalyptrabildung verbraucht wird, in den Stengeln, weil die äussere Zellschicht sich nicht sofort, sondern erst allmählich nach vielen Teilungen sondert. Über diesen Punkt unten, bei der Phanerogamenwurzel (S. 19), mehr.

Bei den polystelen Arten werden die Stelen nicht von der inneren der drei Zellen eines Segmentes gebildet, sondern von der mittleren. Die innere und die äussere bilden dann die Rinde (76).

Ich muss hier sogleich hervorheben, dass mir für eine so bedeutungsvolle Sache die Belege, welche VAN TiEghem für seine Auseinandersetzung gibt, nicht genügend erscheinen. An der erwähnten Stelle gibt Van Tieghem nur ein kurzes Resumé seiner Ergebnisse, während die beweisgebenden Zeichnungen und die Beschreibungen dort nur versprochen werden. Soviel ich weiss, sind diese nur erschienen in den „Recherches comparatives sur l'origine des membres endogènes" von VAN TIEGHEM und Douliot (78), wo solche Belege für die Wurzel (nicht für 
den Stengel) gegeben werden. Die gegebenen Figuren, von Van Tieghem und Douliot nach a us freier Hand angefertigten Schnitten gezeichnet, sind aber sehr schematisch, wie es bei der grossen Zahl der Abbildungen in der ganzen Schrift (mehr als 500 mediane Längsschnitte durch Wurzelanlagen) auch wohl nicht anders sein kann. Es wäre also erwünscht, dass nach neueren Methoden für einige wenige Arten eine eingehende Untersuchung die Ergebnisse Van TIEghems nachprüfte. Zumal, weil von einigen Autoren Verhältnisse angegeben werden, welche zu den VAN TIEghemschen Angaben in direktem Widerspruch stehen.

So gibt Van Tieghem für Angiopteris an (76 S. 373), dass sein Schema auch hier zutrifft. Nun hat L. KocH aber die Zellteilungsvorgänge in der Wurzelspitze von Angiopteris evecta Hoffm. an Mikrotom-Schnittserien eingehend untersucht (111), und dort statt des regelmässigen Schemas VAN TIEGHEMS einen unregelmässigen, auf sehr verschiedene Weise vorsich gehenden Teilungsmodus gefunden.

Weiter wird von WeIss (39) angegeben, dass bei den Polypodiaceen Endodermis, Pericykel und Phloem aus einer Zellschicht entstehen. Diese Angabe steht ebenfalls zu der VAN TIEghemschen in direktem Widerspruch. Wir müssen also über das Spitzenwachstum der Gefässkryptogamen nähere eingehendere Untersuchungen abwarten.

\section{Phanerogamen.}

Bei den Phanerogamen wird es notwendig sein, die Ergebnisse der früheren Arbeiten für die Wurzel und für den Stengel besonders zu besprechen, weil beide nicht unerheblich von einander abweichen. 
1. Das Spitzenwachstum der Wurzel. Das klassische Beispiel für die Unterscheidung in Dermatogen, Periblem und Plerom ist die Phanerogamenwurzel. Wirklich sind in der Spitze dieser Wurzel die Verhältnisse oft sehr regelmässig und einfach, und die Sonderung in verschiedene Schichten ist hier bisweilen eine merkwürdig scharfe. Hanstein konstatieste die Trennung der drei Meristemschichten zuerst (8) füı die Embryonalwurzel, und REINke (9) dehnte sie auf alle Wurzeln aus. Es hat sich indes später gezeigt, dass die Verhältnisse nicht überall so deutlich und einfach waren, wie diese Untersucher meinten; zumal die mehr oder weniger scharfe Trennung der „Histogene” im Vegetationspunkt ist vielen Veränderungen ausgesetzt.

Speziell über diese Verhältnisse im Vegetationspunkt ist zwischen den Jahren 1870 und 1880 eine umfangreiche Literatur erschienen, deren Verzeichnis man am besten findet bei Flahault (35 S. 2), einem der letzten Autoren, welche über dieses Spitzenwachstum Mitteılungen gemacht haben.

Das Hauptergebnis dieser Arbeiten war die Erkenntnis, dass keineswegs bei allen Wurzeln drei Initialschichten zu unterscheiden sind, sondern dass man in dieser Hinsicht die grösste Mannigfaltigkeit finden kann, mit 1 bis 4 verschiedenen Histogenen (das vierte für die Kalyptra) und allen denkbaren Kombinationen.

Dass diesen Unterschieden keine sehr grosse Bedeutung zukommt, folgt schon daraus, dass eine und dieselbe Pflanze sich in verschiedenen Stadien verschieden verhalten kann (Flahault 35 S. 16).

Auch systematisch kommt diesen Unterschieden keine Bedeutung zu, wie die Erfahrung gelehrt hat; denn fast alle Versuche, verschiedene Wachstumstypen aufzustellen, welche 
sich mit systematischen Einteilungen deckten, sind gescheitert (Vergl. Hegrlmaier 37 S. 191). Nur eine einzige Unterscheidung hat sich in dieser Hinsicht etwas besser behauptet: Flahault schliesst (35, S. 158), dass die Kalyptra bei den Monokotyledonen eigene Histogene besitzt, bei den Dikotyledonen dagegen nicht; hier wird die Kalyptra von dem Dermatogen oder auch vom Periblem oder vom Plerom gebildet. Diese Angabe ist jedenfalls richtig, wenigstens finden wir sie von keinem bestritten. Nur hat VAN Treghem schon wieder geltend gemacht, dass sich bei den Nymphaeaceen ebenfalls ein beson. deres Kalyptrogen findet (65). ${ }^{1}$ )

Man hat die Lehre der Histogene künstlich aufrecht zu halten versucht, indem man z. B. von der Kalyptra, welche aus allen Histogenen entstehen kann, erklärte, sie sei eine auf verschiedene Weise erworbene sekundäre Anpassung, daher die verschiedenen Typen (Flahault 35 S. 162, HaberLaNdT 115 S 76). Die Kalyptra hat also, wie FlaHault bemerkt, nur einen physiologischen Wert, morphologisch dagegen ist sie ein sehr verschiedenes Organ. Ahnliches tut Tan Tiegheu, wenn er der Monokotylenwurzel eine Epidermis absriricht,

1) VAN TIEgHeM verwertet aber bekanntlich dieses Verhalten ganz anders: er stellt die Nymphaeaceen mit den Monokotyledonen und den meisten Gefässkryptogamen zusammen als Liorhizes (mit glatter Wurzel); die Dikotyledonen ausser den Nymphacaceen bilden dann mit den Gymnospermen, Lycopodiaceen und Isoetes die Climacorhizes (Traité 101 S. 696). Diese Einteilung hat VaN Tieghem in seinen Éléments de Botanique (123 S. 210) sogar teilweise zu einer systematischen erhoben. Ohne hier nun systematischen Ausspruchen tun $\mathrm{zu}$ wollen, will ich doch bemerken dass mir wenigstens das Auftreten der Liorhizie oder der Klimakorhizie als ein untercoordnetes Merkmal ron weniger Bedeutung erscheint. 
weil diese zur Kalyptrabildung verbraucht wird, während bei den Dikotylen die innerste Schicht des Dermokalyptrogens die Epidermis bildet.

Diese Auffassungen scheinen mil nicht richtig. Die Entwicklungsgeschichte entlehnt ihren Wert ja doch nur der phylogenetischen Bedeutung, welche ihr zukommt. Nun haben offenbar alle Wurzeln eine Haube gehabt und eine äussere Zellschicht, lange bevor die Histogene aufgetreten sind; in den Gefässkryptogamen finden wir ja noch heutzutage Wurzeln mit Scheitelzellen. Von einer „im Laufe der phylogenetischen Entwickelung allmählich erworbenen Anpassungserscheinung" (Haberlandt 115 S. 76), bei der die Kalyptra aus den verschiedenen Histogenen gebildet worden sei, kann also nicht die Rede sein. Für die Epidermis gilt ganz das nämliche: Kalyptra und äussere Zellschicht der Wurzel sind beide offenbar nicht nur physiologisch, sondern auch morphologisch bei den verschiedenen Pflanzen gleichwertig.

Wir sehen somit, dass der Sonderung der Initialen im Vegetationspunkt in den Wurzeln keinerlei grosse Bedeutung zukommt. Es fragt sich nun, ob nicht vielleicht in den weiteren Teilen des Vegationskegels eine Sonderung in Dermatogen, Periblem und Plerom besteht. Vielleicht wäre auf diese Weise die Hansteinsche Sonderung noch zu retten. Wenn man aber die von den Autoren gezeichneten Figuren oder besser noch ein mikroskopisches Präparat betrachtet, so ergibt sich, dass davon eigentlich nicht die Rede sein kann. Wir finden dort in den meisten Wurzeln alle Elemente in vertikalen Reihen angeordnet, zwischen denen überall ähnliche Grenzen besteht. Man kann hier keine besonders hervorragenden Grenzscheidungen auffinden; man kann ebensogut eine einzelne als zehn Grenzen ziehen. 
Die Bedeutung der Hansteinschen Sonderung is nach den vorliegenden Tatsachen also schon geringer, als man nach ihrem Ruf aus der Literatur meinen sollte.

Dazu kommt noch die von Schwevidener angeführte Tatsache, dass auch in solchen Wurzeln, wo der Zellanordnung nach ein deutliches Dermatogen, Periblem und Plerom untersshieden werden kann, dennoch diese nicht immer als embryologisch selbständige Gewebeschichten aufgefasst werden dürfen, dass dagegen bisweilen einzelne genetisch offenbar einheitliche Zellkomplexe verschiedenen Geweben angehören. So bemerkte er, (43 S. 190-192) dass bei vielen Pflanzen (einer Graminee, Tradescantia Sellowii, Maranta Legrelliana, M. Lietzei und Amarantus caudatus) sich einzelne Zellkomplexe im Vegetationspunkt befinden, welche offenbar einer Zelle entstammen, jedoch entweder teils im Plerom und teils im Periblem, oder in Periblem und Dermatogen gelagert sind.

Wir können also behaupten, dass die Gewebeeinteilung Hansteins in der Wurzelspitze, weder rein-anatomisch, noch systematisch von Bedeutung ist. $\mathrm{Ob}$ ihr dennoch eine grössere Bedeutung zukommt dadurch, dass die verschiedenen Histogene, wo solche anwesend sind, sich zu den späteren Geweben VAN TiEghems ausbilden, wird unten natürlich erörtert werden.

2. Das Spitzenwachstum des Stengels. Über das Spitzenwachstum des Stengels ist ebenfalls sehr viel geschrieben worden, allerdings nicht soviel als über die Wurzel.

Eine Zusammenstellung der bezüglichen Literatur findet man bei H. Douliot (83 S. 291 und S. 308) und bei L. KocH (95 S. 491); die Ergebnisse sind hier viel verworrener als bei der Wurzel; wir finden hier viele streitige Angaben. 
Eine der Hauptursachen liegt hier wohl in der Methode der älteren Autoren, welche dicke, aufgehellte Freihandschnitte gebrauchten. (Vergl. z. B. Hanstein 7 S. 111.)

Diese Methode kann vorzügliches leisten, wie die Arbeiten Hansteins und anderer beweisen; es gehört aber eine grosse Genauigkeit und Geschicklichkeit dazu, um nicht zu falschen Resultaten zu kommen. Wirklich ist diese Methode sehr schwierig: verschieden geführte Schnitte geben die verschiedensten Bilder, während über die Führung der Schnitte selbst keine Anhaltspunkte zu gewinnen sind. Dazu kommt noch die sehr natürliche Neigung, entwicklungsgeschichtliche Tatsachen zu hoch anzuschlagen; die Hansteinsche Sonderung ist von vielen Autoren, $\mathrm{zu}$ denen Hanstein selbst später auch gehörte - anfangs nicht, wie wir sehen werden - gewiss in ihrer Bedeutung stark überschätzt worden. So ist es bei den technischen Schwierigkeiten auch nicht befremdend, dass einige Autoren die drei verschiedenen Histogene angegeben haben, auch wo diese sich tatsächlich nicht getrennt vorfinden.

Am stärksten finden wir das wohl bei Doulıo'r (83). Douliot ist von den Autoren, die das Spitzenwachstum des Stengels in umfassender Weise untersucht haben, der einzige, der eine Sonderung in Dermatogen, Periblem und Plerom bei der Mehrzahl der Angiospermen angibt; nur bei wenigen, zumal Monokotylen, sind nach ihm Periblem und Plerom im Vegetationspunkt nicht getrennt.

Bei genauerer kritischer Betrachtung stellt sich nun aber alsbald heraus, dass dieses Ergebnis wohl der oberflächlichen Untersuchung zuzuschreiben ist, durch die diese Methode zu groben Fehlschlüssen Anlass geben kann.

Wenn man die von DouıIot gegebenen Figuren betrachtet, ergibt sich zuerst, dass diese sehr schematisch sind, zweitens 
aber auch, dass seine Präparate mitunter nicht die richtigen gewesen sind. So gibt er in Fig. 5 und 6 auf Pl. 18 zwei Abbildungen eines Längsschnittes durch die Stengel- (oder Rhizom-?) Spitze von Hippuris; dieser Schnitt muss aber, nach der Form des Präparates zu urteilen, ganz schief geführt worden sein, so dass der ganze schlanke Vegetationskegel nicht berührt worden ist. Schon die zwei Blätter in Fig. 6 zeigen das aus; an einem richtigen Schnitt (wie er selbst in Fig. 7 u. 8 angibt) sind alle Entwickelungsstadien der Blätter vorhanden, in Fig. 6 finden sich nur zwei sehr verschiedene.

Einen anderen Beweis dafür, dass Douliot nicht sehr genau untersuchte, hat er uns selbst gegeben. Dошціот beschreibt für die Gramineen-Stengelspitze (83 S. 315) drei verschiedene Histogene. Später (94 S. 93) kommt er davon zurück und nimmt bloss zwei an.

Als Erklärung für diese seine Meinungsänderung gibt Douriot drei Figuren nach einem Schnitt, einem Längsschnitt durch den Vegetationskegel von Phragmites communis; die eine zeigt eine naturgemässe Wiedergabe des Zellwandnetzes, die anderen dasselbe "mit sehr geringen Abänderungen", wodurch die eine Figur die Auffassung, nach der der Stengel 2, die andere die, nach der der Stengel 3 Initialgruppen besitzt, wiedergibt.

Am merkwürdigsten ist dabei, das diese drei Zeichnungen einander so unähnlich sind, dass selbst die Zahl der Zellen in denselben nicht einmal die gleiche ist.

Auch die sonstige Literatur über das Spitzenwachstum des Stengels verdient nicht überall das gleiche Vertrauen; man muss daher die Ergebnisse derselben hier mit sehr kritischen Augen betrachten.

Über die Angiospermen-Stengelspitze sind unsere Kenntnisse 
daher nach der Arbeit Hansteins (7) nicht wesentlich vermehrt worden. Hanstein begründet hier auch für den Stengel die Binteilung in Dermatogen, Periblem und Plerom, welche bei etwa 50 Pflanzen beobachtet hat. Wenn man die I...NSTEInsche Schrift liest, und mehr noch, wenn man die 7 Figuren von Längsschnitten, welche seine Ansicht begründen sollen, betrachtet, so ergibt sich, dass HANSTEIN hier bei weitem nicht eine so scharfe Grenze zwischen diesen Geweben voraussetzt, als man in einer für diese Ansichten grundlegenden Arbeit erwarten dürfte.

Nur das Dermatogen is deutlich abgegrenzt, das Periblem und das Plerom gehen aber allmählich ineinander über. Nur in einer Figur (Fig. 2.) kann man eine Grenze zwischen beiden ziehen, in den 6 andern nicht (Fig. 1, 3, 4, 5, 6, 8). Die Beschreibung Hansteins steht indessen mit diesen Figuren völlig in Einklang. Ich citiere von derselben die folgenden Zeilen: „Zwischen den nur die Oberhaut fortbildenden EpidermInitialen und den Masse erzeugenden Axen-Initialen müssen nun in der Mehrzahl der Fälle noch die unter der Epidermis gelegenen Kappenschichten unterschieden werden. Denn nur selten überzieht allein die Epiderm-Schicht in deutlicher Sonderung diese Axen-Initialen, wie z. B. in einem spitzen Vegetationskegel von Zea, und iu diesem Fall haben wir einfach zwei genetisch von einander unabhängige aber doch harmonisch arbeitende Zelitheilungsvorgänge, deren einer den Hauptkörper, der andere die Bekleidung desselben anlegt. Abgesehen von diesen Ausnahmefällen erscheinen aber gewöhnlich noch ein, zwei oder drei Mieristem-Zellenlagen so unabhängig und so ausschliesslich senkrecht in die Richtung zur Aussenfläche getheilt, dass an ihrer wenigstens zeitweiligen Selbständigkeit nicht zu zweifeln ist. $(1-6,8)$. 
„In manchen Fällen, besonders in den tieferen Lagen, wechseln die senkrechten Theilwände dieser Schicht hier und dort mit tangentialen oder geneigten und die Einheitlichkeit derselben wird dadurch gestört (5). In noch anderen scheint eine ge. wisse, wenn auch nicht als gesetzmässig erkennbare genetische Beziehung zu den Axen-Initialen sich auszusprechen $(1,3)$. Es sieht aus, als ob diese auch schief nach oben Theilzellen abgliedern, die sich jenen Schichten anschlössen und man kann sich auch wohl vorstellen, wie bei lebhafter Entwickelung eine obere Abschnittszelle einer Axen-Initiale durch constante Theilung senkrecht gegen die Scheitelkrümmung eine neue Kappenlage erzeugen, oder wie umgekehrt die Initiale einer Kappenschicht durch allseitige Theilung sich der Axen-Initialgruppe in ihrer Wirksamkeit auschliessen, oder wie endlich eine Einzel-Initiale der Axe durch Einschieben ihres Gipfels zwischen die auseinander weichenden Mittelzellen einer Kappenzellschicht dieselben gewissermassen ihrer Führerschaft wieder unterwerfen kann. Und es ist somit die Zahl und Beständigkeit der Kappenschichten oft eine zweifeihafte, ihr Ursprung scheinbar ein verschiedener und ihre Unabhängigkeit nur eine bedingte oder zeitweilige. Es giebt ferner zahlreiche Fälle, in denen unterhalb einer oder zweier streng gesonderter Zellenlagen eine Schicht kommt, die zwar aus unregelmässig getheilten und gelagerten Zellen besteht, aber dennoch oberhalb der Axen-Initial-Gruppe fortstreicht, ohne sichtlich in dieselbe aufzugehen. Es stellen daher diese Schichten zwischen der streng differenzirten Epidermis und dem nachzubildenden Gewebe gewissermassen eine Uebergangszone dar, die aussen jener, innen diesem ähnlicher ist . . . . .

„Wie dem aber sei, so prägen sich diese die Axe überwölbenden Zellenlagen, besonders die äussersten zunächst dem 
Dermatogen, vermöge ihres ganzen Verhaltens, als gesonderte Meristem-Abtheilung so aus, dass an ihrer Eigenartigkeit nicht zu zweifeln ist.

„Da nun aber diese tieferen, die Axen-Initialen überspannenden Schichten, welche sich nicht nur nach oben stets scharf unterscheiden, sondern meist auch nach unten deutlich absetzen, grade diejenigen Zellenlagen bilden, aus denen nachmals die parenchymatische oder primäre Rinde entsteht, die also auch eine durchgreifende Sonderung bewahren, so wird es passend sein, auch sie als frühzeitig geschiedene Meristemlage mit einer besondern Benennung "Periblema" und ihre mittleren Führerzellen als "Periblem-Initialen” zu bezeichnen. Und im Gegensatz zu diesem zur Umhüllung werdenden Periblem könnte dann die mittlere mit ihren Erzeugnissen das ganze Spross-Innere erfüllende und aufbauende MeristemMasse möglichst kurz "Pleroma”, gleichsam „Füllgewebe”, genannt werden." ( 7 S 118-120)

Wie man sieht, fasst Hanstein diese Trennung der Meristeme im Vegetationskegel nicht sehr scharf, jedenfalls nicht so, dass es genügt als eine entwickelungsgeschichtliche Basis für die Stelärtheorie.

Später hat man - wohl unter dem Einfluss einer zweiten Schrift Hansteins übel: „Die Entwickelung des Keimes” ( ) und der Arbeiten der Schüler Hansteins - seine Theorie weit schärfer gefasst. Die drei primären Gewebe wurden als prinzipiell scharf unterschiedene Dinge betrachtet. Ein einziges Beispiel wird das sofort darlegen. P. Groom, der das Scheitelwachstum der Phanerogamen untersucht hat (50), kam dabei zu folgendem Ergebnis: „Bei den Gymnospermen treffen wir öfters kein unterschiedliches Dermatogen, Periblem und Plerom. Bei den Angiospermen scheint das Dermatogen immer scharf differenzirt 
zu sein, nicht aber überall das Periblem und Plerom, welche allerdings in vielen Fällen gut geschieden sind." (50 S. 311) Man wird bemerken, dass dieses Ergebnis, soweit es die Angiospermen betrifft, völlig identisch ist mit demjenigen Hansteins. Groom folgert nun aber: "Auch die Hanstern'sche Lehre von den Histogenen kann nicht auf alleVegetationskegel ausgedehnt werden.... Das Scheitelwachstum muss also von einem neuen Gesichtspunkt aus betrachtet werden." Hieraus ergibt sich also, dass Groom unter der Haxsteinschen Lehre tatsächlich etwas ganz anderes verstand als Hanstein selbst in seiner „Scheitelzellgruppe" niedergelegt hatte.

Für den Angiospermen-stengel ist nun, wie gesagt, nicht viel mehr ermittelt worden, als von Hanstein schon geschehen war.

Das einzige Bedeutende, das man für die Angiospermen findet, ist die scharfe Trennung von Periblem und Plerom in der Stengelspitze von Hippuris, welche von vielen Autoren abgebildet und sogar mehr oder weniger beschrieben worden ist. (Sanio 3 S. 228, de Bary 28 S. 9, Strasburger 119S. 291).

Weiter sind noch etliche Fälle von Sonderungen, welche nicht schärfer sind als die, velche Hanstein beschreibt, von den verschiedensten Autoren gelegentlich ermittelt worden.

Schliesslich hat Gwrnne Vaughan sich noch die Frage gestellt, wie die Stengelspitze bei den polystelen Primeln aussehen würde (117 S. 323). Er fand, wie auch wohl zu erwarten war, ganz dieselben Strukturen wie in dem ausgebildeten Stengel. Wo die Stelen in einem Kreis angeordnet sind (Primula japonica, $P$. involucrata), sind auch die Prokambiumbündel in der Spitze in einem Kreis angeordnet, soảss ein anscheinendes Plerom entsteht; wo die Stelen unregelmässig zerstreut stehen ( $P$. Auricula), ist von einem Plerom nicht mehr die Rede. 
Für die Gymnospermen finden wir mehrere Angaben. Von L. Koch (95) ist eine genaue Bearbeitung des Stammscheitels vermittelst Schnitt-Serien vorgenommen worden. KocH kommt dabei zu dem Ergebnis, dass eine Sonderung der Gewebe im Sinne Hansteins nicht vorliegt. Für die sehr genau untersuchte Tsuga canadensis Carr. z. B. beschreibt er erstens, dass das Dermatogen hier nicht abgegrenzt ist, die Epidermis trennt sich elst spät ab, nach vielen tangentialen Teilungen in der jemaligen äussersten Zellschicht (95 S. 549). Aber auch ein Periblem und Plerom sind hier nicht zu unterscheiden; denn der einzige differenzierte Teil des Vegetationskegels ist eine centrale Partie, welche nur das Mark bilden wird; die Rinde und die vaskulären Gewebe entstehen mit der Epidermis aus nur zwei peripheren Zelllagen, von denen die äussere die Epidermis und einen Teil der Rinde, die innere die Hauptmasse der Rinde und die Gefässbündel hervorbringt.

Auch bei den übrigen untersuchten Gymnospermen kommt KocH zu ähnlichen Verhältnissen, obwohl hier das Dermatogen bisweilen etwas schärfer abgegrenzt ist.

Resumierend können wir also feststellen, dass beim Spitzenwachstum des Stengels eine Sonderung der Gewebe in Dermatogen, Periblem und Plerom nur in wenigen Fällen scharf angegeben ist. Das Dermatogen ist bei den Angiospermen meistens wohl abgegrenzt, bei den Gymnospermen nicht. Periblem und Plerom sind nur selten deutlich anzugeben, recht scharf eigentlich nur bei Hippuris.

Nach dem vorhergegangenen ist es also nicht befremdend, dass wir in der Literatur wiederholt die Behauptung finden, dass die Hansternsche Sonderung tatsächlich nicht besteht.

Wir finden dies schon von NäGELI auf der Versammlung deutscher Naturforscher und Ärzte in München 1877 ausge- 
sprochen (31), und in "Das Microscop" von NÄGELI und Schwendener (32 S. 574); weiter von Gulluavd. Letzterer schreibt: "Ce n'est que bien au-dessous du sommet que l'on peut dire, voilà des cellules pour la moelle, pour l'épiderme, pour les faisceaux, etc.; mais alors c'est déjà l'état durable qui commence. Auparavant on ne peut s'en tenir qu'a cette prévision nécessaire, qui veut que l'épiderme naisse à la périphérie et les faisceaux vers le milieu." (36 S. 91).

WARMing hat sich im gleichen Sinne geäussert. Zwar findet er die anatomischen Verhältnisse gerade so, wie Hanstein sie beschrieben hatte, er folgert daraus aber mit Recht: "Je dois donc conclure que la différence essentielle que M. Hanstein a établie entre le périblème et le plérome, à savoir que le premier constitue le méristème d'où les phyllomes, les kaulomes et toute l'écorce primaire tirent leur origine, tandis que le second est le méristème-mère du système fibro-vasculaire, que cette différence, dis-je, en beaucoup de cas, n'est pas reconnaissable dans l'histologie du sommet de la tige, fait que M. Hanstein n'a du reste pas manqué de signaler dans "Die Scheitelzellgruppe” p. 128" (22 S. V).

Sehr hübsch ist WARMings Beschreibung der Verhältnisse, die wirklich einen natürlichen Eindruck wiedergibt: „Mais, même dans les cas où l'arrangement des cellules dans le sommet de la tige est régulier, .... on reçoit l'impression que les couches du périblème ne sont que des séries de plérome qui se réunissent regulièrement en haut, et les séries du plérome, des couches de périblème qui, dans la partie supérieure, se confondent les unes avec les autres, et par suite sont interrompues et se terminent par un groupe de cellules plus irrégulier." (22 S. V).

Lianier kommt in seiner "Anatomie des Cálycanthacées, 
Mélastomacées et Myrtacées" (74) zu der Überzeugung, dass von den drei primären Gewebeschichten Hansterss nur das Dermatogen wirklich besteht. Die Rinde ist erst nach dem Auftreten des Bildungsringes deutlich zu unterscheiden (nach BARANETZKY 129 S. 265).

HABERLANDT vertritt in seiner Physiologischen Pflanzenanatomie eine ähnliche Auffassung. „Eine allgemeine Bedeutung kann natürlich diese Gliederung nicht beanspruchen, denn die Mannigfaltigkeit des Scheitelwachsthums mit mehreren Initialzellen bewegt sich innerhalb viel weiterer Grenzen", schreibt er auf S. 75 (115).

Endlich hat auch L. КосH auf Grund seiner Untersuchungen und Anschauungen über das Scheitelwachstum gegen die Hansternsche Einteilung Bedenken erhoben. (111 S. 386).

Wir sehen also, dass wirklich viele Forscher dazu gelangt sind, die Hansteinsche Einteilung ganz zu beseitigen. Ich glaube aber nicht, dass das ohne weiteres berechtigt ist. Wenn wirklich die drei Histogene in denjenigen Fällen, wo sie getrennt vorkommen, sich später immer ausbilden zu den drei primären Geweben VAN TrEghems, so ist das an sich schon eine sehr wichtige Sache. Die Histogene müssen dann die ontogenetische Wiederholung der phylogenetisch früh àugetretenen Sonderung in Epidermis, Rinde und Centralcylinder sein.

Dass dieses nicht in allen terminalen Meristemen $\mathrm{zu}$ finden ist, kann diese Bedeutung nicht beeinträchtigen: die Ontogenie ist ja öfters mehr oder weniger entstellt und undeutlich geworden. Auch die Keimblätter in der zoologischen Embryologie sind nicht immer so leicht nachzuweisen, dennoch beruht auf deren Unterscheidung die ganze zoologisch-embryologische Wissenschaft. Zur richtigen Beurteilung der Hansteinschen Einteilung 
sind somit weitere Untersuchungen nach der Übereinstimmung mit den VaN Tiguhemschen Geweben notwendig. Hierüber Näheres in zweiten Kapitel.

\section{\$3. Die Anlage seitulicher Organe.}

Die Anlage der seitlichen Organe muss hier ebenfalls besprochen werden, weil es von Interesse ist, zu untersuchen, aus welchen primären Geweben die Gewebe des neuen Organes gebildet werden. Die bezüglichen Daten, welche ich hier anführe, sind, wenn eine andere Quelle nicht genannt wird, dem Traité de Botanique VAN TIEghems entnommen, wo man auch die Literatur zusammengestellt findet (101 S. 700, 702, 707, 713, $780,783,860,863)$.

1. Die Wurzel. Bei den Gefässkryptogamen entstehen die Seiten- sowie die Nebenwurzeln aus einer einzigen Zelle der Endodermis. Die andern Gewebe beteiligen sich nicht am Aufbau der jungen. Wurzel, nur das Rindenparenchym bildet zuweilen eine "poche digestive" um die Wurzel herum, welche durch Enzyme die übrigen Rindenzellen auflöst.

Bei den Phanerogamen dagegen bildet sich die Nebenwurzel auf Blatt, Stengel und Wurzel aus einer Zellschicht des Pericykels. Die Endodermis hat dabei höchstens die Aufgabe, die "poche" zu bilden.

Diese Bildungsweisen haben nur Geltung für die in einem mittleren Alter der Pflanzenorgane entstehenden Wurzeln; sowohl die auf sehr jungen Organen, also schon im Vegetationskegel entstehenden Seitenwurzeln, als die auf älteren Organen auftretenden Wurzeln werden anders gebildet.

Die sehr früh entstehenden Wurzeln entstehen nicht endogen, sondern exogen, bei den Gefässkryptogamen (Selaginella, Equi- 
setum) aus einer oberflächlichen Zelle des Meristems; bei den Phanerogamen (Einige Cruciferen, Ficaria, Linaria und Ophrydeen) aus mehreren oberflächlichen Zellschichten. Die Epidermis bildet sich aus der Epidermis des Mutterorganes. dessen oberste. Rindenschichten Rinde und Centralcylinder der jungen Wurzel bilden.

Die sehr spät entstehenden Adventivwurzeln auf dem Stengel entstehen ebenfalls nicht im Pericykel, sondern tiefer, im Phloemparenchym.

2. Der Stengel. Bei der Bildung von Knospen muss man stets unterscheiden zwischen Knospenbildung auf der Wurzel und auf dem Stengel. Die Knospenbildung auf der Wurzel findet bei den Phanerogamen im Pericykel statt, ausgenommen bei Linaria, wo sie ebenso wie die Wurzelbildung exogen erfolgt. Der Pericykel bildet alle Teile der jungen Knospe.

Die Knospenbildung auf dem Stengel geht dagegen bei Gefässkryptogamen und Phanerogamen normal sehr früh vor sich, schon im Vegetationskegel, dementsprechend also exogen. Bei dem Gefässkryptogamen geht der Stengel ganz aus einer oberflächlichen Zelle hervor, bei den Phanerogamen aus einigen Zellschichten: aus der Epidermis und einigen Rindenschichten. Diese letzteren Verhältnisse, welche schon von HANstern beobachtet worden sind, sind später oftmals bestätigt worden, u. a. von Karsten (60 S. 26), von Pfefrer (11 S. 9), und von Koch (95 S. 532) für die Gymnospermen.

Die Knospenbildung auf dem Blatte kann auf sehr verschiedene Weise erfolgen; die Knospe kann aus der Epidermis hervorgehen (z. B. Begonia) oder aus Epidermis und Rinde (Bryophyllum, Cardamine, Streptocarpus), oder auch allein aus der Rinde (Peperomia, Achimenes).

3. Das Blatt entsteht bei den Gefüsskryptogamen nach 
VAN TIEghem aus einer einzigen oberflächlichen Zelle (101 S. 860,861$)$.

Nach Karsten gibt es jedoch Ausnahmen von dieser Regel (60 S. 13-15), er beschreibt wenigstens für Selaginella Martensii Spring., Lycopodium inundaturn, L. clavatum und Selago, dass die Blätter von den 4-6 äusseren Zellschichten gebildet werden.

Bei den Phanerogamen entsteht aber jedenfalls das Blatt aus Epidermis und Rinde zusammen. Wir finden das schon von Hanstein (7 S. 121, 122) ermittelt, später auch bestätigt von Karsten (60 S. 19-28) für Gymnospermen und Angiospermen, weiter von StrasbUrger (9 S. 323 ff.) und von Koch für die Gymnospermen (90 S. 530).

Nur hebt Koch hervor (90 S. 530), dass auch hier kein Dermatogen abgetrennt ist. "Die nach aussen abgetheilten Zellelemente" (des jungen Blattes) „einer früheren Decklage übernehmen denselben” (d. h. den epidermalen Abschluss), „indem sie sich von jetzt ab nur noch senkrecht zur Oberfläche theilen. Die Epidermis entsteht somit erst nachträglich. Sie ist ebenfalls eine secundäre, von dem embryonalen Gewebe abzuleitende Bildung."

Ausserdem ist die Entstehung der Blätter aus dem Periblem noch von Warming (22 S. VI) bei einer grossen Zahl Phanerogamen und von Schmitz für einige weitere (19 S. 11) ermittelt worden.

Dagegen behauptet neuerdings FLOT, dass das Entstehen des Blattes aus Dermatogen und Periblem nicht feststeht (132 S. 1319). Wenn ich es wohl verstehe, soll "seine eigene Untersuchung uns belehren, dass im Gegenteil Epidermis, Rinde und Gefässgewebe des Blattes aus Dermatogen, Periblem und Plerom des Sprosses hervorgehen. Hinreichende Beweise gibt FLOT dafür aber nicht. 
Ähnliches als das, was KocH für die Gymnospermen-Epidermis angibt, findet sich nach Douliow in noch stärkerem Grade (94 S. 96) bei den Gramineen. Hier wird sogar die ganze Blattspreite aus der Epidermis gebildet; die Blattscheide dagegen aus Epidermis und Rinde. Wenn man den beigegebenen Figuren trauen darf, so ist eine tangentiale Teilung der Epidermiszellen nicht zu leugnen.

Wir sehen also, dass bei der Bildung von Seitenorganen die Gewebeschichten der jungen Organe mit den Schichten, aus denen sie hervorgehen, mit Bestimmtheit nicht übereinkommen.

§ 4. ZUSAMMENFASSUNG DER IN DIESEM KAPITEL BeSPROChENEN Tatsachen.

Bei den Gefässkryptogamen besteht im Vegetationspunkt keine Gewebesonderung (Scheitelzelle), ebensowenig wie im Embryo. Über das erste Auftreten einer Sonderung in der Spitze sind uns keine genügenden Angaben bekannt.

Bei den Phanerogamen kann man eine Unterscheidung in Dermatogen, Periblem und Plerom in vielen Fällen annehmen. Wir haben oben aber gesehen, dass die Verhältnisse in der Spitze derart wechseln, dass die Einteilung anatomisch nur sehr mangelhaft begründet ist. Wenn ihr also aus anderen Gesichtspunkten keine höhere Bedeutung zukommt, so wird man ihr im allgemeinen nur wenig Gewicht beilegen können. In den Wurzeln ist sie noch am besten ausgebildet, in den Stengeln fast gar nicht. Am konstantesten ist noch das Dermatogen, weil dieses, obwohl es in den Wurzeln sich sehr verschieden verhalten kann, in den Stengeln meistens gesondert in der Spitze vorkommt. 
In Übereinstimmung hiermit tritt auch im Embryo die Der. matogensonderung am frühesten auf, meistens schon lange vor der Erscheinung der äusseren Differenzierung, während diejenige in Periblem und Plerom im Embryokörper später auftritt, und dazu eigentlich nur in der Keimwurzel.

Bei der Anlage der Seitenorgane werden die Gewebeschichten der neuen Organe nicht aus den übereinstimmenden Geweben der tragenden Organe gebildet.

Im folgenden Kapitel haben wir nun zu untersuchen, ob wirklich diese Sonderung in Dermatogen, Periblem und Plerom, wo sie vorkommt, mit derjenigen in Epidermis, Rinde und Centralcylinder übereinstimmt; das heisst, ob wirklich das Dermatogen die Epidermis bildet, das Periblem die Rinde, das Plerom den Centralcylinder.

\section{KAPITEL.}

Die Übereinstimmung zwischen den primären Geweben Hansteins und denjenigen Van TIEghems.

\section{$\S 1$. Literatur.}

Wir müssen also wissen, ob wirklich das Dermatogen die Epidermis bildet, das Periblem die Rinde und das Plerom den Centralcylinder.

Wir können hier vorausschicken, dass die Ubereinstimmung zwischen Dermatogen und Epidermis wohl in den meisten Fällen angenommen werden darf. Sind beide doch durch ihre periphere Lage äusserst leicht zu identifizieren. Der einzige Unterschied, welcher zwischen beiden bestehen kann, ist der, 
dass das Dermatogen durch tangentiale Teilung nicht nur die Epidermis, sondern auch einen Teil der Rinde bildet. Tatsächlich ist das in einigen Pflanzen der Fall, wie wir schon oben sahen (S. 2), die Regel ist es aber gewiss nicht. Zwar ist dies noch nicht direkt in genügendem Masse untersucht worden, wir wissen aber aus gelegentlichen Mitteilungen, dass tangentiale Teilungen des Dermatogens verhältnismässig selten sind. Vielleicht würde sich bei genauerer Untersuchung die Zahl der Fälle wohl vermehren lassen; bis jetzt beschränken sie sich im wesentlichen auf drei: die Sprossspitze der Gymnospermen, das Blatt der Gramineen und das Embryo von Cuscuta, Geranium und Tropaeolum (Siehe oben S. 12). Im allgemeinen aber bildet das Dermatogen nur die Epidermis. In denjenigen Fällen, wo eine zusammengesetzte Epidermis vorkommt (Vergl. S. 2), treten natürlich auch in dem Dermatogen tangentiale Teilungen auf. Weil aber die vielschichtige Epidermis wahrscheinlich wohl als der normalen einschichtigen Epidermis homolog betrachtet werden darf, so ist es keine Ausnahme von der Regel, dass das Dermatogen nur die Epidermis bildet.

Etwas anderes finden wir bei Plerom und Periblem. Dies? sind nicht so leicht mit Rinde und Centralcylinder zu identifizieren. Es gilt hier die Grenze zwischen Periblem und Plerom scharf $\mathrm{zu}$ fassen und $\mathrm{zu}$ beweisen, dass sie dieselbe ist, wie die spätere Grenze zwischen Rinde und Centralcylinder, oder genauer zwischen Endodermis und Pericykel.

In der Einleitung habe ich schon angeführt, dass über diese Frage von den verschiedenen Autoren in verschiedenem Sinne geurteilt worden ist.

Viele von ihnen haben, ohne dafür einen Nachweis zu liefern, einfach die Übereinstimmung der zwei Einteilungen angenommen. 
In erster Linie gehören hierher alle diejenigen Autoren, welche die Gewebeteile im Vegetationskegel als Epidermis, Rinde und Centralcylinder bezeichnen, ohne zu beweisen, dass die bezeichneten Teile wirklich diesen Namen entsprechen. Wir finden dies $u$. a. bei Janszewsiki (16 und 17), Flahault (35), Van Tieghem und Douliot (78), welche alle statt der Namen Dermatogen, Periblem und Plerom einfach Epidermis, Rinde und Centralcylinder setzen; weiter bei ERIKsson (30 und 34), der bei seinen Figuren von Wurzelspitzen $k s$ und $p k$ (Kernscheide und Pericykel) schreibt; und DE BARY (28 Fig. 2 S. 10), der die äussere Pleromschicht als Pericykel beschreibt; alles dieses gilt für die Wurzel. Für den Stengel finden wir dasselbe bei Douliot (83), der ebenfalls die Namen Epidermis usw. auf die Histogenen anwendet, und bei DE BARY (28 Fig. 1 S. 9).

Es gibt in der Literatur aber auch eine Reihe positiver Versicherungen, aus welchen die Übereinstimmung zwischen Periblem und Rinde oder zwischen Plerom und Centralcylinder hervorgehen soll.

So schreibt VESQUE (20 S. 96): „c'est cette partie externe désignée dans cet état embryonnaire sous le nom de périblème, qui devient directement l'écorce primaire."

SAcHS schlägt in seinem Lehrbuch vor, für die Schutzscheide Casparys den Namen Pleromscheide zu gebrauchen; man könnte daraus folgern, dass auch SAcHs die Identität von Plerom und Centralcylinder annahm. Dies wäre um so merkwürdiger, weil SACHS über den Aufbau der Pflanzenorgane bekanntlich ganz andere Ansichten hatte als HANstein; seine auf die rechtwinklige Schneidung der Zellwände begründete Theorie (38) steht zwar mit der Hansteinschen nicht in direktem Widerspruch, sie beeinträchtigt dieselbe aber doch sehr. In 
seinen Vorlesungen heisst es darūber (42 S. 510, 511): „Je nach den verschiedenen Pflanzenformen ist jedoch diese beginnende Differenzirung der Gewebe im Vegetationspunkte sehr verschieden. Die von Hanstein aufgestellte Lehre von den sogenannten drei Histogenen, wonach im Vegetationspunkte selbst ausser der späteren Epidermis ein sogenanntes Periblem (junge Rinde) und ein Plerom angedeutet ist, lässt sich daher nicht allgemein durchführen."

Morot, der sich sonst ebensowenig wie Van Treghem auf entwicklungsgeschichtliche Tatsachen stützt, hat sich gegen D'Arbaumont (62 S. 204) wie folgt geäussert: „Si l'on pratique une section transversale ou longitudinale dans le voisinage du point végétatif d'une tige, on peut avec Hanstein y distinguer sous le dermatogène, c'est-à-dire l'épiderme, le périblème qui doit constituer l'écorce, et le plérome destiné à former le cylindre central."

Falkenberg hat die Entwicklung der Gewebe aus dem Meristem bei einigen Monokotylen beobachtet (24). Er fragt sich dabei, ob "die Rinde auf das Periblem, der Centralcylinder auf das Plerom Hansteins zurückgeführt werden kann. Dass dieses in der That der Fall ist, ergab die Beobachtung der Stengelspitzen von Asparagus und Tradescantia, bei welchen die unterhalb der innersten Periblemschicht gelegenen Zellen sich zu den später verholzenden Zellen der Aussenscheide entwickeln”, (= der holzige Pericykel) „welche die äussere Grenze des ausgebildeten Centralcylinders bildet. In derselben Weise entwickeln sich die Grenzzellen des Centralcylinder's von Epipactis palustris, obwohl hier eine Sonderung des Meristems der Stengelspitze in Periblem und Plerom nicht vorhanden ist." (24 S. 130). Er stellt sich dann noch die Frage, ob in solchen Fällen, wo die Sonderung in Periblem und Plerom 
nicht besteht, dennoch ein Grund vorliegt, eine Trennung in Rinde und Centralcylinder anzunehmen. Weil aber die Homologie der Centralcylinder verschiedener Pflanzen feststeht, kommt er zu folgendem Ergebnis: „Ob derselbe" (der Centralcylinder) "bereits im Vegetationspunkt als Plerom von der peripherischen Gewebeschicht differenzirt erscheint, wie bei Asparagus, oder sich aus einem regellosen Urmeristem erst weiter abwärts im Stengel ausbildet, wie bei Epipactis, ist eine Frage von nur untergeordneter Bedeutung." (24 S. 131). Über die Wurzeln berichtet er: „Viel regelmässiger und schärfer ausgeprägt als im Stengel der Monocotylen wiederholt sich die gleiche Sonderung der Gewebe in den Wurzeln, in denen sich auch die Entwicklung des Centralcylinders aus dem Plerom des Vegetationspunktes mit grösserer Regelmässigkeit vollzieht." (24 S. 132-133). Im speziellen Teil der Arbeit FadKenbergs wird aber für die Wurzel keine Untersuchung erwähnt, und für die Stengel nur eine nicht sehr eingehende, denn nur für Asparagus findet man angegeben: „Die Zugehörigkeit der Bastfasern zu dem Grundgewebe des Centralcylinders und ihre Absonderung von der Rinde ist schon im Vegetationspunkt angedeutet, indem dessen Urmeristem in Periblem und Plerom gosondert ist, von denen das erstere die Rinde, das Plerom den Centralcylinder mit seinen peripherischen Bastfasern liefert". (24 S. 59). Bei Epipactis und Tradescantia wird von dem Urmeristem nicht gesprochen.

Flahault gibt nicht nur in seinen Abbildungen den Gewebeteilen im Vegetationskegel die Namen Epidermis, Rinde und Centralcylinder, ohne zu beweisen, dass diese Gewebe aus den entsprechenden Meristemteilen entstehen, sondern er stellt sogar die Behauptung auf, die Hansteinschen Namen seien ganz und gar überflüssig und man brauche nur die Bezeichnungen Epidermis usw. anzuwenden (35 S. 21). 
WARMing, von dem ich oben anführte, dass er der HaNstæINschen Sonderung kein grosses Gewicht beilegte, schreibt an derselben Stelle: „Un autre question qui se présente ensuite, est de savoir si la distinction tranchée entre des couches et des séries de cellules, qu'on peut constater en beaucoup d'autres endroits, nous indique réellement la limite entre le méristèmemère de l'écorce primaire et celui du système fibro-vasculaire; je n'ai pu porter sur ce point toute l'attention convenable, mais n'ai aucune raison de douter de l'exactitude des assertions de N.M. Hanstein, Schmitz et Reinke à cet égard" (22 S. V). Dieser Auffassung ist WARMing bis heute treu geblieben, denn in der neuesten Auflage seines Lehrbuches (144) gibt er S. 214 und S. 285 an, dass Epidermis, Rinde und Centralcylinder aus Dermatogen, Periblem und Plerom entstehen.

Auch DE BARY vertritt in seiner "Vergleichenden Anatomie", wenigstens für Rinde und Centralcylinder der Angiospermen, die gleiche Auffassung; er schlägt sogar vor, den Begriff Plerom so zu ändern, dass es, unabhängig von der Zellanordnung im Scheitel, mit Centralcylinder identisch wird. „Plerom wäre hiernach der axile Cylinder, welcher sich in der einen Reihe von Fällen erst durch die Differenzirung des Initialcylinders" (man denke dabei nicht an Initialen; gemeint ist wohl die definitive Ausbildung des Centralcylinders) „in seiner Aussenseite von dem Periblem abhebt, und welcher sich in der anderen Reihe von Fällen scharf begrenzt bis in den äussersten, ausser den primären Meristemschichten keine Differenzirung zeigenden Stammscheitel fortsetzt" (28 S. 412).

Dass endlich bei BeYerinck auch der Gedanke vorlag, die Einteilung Hansteins sei mit der Van Tieghemschen identisch, geht wohl aus seiner Ausserung hervor, dass Haisstein in seiner "sogenannten Plerom-Periblemtheorie” eigentlich lange 
vor Van Tieghem "essentiell die Allgemeinheit des Vorkommens des Centralcylinders in den Stengeln" ausgesprochen hatte (71 S. 11).

Aus neuerer Zeit sind mir nur zwei Autoren bekannt, die eine ähnliche Äusserung veröffentlicht haben, nämlich BRunctre und Mrrande, in „Recherches embryogéniques et anatomiques sur quelques espèces d'Impatiens et de Tropaeolum" (BRunotTe, 130) und in "Recherche physiologiques et anatomiques sur les Cuscutacées". (Mirande, 136). Brunotre gibt weder detailierte Beschreibungen der Verhältnisse, noch zuverlässige Figuren, denn die seiner Arbeit beigegebenen Photogramme sind, wenn sie je für das Spitzenwachstum lehrreich gewesen sind, bei der Reproduktion gänzlich verdorben durch die mit Tinte hineingezogenen Grenzlinien, die gerade das, was sie angeben sollten, undeutlich machen.

Weit besser ist in dieser Hinsicht die Arbeit Mrrandes. Zwar sind auch die Belege, die er für die Übereinstimmung der Gewebe anführt, bei den Stengeln der einen Abteilung, der Distylées, ungenügend, ebenso wie die Belege, die er bei den Wurzeln angibt; bei den letzteren, weil die Deutung von Periblem und Plerom äusserst willkürlich ist, und bei den Stengeln, weil dort keine Endodermis oder ein sonstiges Kennzeichen der ausgewachsenen Verhältnisse angeführt wird. Für die Stengeln der andern Abteilung, der Monostylées, dagegen gibt er bessere Belege. Hier wird die Untersuchung ungemein erleichtert durch das Auftreten der pericyklischen Milchgefässe, die sich weit in den Scheitel hinein ausstrecken. Aus seinen Beschreibungen (S. 136) und den Figuren 9 auf S. 137 und 1 auf Pl. V wird es sehr wahrscheinlich, dass hier die Rinde ganz entsteht aus den zwei Kappenschichten unterhalb des Dermatogens, während das innere Gewebe den Centralcylinder 
bildet. Den strengen Beweis halte ich damit aber noch nicht für geliefert; einen solchen kann auch erst eine sehr eingehende Detailuntersuchung liefern.

Aus der älteren Literatur ist SAnro der einzige, der für seine Behauptung einen Beweis gibt. Sanio hat bei Hippuris die Bildung der Gewebe des Stengels aus dem Vegetationskegel ausführlich beschrieben $(3 \mathrm{~S} .223$ in einer nachschriftlich beigefügten Notiz). Auf Längsschnitten geht er der Entwicklung der Rinde nach und findet, dass die fünf Periblemkappen die Rinde bilden. Die innerste Kappe, welche sich noch besonders benimrnt, bildet als innerste Zellschicht die CASPARYsche Schutzscheide. Wir werden unten auf diese Verhältnisse noch mehrmals zurückkommen.

Aus dem vorhergehenden ergibt sich also, dass von einer grossen Zahl von Forschern die Übereinstimmung zwischen Plerom und Centralcylinder angenommen oder doch als höchst wahrscheinlich betrachtet worden ist.

Diesen Anschauungen stehen in der Literatur aber auch entgegengesetzte Behauptungen gegenüber, nach denen eine Übereinstimmung dieser Gewebe nicht besteht.

So schreibt Vöchтाrg in seiner Arbeit über die Melastomeen (21 S. 45): „Auch über die Frage, ob das Procambium dem Plerom oder dem Periblem Hanstrins angehöre, ist im vorliegenden Falle schwer eine Entscheidung zu treffen. Beide Gewebe gehen in einander über, und die jungen Bündel sind weder auf der äussern, noch auf der innern Seite scharf umgrenzt. Doch habe ich überall da, wo gut geführte Längsschnitte eine nur einiger Maassen sichere Deutung zuliessen, mich entscheiden müssen, ihre Anlage, wenigstens der Hauptmasse nach, dem Periblem, und nicht dem Plerom, zuzuerkennen." 
BARANETZKY gibt in zwei gesonderten Abhandlungen (116 und 129) verschiedene Tatsachen an, aus denen gefolgert werden muss, dass weder bei Dikotylen noch bei Monokotylen die primären Gewebe aus bestimmten Meristemzonen hervorgehen. In den ersteren dieser beiden, „Sur le développement des points végétatifs des tiges chez les Monocotylédones" sucht Baranetzky darzutun, dass bei den Monokotyledonen die Dauergewebe der Stengel sich nur selten im Urmeristem bilden; gewöhnlich treten eine oder zwei kambiale Zonen dazu. Die Rinde, als embryologisch selbständige Gewebeschicht, besteht bei den Monokotyledonen nicht (116 S. 361).

Wenn man inzwischen die Belege Baranetzkys liest, so ergibt sich alsbald, dass diese letztere Folgerung sehr schlecht begründet ist, denn auf die Untersuchung einiger weniger Querschnitte will BARANETZKY seine Ansicht gründen.

Dass man mit Querschnitten bei den Monokotylen-Vegetationskegeln, welche häufig ganz flach oder sogar eingesenkt sind, mitunter leicht in Irrtümer geraten kann, ist wohl selbstverständlich. Das möge das folgende Beispiel erläutern. Baranetzky kommt in seiner Arbeit auch zu dem Schlusse, dass es bei Dracaena keine Kambien im Vegetationskegel gibt, dass aber alle Dauergewebe hier direkt aus dem Urmeristem hervorgehen. Die Gefässbündel bilden sich dabei "endogen", d. h. die innersten auf dem Querschnitt sind die jüngsten. (116 S. 352).

Von vornherein liess sich aber vermuten, dass diese beiden Angaben unrichtig sein müssen, weil bei Dracaena im Centralcylinder die Gefässbündel ebensogut nach dem Palmenschema angeordnet sind als bei den meisten andern Monokotyledonen. Dieser eigentümliche Verlauf findet nun seine Erklärung gerade in dem exogenen Ursprung der Gefässbündel, vereinigt mit einem am äusseren Centralcylinderrande 
stattfindenden kambialen Dickenwachstum (von MoHL 1 S. 188, Schovte 150 S. 34).

Die Untersuchung eines Vegetationskegels von Dracaena marginaia gracilis ${ }^{1}$ ) lieferte mir auch den Beweis, dass BARANETZk y sich in beiden Punkten geirrt hat. Denn wirklich zeigt der Längsschnitt des Vegetationskegels im Centralcylinder hart an dem Vegetationspunkt eine starke radiale Anordnung, während das Bild des Gefässbündelverlaufs fast identisch ist mit dem von mir (150 Fig. 5) gegebenem Bilde Dasylirions, was nur in einer exogenen Entstehung seine Erklärung finden kann. Ich habe gerade D. marginata gewählt, weil dies eine sehr schlanke Dracaena-Art mit einem geringen kambialen Dickenwachstum ist; wenn hier schon ein solches auftritt, ist es doch a fortiori bei den dickästigen Arten zu erwarten.

Es ist demnach klar, dass BARANETZKY sich in dieser Hinsicht geirrt hatte; sein Irrtum ist wohl der unvollkommenen Methode zuzuschreiben. Es braucht als o nicht weiter dargelegt zu werden, dass auch BarANetSkys sonstige Schlüsse, denen ebenfalls nur Querschnitte $\mathrm{zu}$ Grunde gelegt sind, nicht viel mehr Vertrauen verdienen; dass somit seine Folgerung, den Monokotylen komme keine selbständige Rinde zu, ebenfalls einer Nachprüfung bedarf. Dazu kommt noch, dass von FALKENBERG eine gesonderte selbständige Rinde im Vegetationskegel des Stengels der Monokotylen angegeben wird (24 S. 163); wir tun daher am besten, wenn wir vorläufig die Selbständigkeit der Rinde im Vegetationskegel annehmen.

In seiner zweiten Abhandlung (129) gibt Baranetzky eine sehr ausführliche Besprechung der Theorie Hansteins und die

1) Katalog des Groninger Gartens No. 202. 
Übereinstimmung der embryonalen Gewebe mit den definitiven, ohne eigentlich neue Tatsachen anzuführen. Er schliesst: "Chez les Dicotylédones, non moins que chez les Monocotylédones, la formation de tels ou tels tissus primaires n'est point liée à quelques couches définies et tant soit peu distinctes du méristème primitif." (S. 325).

Schliesslich schreibt Strasburger in seinem Lehrbuch (122 S. 124): "Bei den eine Sonderung in Epidermis, primäre Rinde und Centralcylinder aufweisenden Gewächsen bildet das Dermatogen in Allgemeinen die Epidermis, das Periblem die primäre Rinde, das Plerom den Centralcylinder; doch brauchen diese Beziehungen nicht überall $z u$ bestehen und setzt sich die Gewebesonderung thatsächlich nicht bis in das embryonale Gewebe der Vegetationspunkte fort. Es sind vielmehr mechanische Momente, welche die Zellordnung dort bestimmen".... "Die Termini Dermatogen, Periblem und Plerom sollen somit nur die kurze Bezeichnung bestimmter Zellenschichten des Vegetationskegels erleichtern, nicht aber das Vorhandensein distincter Gewebebildner, Histogene, wie man sich ausgedrückt hatte, dort bezeichnen."

Nach dem vorhergehenden sind wir somit völlig berechtigt zu der Behauptung, dass zur Zeit hier noch keine Gewissheit besteht. Ob zwischen Periblem und Rinde und zwischen Plerom und Centralcylinder eine Übereinstimmung besteht, bleibt näher zu untersuchen.

Als eine Tatsache, welche auf die Selbständigkeit der Rinde in entwicklungsgeschichtlicher Hinsicht hinweist, will ich noch den Umstand hervorheben; dass die innersten Rindenzellen vielfach radial angeordnet sind, der Pericykel dagegen sich bei dieser Anordnung nicht anschliesst (Vergl. hierüber SANIo 3 S. 222 , Van Tieghem 101 S. 674). 
Dem steht aber gegenüber, dass bei den Farnen Pericykel und Endodermis öfters aus einer einzigen Zelllage entstehen, (Van Tieghem 101 S. 753, Bretland Farmer and Hill 146 S. 388). Auch bei den Rhizomen der Monokotyledonen soll nach Guillaud (36 S. 141) dasselbe der Fall sein, obwohl diese Angaben einer Nachprüfung bedürfen.

\section{§ 2. Eigene UnTERsuchung.}

Diese Untersuchung erstreckt sich nur auf einige wenige Formen. Denn ich habe mich dabei bemüht, lieber einige Beispiele mit möglichster Sorgfalt $z u$ erforschen, als viele Formen in mehr oberflächlicher Weise zu studieren.

Die Methoden, die ich dabei befolgte, sind wieder verschieden, je nachdem eine Wurzel oder ein Stengel untersucht wurde; ich werde sie daher gesondert besprechen.

\section{Untersuchungen an Wurzeln.}

1. Methodisches. Wie schon wiederholt gesagt worden ist, war es meine Aufgabe, die Identifizierung der Grenze zwischen Periblem und Plerom mit derjenigen zwischen Rinde und Centralcylinder zu versuchen.

Es lag also nahe, zu versuchen, einen gut geführten medianen Längsschnitt einer Wurzel zu bekommen, auf dem man im oberen Teil die Grenze zwischen Periblem und Plerom und im unteren diejenige zwischen Rinde und Centralcylinder sehen konnte, wobei z. B. die Anwesenheit einer Endodermis mit Casparyschen Punkten den nötigen Anhalt geben könnte.

Nach einigen vergeblichen Versuchen stellte sich aber heraus, dass dieser Weg nicht der richtige war. Wenn man die Sache 
nämlich genau untersuchen will, kann man sich nicht mit den dicken Freihandschnitten der älteren Autoren begnügen, (HANSTEIN 7 S. 111, Schmitz 19 S. 11), sondern man braucht Schnitte, welche nicht dicker sind als eine Zelle, besser noch solche, die etwa die Hälfte einer Zelle dick sind. Solche. Schnitte dürfen also nicht viel dicker sein als $5 \mu$. Diese lassen sich bekanntlich nach gehöriger Paraffineinbettung mit dem Mikrotom sehr leicht herstellen. Die Schwierigkeit liegt hier aber an anderer Stelle. Bei den Phanerogamenwurzeln entwickelt sich die Endodermis - im Gegensatze zu derselben bei den Gefässkryptogamen - erst spät, oft erst in etwa $1 \mathrm{~cm}$ Entfernung von, dem Vegetationspunkt, oder noch später. ${ }^{1)}$ Dazu kommt noch, dass sich bei der Betrachtung der Serienschnitte herausstellte, dass, wenn eine Schutzscheide nicht sehr deutlich ist, sie auf dem Querschnitt schwierig,

1) Ich habe dieses Verhalten bei mehreren Keimwurzeln gelegentlich (an Freihandschnitten) untersucht; für diejenigen, die sich dafür interessieren, gebe ich nachstehende Tabelle. Wenn in einer Wurzel auf mebr als $0.6 \mathrm{~cm}$ von der Spitze keine deutliche Schutzscheide gefunden war, so wurde diese Wurzel, weil sie für mein Ziel unbrauchbar war, nicht weiter untersucht.

\begin{tabular}{l|c|c}
\hline \hline N A M E N. & $\begin{array}{c}\text { em von } \\
\text { der Spitze. }\end{array}$ & Art der Schutzscheide. \\
Allium Cepa L. & 1.4 & nicht zu beobachten. \\
Avena sativa L. & 0.7 & " " " \\
Hordeum vulgare L. & 1.2 & nicht deutlich. \\
Hyacinthus orientalis L. & 1.7 & sehr deutlich. \\
Zea Mays L. " & 0.4 & " " \\
1. Zuckermais & 0.7 & nicht deutlich. \\
2. Pferdezahnmais & 3.5 & schwach differenziert.
\end{tabular}


auf dem Längsschnitt aber gar nicht zu beobachten ist; wahrscheinlich rührt das von der geringen Schnittdicke her. Auch mit Reagentien gelang es mir nicht, sie deutlich hervortreten zu lassen. Der mediane Längsschnitt hätte sich also in den günstigsten Fällen über mehr als $5 \mathrm{~mm}$, in den meisten Fällen sogar über $1 \mathrm{~cm}$ ausdehnen müssen.

\begin{tabular}{|c|c|c|}
\hline$N$ A M E N. & $\begin{array}{c}\text { cm von } \\
\text { der Spitze. }\end{array}$ & Art der Schutzscheide. \\
\hline $\begin{array}{l}\text { 3. Gewöhnlicher Mais } \\
\text { Cucurbita Pepo L. } \\
\text { Ranunculus Ficaria L. } \\
\text { Helianthus annuus L. } \\
\text { " " } \\
\text { Lathyrus odoratus L. } \\
\text { Linum usitatissimum L. } \\
\text { " " } \\
\text { Pisum sativum L. } \\
\text { Polygonum Fagopyrum L. } \\
\text { Raphanus sativus L. } \\
\text { " " } \\
\text { Solanum tuberosum L. } \\
\text { (Stolones) } \\
\text { Vicia Faba L. } \\
\text { " " }\end{array}$ & $\begin{array}{l}3 \\
1.5 \\
1.1 \\
0.3 \\
1.2 \\
0.55 \\
1 \\
1.1 \\
0.4 \\
1 \\
1.0 \\
1.3 \\
0.9 \\
1.1 \\
0.65 \\
3 \\
1.4\end{array}$ & $\begin{array}{l}\text { deutlich. } \\
\text { nicht deutlich. } \\
\text { sehr undeutlich. } \\
\text { deutlich. } \\
\text { ziemlich deutlich. } \\
\text { weniger " } \\
\text { nicht zu beobachten. } \\
\text { ziemlich deutlich. } \\
\text { nicht zu beobachten. } \\
\text { sehr undeutlich. } \\
\text { nicht sehr deutlich. } \\
\text { "zu beobachten. } \\
\text { nicht sehr deutlich. } \\
\text { " " " " " } \\
\text { nicht zu beobachten. }\end{array}$ \\
\hline
\end{tabular}

Diese Angaben sind nicht immer scharf, es ist schwer zu sagen, ob eine Schutzscheide deutlich ist oder nicht. Als deutlich betrachtete ich sie, wenn ich die Schutzscheide von Zelle $z u$ Zelle bestimmt angeben konnte, entweder in Glycerin oder in Phloroglucin-Salzsäure. 
Es ist aber nicht möglich, eine Wurzel über eine solche Länge überall genau median zu treffen. Nicht, dass die Technik des Mikrotoms das nicht gestattet, denn nach einigen besonderen Massnahmen kann man äusserst genau sein Objekt richten, wie ich unten beschreiben werde, sondern weil die Wurzeln selbst nie genügend gerade sind.

Ich habe speziell zu diesem Zwecke Wurzeln von verschiedenen Pflanzen in Wasser wachsen lassen, und bekam dann wohl sehr gerade Wurzelspitzen; trotzdem konnte ich mit diesen nicht fertig werden. Denn wenn man in den Präparaten auch nur einmal von einer Längs-Zellreihe auf die nächste übergeht, ist das Bild schon wieder unklar.

Ich habe es deshalb auf andere Weise versucht. Von einer eingebetteten Wurzelspitze machte ich von der Basis her Querschnittserien, bis die Wurzel bis auf $1 \mathrm{~mm}$ ganz aufgeschnitten war. Alsdann löste ich den Paraffinklotz von dem Schüsselchen, und klebte ihn auf diesem in anderer Stellung wieder an, so dass er sich nunmehr für Längsschnitte eignete; den Rest der Wurzel schnitt ich dann nach dieser Richtung ganz auf.

Dieses Verfahren bietet zwei Vorteile. Erstens kann man natürlich Wurzeln von beliebiger Länge benutzen, auch solche, welche nicht vollkommen gerade sind, ja man kann selbst sehr krumme gebrauchen, wenn nur das letzte Spitzchen gerade ist. Zweitens aber kann man auf den Querschnittserien die Endodermis und den Pericykel mit weit grösserer Sicherkeit verfolgen. Denn auf dem Längsschnitt sieht man von jedem Gewebe nur zwei Zellreihen, eine rechte und eine linke, auf dem Querschnitt dagegen sieht man den ganzen Umkreis und die Querschnittform der Zellen. Hat man auf dem Längssichnitt eine Strecke, welche nicht durch eine Endodermiszellreihe 
hindurch geht, sondern zwischen $\mathrm{z}$ wei, so kann man natürlich keine von beiden gut beobachten. Alle Unbequemlichkeiten, welche den dünnen Längsschnitten anhaften, und welche die älteren Autoren zur Benutzung dicker aufgehellter Schnitte veranlassten, sind also durch dieses Verfahren beseitigt, wenigstens für den grössten Teil der Wurzel, nicht für den eigentlichen Vegetationskegel.

Nur für das letzte Spitzchen bleibt man auf dünne Längsschnitte angewiesen; es sind dies auch die einzigen Schnitte, aus denen man die Struktur desselben studieren kann.

Bei diesem Verfahren ist es notwendig, dass man den Paraffinklotz sehr genau richten kann. Dazu empfiehlt es sich in erster Linie, dass man die farblosen Würzelchen vor dem Einbetten durchfärbt. Die Grenachersche Borax-Karminlösung ist dazu sehr geeignet. Diesen Borax-Karmin, welcher gewöhnlich nur mit $35 \%$ Alkohol zubereitet wird, machte ich, um unnötiges Dialysieren umgehen zu können, mit $85 \%$ Alkohol. Einige Stunden Aufenthalt in dieser Lösung genügen vollkommen; die Wurzeln haben dann eine tiefrote Farbe angenommen. Zweitens ist es von Vorteil, hier einen guten Definierapparat (MoLL 120, S. 27) zu benutzen, weil man damit das Paraffin weit besser rechtwin. kelig abschneiden kann, und weil man dann dem sich darin befindenden Objekt viel näher kommen kann, was wieder das Objekt viel deutlicher durchschimmern lässt. Auf diese Weise kann man leicht auch die kleinsten Stückchen äusserst genau richten.

Dazu machte ich noch von einer anderen Kontrolle Gebrauch. Wenn der Paraffinklotz für das Längsschneiden möglichst genau orientiert war, fing ich in gewöhnlicher Weise an zu schneiden, bis eine gerade Schnittfläche an dem Paraffin ge- 
bildet war; ich sorgte aber dafür, dass ich nicht zu weit schnitt, damit das Objekt unberührt blieb. Alscaann schraubte ich die ganze Paraffinschüssel vom Mikrotom ab, und betrachtete den Paraffinklotz mit dem durchschimmernden Objekt unter dem Mikroskop. Darauf wurde der Abstand vom Centrum des Centralcylinders an der Basis des Spitzchens bis zur Schnittfläche in $\mu$ gemessen, was sehr leicht geschehen konnte, weil die Basis durch das vorherige Querschneiden an der Oberfläche des Paraffins gelagert war. In gleicher Weise mass ich den Abstand von der Spitze der Kalyptra bis zur Schnittfläche. Waren diese beiden Abstände einander gleich, so war eine mediane Schnittführung gesichert.

Nach dieser Kontrollierung schraubte ich die Paraffinschüssel wieder auf das Mikrotom und brachte das Objekt so wieder in genau dieselbe Lage wie vor der Kontrolle. Dieses letztere Verfahren ist natürlich nur bei einem sehr gut gearbeiteten Mikrotom möglich; zu meiner Verfügung stand das ReINHoLdGiltay-Mikrotom, bekanntlich eines der best konstruierten, die es gibt (MoLl 104, S. 445).

Während der ganzen Manipulation notierte ich stets sofort die Form der Schnitte, die Krümmung des Bandes, wenn diese sich zeigte, und die Lagerung des Objektes. Denn erstens musste ich natürlich später immer feststellen können, wie die Schnitte aufeinander gepasst hatten, was also die morphologische Oberseite der Schnitte war. Zumal bei der Umlegung des Paraffinklotzes, wenn ich von der Querschnittrichtung zur Längsschnittrichtung überging, musste ich genau auf das Verhältnis der Lagerungen achten. Grossen Nutzen boten mir diese Notizen bei dem Aufkleben der Schnitte. Die kleinen Bänder waren nämlich nicht sehr leicht zu handhaben. Wenn ich die Bänder in bestimmte Stücke teilte, und diese Stückchen 
zum Aufkleben auf ein Objektglas legte, so konnte es vorkommen, dass die Bänder durch eine ungeschickte Bewegung oder eher noch durch eine ungeschickte Athmung umgedreht wurden oder durcheinander gerieten. In solchen Fällen, und auch wenn die Bänder schon vorher zerrissen oder umgedreht wurden, konnte ich mit Hilfe dieser Notizen immer die richtige Folge und Anordnung zurückfinden, zumal weil ich die Paraffinklötze nicht rechtwinkelig abschnitt, sondern so, dass die Schnittfläche ein rechtwinkeliges Trapezium war. Wenn später dann auch die Anordnung zerstört wurde, so war an jedem Stückchen Unter- und Oberseite zu erkennen, ebenso die rechte und linke Seite. Die richtige Folge war dabei meistens auch wiederzufinden; nötigenfalls war dies aber bei nicht zu sehr zerstückelten Bändern immer an dem fertigen Präparat noch ganz genau zu erkennen, wenn man nur auf solche untergeorineten Merkmale achtete, die sich in den aufeinanderfolgenden Schnitten annähernd gleich verhielten.

Wenn alles in solcher Weise fertig gestellt war, sollte der mediane Längsschnitt mit dem letzten Querschnitt genau verglichen werden. Von vornherein würde man sich diese Vergleichung so denken: ich kenne die Richtung nach der der Längschnitt auf den Querschnitt gepasst hat; ich zähle nun in dem Querschnitt die Zahl der Rindenschichten in dieser Richtung an beiden Seiten; dann zähle ich auf dem Längsschnitt eben so viele Zellschichten innerhalb der Epidermis ab und finde so die Endodermis. Auf solche Weise würde man aber nicht weiter kommen, denn man kann die Zahl solcher Schichten nicht so genau feststellen. Wo der Längsschnitt zwischen zwei Zellen durchgeht, fehlt eine Schicht des Querschnittes; wo dagegen auf dem Querschnitt zwei Zellen einer und derselben Schicht etwas in tangentialer Richtung an 
einander vorbeischieben, kann man auf dem Längsschnitt zwei Schichten finden. Es müssten also auf andere Weise die Endodermis und der Pericykel auf dem Längsschnitt aufgefunden werden, nämlich nach dem Grössenunterschied, nach der Lagerung neben den Xylemgefässen, und ähnlichen Merkmalen.

Über die sonstigen Methoden brauche ich nicht viel zu sagen. Das angewandte Material war ausnahmslos mit $1 \%$ Chromsäure fixiert, und in gewöhnlicher Weise eingebettet. Als Durchgangsmedium wurde Terpentin oder Xylol benutzt. Das Paraffin war von der Cambridge Society, Schmelzpunkt $55^{\circ}$. Die Schnittdicke war bei den Querschnitten 8-10 $\mu$, bei den Längsschnitten $5 \mu$. Die Schnitte wurden mit Eiweiss aufgeklebt, und unter Umständen mit Hämatoxylin, Safranine oder Kongorot nachgefärbt.

2. Hyacinthus orientalis. L. Von dieser und von den folgenden untersuchten Pflanzen findet sich in der Literatur schon eine Untersuchung des Spitzenwachstums mit einer Abbildung, in welcher Periblem und Plerom angegeben worden sind. Denn weil die Unterscheidung von Periblem und Plerom, wie schon aus der Literatur mit ihren vielen streitigen Angaben hervorgeht, manchmal eine missliche Sache ist, so habe ich mich in der Wahl der Pflanzen stets auf solche beschränkt, von denen mir die Grenze zwischen Periblem und Plerom aus einer Abbildung eines früheren Autors bekannt war. Die Abbildung von Hyacinthus findet man bei Treub (25 Pl. II Fig. 5).

Das Material zu dieser Untersuchung entnahm ich einer auf Wasser gestellten, im Zimmer gezogenen Pflanze, gegen Ende Februar 1901.

Die Querschnittserie dehnte sich, mit Unterbrechungen, von 
$6 \mathrm{~mm}$ unterhalb der Spitze bis an $1.5 \mathrm{~mm}$ unterhalb derselben aus.

Der letzte Querschnitt, also der jüngste, der in der Wurzel der Spitze am nächsten gewesen war, wurde nun genau beschrieben und die Zahl, die Beschaffenheit und die Dimensionen der Zellschichten ermittelt. Ich will aus dieser Beschreibung nur hervorheben, dass an der Innenseite der 10-11 Zellschichten starken Rinde die Endodermis sehr gut zu erkennen war. Die Casparyschen Punkte waren hier vielleicht schon angedeutet, mit Gewissheit war das aber nicht zu sagen. Die Vergleichung mit den älteren Stadien aber zeigte mit grosser Sicherheit, dass die betrachtete Zellschicht die Endodermis war. Der einschichtige Pericykel war der Endodermis sehr ähnlich, war aber ebenfalls ganz sicher zu bestimmen, zumal durch die an ihm nach innen angrenzenden 9 Xylemgefässe, welche in der Bildung begriffen waren; die Wurzel war ennearch.

Die letzte, $1.5 \mathrm{~mm}$ lange Spitze der Wurzel war der Länge nach aufgeschnitten. Die Schnitte wurden alle gezählt und mit einer Folgenummer belegt; diese Zahlen schrieb ich auf dem Klebezettel neben das Präparat. Es galt nun, den Medianen unter den Schnitten aufzufinden.

Man konnte dazu natürlich einfach die blosse Zahl der Schnitte gebrauchen: wenn es also 200 Schnitte gab, so waren 100 und 101 die Medianen. Dies ist aber nicht genau, weil der Centralcylinder öfters etwas excentrisch in der Wurzel orientiert ist; man tut daher besser, enger liegende Schranken zu wählen, wie z. B. das beiderseitige Auftreten von markähnlichen Zellen, weiter von Xylemelementen, des Centralcylinders selbst, oder einer Abrundung an der Spitze des Schnittes.

Je enger die Schranken, um so sicherer wird man die organische Mitte der Wurzel bestimmen können. Für das gewählte 
Merkmal bestimmt man also den Schnitt, in dem es auftritt und wo es in der Schnittserie wieder verschwindet; gerade in der Mitte zwischen diesen beiden äusseren Punkten muss dann der mediane Schnitt liegen, wenigstens wenn die Wurzel hinreichend symmetrisch gebaut ist. Liegt dagegen die Mitte etwas exzentrisch, so ist das in dem letzten Querschnitt ganz sicher zu bestimmen; in solchen Fällen muss man bei der Bestimmung des Medianen damit Rechnung halten.

Hier bei Hyacinthus wurde das Auftreten der inneren markähnlichen Zellen zur Bestimmung des Medianen gewählt. In dem auf solche Weise bestimmten medianen Längsschnitt war es nun sehr leicht, an der Basalseite durch Vergleichung mit dem letzten Querschnitt Endodermis und Pericykel mit Gewissheit anzugeben.

Die auf solche Weise bis hoch in die Wurzel bestimmte Grenze zwischen Rinde und Centralcylinder sollte nun noch mit derjenigen zwischen Periblem und Plerom verglichen werden.

Wenn ich den medianen Längsschitt des Vegetationskegels aber betrachtete, so war eine auffallende Grenze darin nicht anzugeben, man konnte ebensogut andere Grenzen ausfindig machen.

Auch die Figur Treubs konnte ich leider nicht benutzen, weil die zwei Bilder - seine Figur und mein Präparat einander nur wenig ähnlich waren: die von Treub untersuchte Wurzel hatte einen sicher dreimal so breiten Vegetationskegel. Dies rührte wahrscheinlich daher, dass mein Material der Pflanze entnommen war, als die Wurzeln schon etwa $20 \mathrm{~cm}$ lang waren, also vielleicht nicht mehr stark wuchsen; vielleicht war das Material Treubs eben austreibenden Zwiebeln entnommen, wenn die Wurzeln noch viel stärker sind.

Es blieb mir also nichts anderes übrig, als zu untersuchen, 
ob die Trennung von Rinde und Centralcylinder sich auch nach der Spitze zu bewährte. Wenn z. B. Endodermis und Pericykel zusammen aus einer Zellschicht entstanden, so wäre allerdings die gesuchte Übereinstimmung nicht vorhanden.

Als ich aber die zwei Zellschichten nach oben hin verfolgte, ergab sich, dass deren Trennung sich im Vegetationspunkt trefflich bewährte. Ja, wenn man von der einen Seite aufsteigend der Grenzlinie über die Spitze herum bis an die andere Seite folgte, kam man dort von selbst auf die Grenze zwischen Endodermis und Pericykel aus, ohne dass man dabei fehl gehen konnte. Die so in der Spitze bekommene Grenzlinie liess sich auch sehr gut als Grenze zwischen Periblem und Plerom auffassen. In Figur 1 kann man die so gefundene Grenze

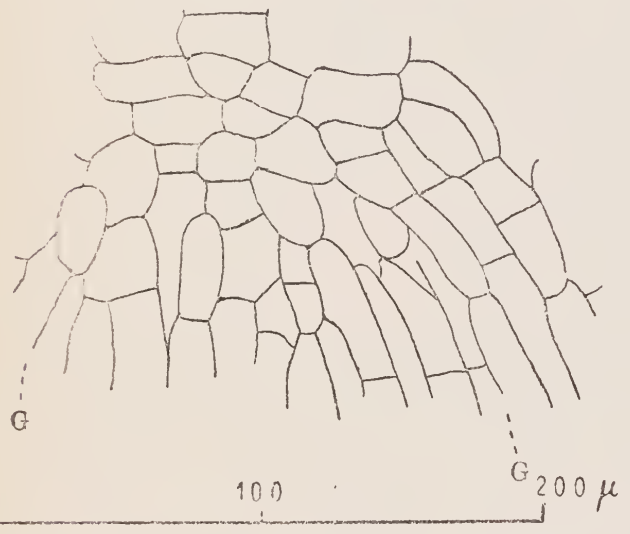

Fig. 1. Medianer Längsschnitt durch die Wurzelspitze von Hyacinthus. G. Grenze zwischen Endodermis und Pericykel. im Vegetationspunkt beobachten. Die Kontinuität der Grenze über den Scheitel herum ist auch hier wohl zu sehen.

Wir sehen also, dass, wenigstens wenn man die von mir in der Spitze gefundene Grenzlinie als Trennung von Periblem und Plerom auffassen will, bei dieser Wurzel die gesuchte Übereinstimmung tatsächlich besteht.

3. Helianthus annuus. Versuche, die ich vorher eingestellt hatte, die Keimwurzeln von Helianthus in Wasser wachsen zu lassen, scheiterten vollständig. Die Wurzeln nämlich dringen nur sehr wenig in das Wasser hinein, krüm- 
men sich dann aber aufwärts und schwimmen, auch wenn der Same gut befestigt worden ist.

Andere, in Sägemehl gestelite Samen keimten sehr gut, und die Wurzeln dieser Pflänzchen liessen sich sehr gut benutzen.

Eine Untersuchung und eine Abbildung von Helianthus finden wir zuerst in der Arbeit Reinkes (9 Taf. 1 Fig. 1 und 5). Diese Untersuchung bildet den Ausgangspunkt für alle späteren Forschungen über das Spitzenwachstum der Wurzel. Dem „Typus Helianthus” begegnet man in der späteren bezüglichen Literatur auf jedem Schritt. Später ist Helianthus annuns ebenfalls von JANCZEwskI untersucht worden (16 S. 180, Pl. 15 Fig. 5). Es lag also nahe, auch dieses klassische Beispiel zu untersuchen.

Bei dieser Wurzel verfuhr ich in ganz ähnlicher Weise wie bei Hyacinthus; ich habe hier auf solche Weise von zwei Wurzelspitzen Präparate gemacht, von denen aber nur die eine eingehend untersucht, die andere zur Kontrolle herangezogen wurde. Ich werde hier nur das am genauesten untersuchte Exemplar beschreiben. Auf dem letzten Querschnitt waren Endodermis und Pericykel mit Hilfe der älteren Querschnitte leicht zu bestimmen; ausserdem waren drei Xylemgefässe zu beobachten, zwei dicht nebeneinander, ein diametral dagegenüber; durch diese war es leicht den Pericykel anzugeben. Die Endodermis hatte sich auf zwei Strecken, an den Stellen gegenüber den späteren Phloemsträngen, verdoppelt, und bildete hier schon die für die Compositen charakteristischen schizogenen Harzgänge (Vergl. SolEREder 128 S. 520, daselbst auch die bezügliche Literatur). Auf dem Querschnitt waren diese Harzgänge aber noch nicht von den ihnen ganz ähnlichen viereckigen Intercellulärräumen in der Rinde zu unterscheiden, nur die Lagerung in zwei Bogen war charakteris- 
tisch; den Xylemteilen gegenüber war die Endodermis einschichtig. Auf dem Längsschnitt dagegen waren diese Harzgänge selbst in der nur $1 \mathrm{~mm}$ langen Spitze sehr deutlich als schmale, durch Diaphragmen gefächerte Gänge zu erkennen. Diese Diaphragmen befanden sich in Abständen von $2-20 \mu$, ziemlich unregelmässig, sie korrespondierten gar nicht mit den horizontalen Wänden in den Zellen der Endodermisreihen, die den Intercellulärgang begrenzten.

Anfangs hielt ich diese Gebilde für in der Bildung begriffene Phloemgefässe. Die Vergleichung mit den Querschnitten zeigte aber bald, das dem nicht so war. Ich werde hierauf etwas näher eingehen, um zu zeigen, welche grossen Vorteile das Arbeiten mit einem solid konstruierten Mikrotom darbieten kann.

Wenn es Phloemgefässe waren, so mussten sie natürlich innerhalb des Pericykels vorkommen. Der Centralcylinder ohne Pericykel war nun in dem obersten Querschnitt $110 \mu$ breit, die gefässartigen Elemente beobachtete ich dagegen in Präparat 56 bis 51 und in 27 bis 25, also auf 31 Präparaten $=155 \mu$ Abstand. Ich kam dadurch also zu der Vermutung, dass es die endodermalen Intercellulären sein mussten, obgleich mich das wunderte, weil diese den Intercellulären der Rinde auf dem Querschnitt ganz ähnlich waren, eine besondere Natur der Endodermis-Intercellulären also nicht nahe lag. Zur Kontrolle betrachtete ich nun den letzten Querschnitt und berechnete aus den Verhältnissen desselben, in welchen Längsschnitten sich Endodermis-Intercellulären finden mussten. Das war - weil diese Intercellulären sich in zwei Bogen angeordnet fanden - an der linken Seite von $65 \mu$ vor den Medianen bis $35 \mu$ nach den Medianen, und an der rechten Seite von $40 \mu$ vor bis $90 \mu$ nach den Medianen. Tatsächlich fanden die Harzgänge sich an der linken Seite von Präparat 
25 bis Präparat 44, an der rechten Seite von Präparat 30 bis 56. Rechnet man das aus, dann bekommt man: links von $65 \mu$ vor bis $35 \mu$ nach dem Medianschnitt, rechts von $40 \mu$ vor bis $85 \mu$ nach den Medianen, wenn man als median die Grenzfläche zwischen Schnitt 37 und 38 annimmt.

Die Übereinstimmung ist also äusserst genau. Auch die Zahl der Gänge war beweisend: in dem Querschnitt fanden sich links 9, rechts 10 dieser Gänge, in den Längsschnitten fand ich von diesen links 7 , rechts 10 wieder. Dass mir zwei Gänge links auf den Längsschnitten entgangen sind, ist nicht befremdend, weil die kleinsten Gänge nur $2-3 \mu$ breit waren, also in $5 \mu$ dicken Schnitten leicht übersehen werden konnten.

Das Reinhold-Giltay-Mikrotom hat sich also hier als äusserst exakt gezeigt. Denn wenn die Schnittdicke nur ein wenig variabel gewesen wäre, so hätten alle oben gezogenen Schlüsse nicht in so vollkommener Weise bestätigt werden können.

Ausser diesen Endodermal-Gängen waren auch die Xylemgefässe in den Längsschnitten sehr gut zu beobachten. Diese beiden Elemente, endodermale Harzgänge und Xylemgefässe, gaben also in den Längsschnitten die sichersten Anhaltspunkte für die Bestimmung von Endodermis und Pericykel.

Der mediane Längsschnitt war auch wieder sehr genau zu bestimmen.

Wie wir oben schon sahen, und wie auch auf andere Weise bestätigt wurde, waren No. 37 und 38 etwa die Medianen. Zum Studium wurde No. 37 gewählt; besonders deshalb, weil in 37 an beiden Seiten ein Endodermalgang zu sehen war, was natürlich der Untersuchung eine grössere Sicherheit verleihen konnte.

Der linke Endodermalgang setzte sich nun von der Basis 
$600 \mu$ nach dem Vegetationspunkt fort (die ganze Spitze war $700 \mu)$; von der Basis bis $200 \mu$ höher in No. 37, von $200-400 \mu$ in No. 36, von $450-600 \mu$ wiederum in No. 37. Die Grenze zwischen Rinde und Centralcylinder war noch weiter nach oben, bis in den Vegetationspunkt, ganz sicher zu verfolgen. An der rechten Seite war es nicht so leicht die Grenze nach oben zu verfolgen, denn in halber Höhe des Schnittes hörte der Endodermalgang plötzlich auf, weder in 36 noch in 38 war er weiter zu verfolgen; anstatt der Endodermiszellen mit Intercellulärgang trat ein anderer Zellkomplex auf, 2 andere, breitere Zellreihen ohne Harzgang. Der Pericykel aber liess sich ungestört verfolgen, die Grenze konnte rechts ebensohoch, bis in den Vegetationspunkt, gesehen werden. Eine Kontinuität dieser Grenze über den Scheitel hin, wie bei Hyacinthus, war jedoch nicht vorhanden, sie war sichtlich gestört. Dies rührte von den sich im Marke befindlichen zentralen Zellreihen her. Es wird sich lohnen, auf diese Verhältnisse etwas näher einzugehen, weil das auf das ganze Spitzenwachstum einiges Licht werfen kann.

In dieser Wurzel fanden sich im letzten Querschnitt zwei grosse zentrale Zellreihen, welche auf den Längsschnitten natürlich auch zu finden waren. Diese Zellen, welche sich zu zentralen Markzellen entwickeln, werden von JANCzEwski fälschlich als künftige Gefässe beschrieben (16 S. 180, 181). Diese Zellreihen nun liefen keineswegs ungestört bis in den Vegetationspunkt hinein; die eine derselben hörte $80 \mu$ unterhalb des Vegetationspunktes auf; auf seiner Spitze stand dort, schief aufgesetzt, eine andere grosszellige, aber kürzere Zellreihe, die aus 7 Zellen bestand. Diese Zellreihe ist in Fig. 2 bei M teilweise zu beobachten. Die andere grosse Zellreihe 
lag in einem anderen Schnitt; diese reichte weiter in die Wurzel hinauf, ihr oberes Ende kam mit der obersten Zelle der 7 zelligen Reihe gleich. Auf der Spitze dieser zwei Zellreihen nun standen, ganz oben im Vegetationspunkt, drei sehr kurze

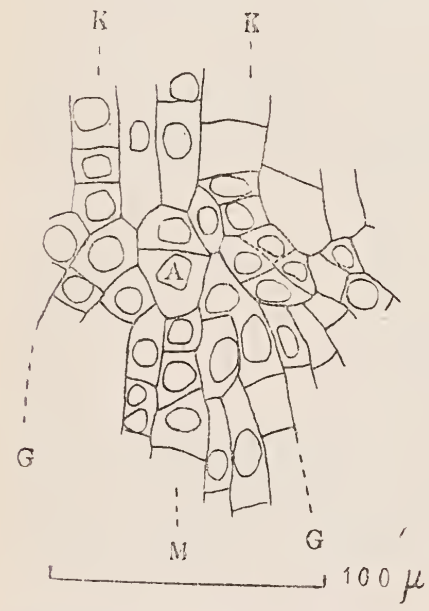

Fig. 2. Medianer Längsschnitt (No.37) durch die Wurzelspitze von Helianthus. G. Verlängerung der Grenze zwischen Endodermis und Pericykel. M. Markähnliche Zellreihe. K. Kalyptrazellen. A. Siehe Text. Zellreihen nebeneinander, von denen eine im abgebildeten Schnitt lag (Fig. 2, A); eigentlich waren es nur drei grosse Zellen, von welchen sich jede durch eine senkrecht zur Achse der Wurzel gehende Wand geteilt hatte. Diese drei Zellreihen nun ragten mit ihrem oberen Ende durch die Grenze zwischen Periblem und Plerom und grenzten dort an unzweideutige Kalyptrazellen (Fig. 2, K). Es bestand somit zwischen den Mark- und den Kalyptrazellen eine ununterbrochene Kontinuität, wie das auch bei den Leguminosen vorkolismt. (Vergl. die Literatur z. B. bei DE BARY 28 S. 13, Fig. 5).

Im zweiten Exemplar war eine derartige Kontinuität von Mark und Kalyptra ebenfalls nachzuweisen; das Bild dieser Wurzel war dem der vorigen im allgemeinen zum Verwechseln ähnlich.

Welche Schlussfolgerung können wir für unsere Zwecke aus dieser Untersuchung ziehen?

Die Grenze zwischen Rinde und Centralcylinder lässt sich bis sehr hoch in die Spitze hinein verfolgen. Ist diese Grenze nun identisch mit der zwischen Periblem und Plerom? Die Vergleichung der gefundenen Grenze mit derjenigen zwischen Periblem und Plerom, wie sie von REINke angegeben worden 
ist, bringt uns nicht weiter. Wirklich ergibt sich, wenn man das natürliche Präparat mit der Zeichnung Reinkes vergleicht, dass letztere sehr schematisch ist, und nicht naturgetreu sein kann. Dasselbe Urteil ist schon früher von JANczewski ausgesprochen worden, (16 S. 164), der ebenfalls Helianthus untersucht hatte.

Weit besser ist die Figur Janczewskis (16 Pl. 15 Fig. 5), welche sehr naturgetreu ist. Dennoch ist es sehr schwierig, eine Grenze zwischen Periblem und Plerom aus einer Zeichnung auf ein Präparat zu übertragen; die Zellen sind in den Vegetationskegeln einander alle so sehr ähnlich, dass ein Anhaltspunkt dabei nicht zu finden ist. Dazu sind die Verhältnisse offenbar sehr variabel. So hat JANczewski z. B. ein kontinuierliches Dermo-Kalyptrogen über den Scheitel hin gefunden. Bei den von mir untersuchten Wurzeln war in beiden Exemplaren das Dermatogen nicht kontinuierlich; wenn man die Epidermis von unten auf verfolgte, kam man von beiden Seiten her in die Kalyptra hinein, ganz wie bei den Leguminosen-Wurzeln. Diese Verschiedenheiten rühren wahrscheinlich von der Verwendung verschiedenen Materials her.

Wenn es also nicht sicher war, dass die von mir aufgefundene Grenze dieselbe war wie diejenige, welche JANCzEwsKI annahm, so war dies doch ebensowenig unwahrscheinlich.

Wir müssen also auch hier wieder schliessen, dass die von mir gefundene Linie im Vegetationskegel, welche sich ungezwungen als Grenze zwischen Periblem und Plerom deuten lässt, identisch ist mit der späteren Grenze zwischen Endodermis und Pericykel. In Abweichung von Hyacinthus ist diese Grenze im Vegetationspunkt nicht kontinuierlich, sondern wir haben hier einen Übergang zum Legu- 
minosentypus. Den "Typus Helianthus" finden wir also bei Helianthus wenigstens in diesem Falle nicht.

4. Linum usitatissimum. L. Die Wurzel dieser Pflanze ist schon früher von ED. DE JANCZEWSKI in derselben Schrift wie die Wurzel von Helianthus untersucht und abgebildet worden (16 S. 185, Pl. 16. Fig. 2). Hier war zum erstenmal mein Präparat der Zeichnung ganz ähnlich,

Die Querschnitte gingen hier bis $\pm 750 \mu$ von dem Vegetationspunkt. In dem letzten derselben waren Endodermis und Pericykel wiederum mit Gewissheit zu erkennen, zumal durch das Auftreten von zwei Gefässen an der Innenseite des einschichtigen Pericykels.

Von den Längsschnitten war $N^{0} .30$ etwa der Mediane. Weil aber einer der zwei Gefässe in 28 und 29 sichtbar war, so wurde $N^{0} .29$ zur Untersuchung gewählt. Wenn man die Grenze zwischen Rinde und Centralcylinder nach oben verfolgte, ergab sich auch hier, dass der Centralcylinder schon im Vegetationspunkt scharf abgeschieden war.

Die so im Vegetationspunkt aufgefundene Grenze war derjenigen in der Figur JANCZEwskis völlig ähnlich; es ist deshalb. auch nicht nötig, eine Figur von Linum zu geben.

Hier können wir also schliessen, dass Rinde identisch ist mit Periblem, Centralcylindermit Ple rom.

5. Ficaria ranunculoides. Die drei oben beschriebenen Wurzeln waren alle drei solche, von denen in der Litteratur eine deutliche Gewebesonderung in der Spitze angegeben worden ist. Obwohl die Aussicht auf ein Resultat von vornherein als äusserst dürftig betrachtet werden konnte, so habe ich dennoch ebenfalls eine Wurzel untersucht, von der angegeben wird, dass sich keine Gewebesonderung in der Spitze beob- 
achten lässt. Von Ficaria ranunculoides finden wir eine solche Angabe bei ERIKSson (23 S. 642). Zur Untersuchung kamen hier die Übergangsformen zwischen den gewöhlichen Wurzeln und den Wurzelknollen.

Die Untersuchung ging ganz wie bei den vorigen Wurzeln von statten. Die Endodermis und den Pericykel bis an die Basis des medianen Längsschnittes zu bestimmen, machte keine Schwierigkeiten; die Grenze aber höher in den Vegetationskegel hinauf zu verfolgen, war schwieriger, und wurde schliesslich nicht tunlich. Von dem medianen Längsschnitt und den zwei vorhergehenden und den zwei folgenden Schnitten habe ich noch Mikrophotographien gemacht, um so vielleicht ein besseres, räumliches Bild der Zellanordnung zu bekommen, und noch etwas höher hinauf die Grenze verfolgen zu können. Mit diesen Hilfsmitteln konnte ich die Grenze an der einen Seite bis $600 \mu$ von der Basis des Schnittes (500 $\mu$ vom Vegetationspunkte) verfolgen. Dort aber zeigte sich dieselbe Erscheinung, auf die ich schon bei den zentralen Zellreinen von Helianthus aufmerksam gemacht habe: die Zellreihe der Endodermis hörte auf, und an deren Stelle traten eirige andere. Höher im Vegetationskegel war dieselbe Erscheinung an vielen Stellen auch bei anderen Zellreihen zu beobachten, je höher man kam, desto kürzer wurden die einheitlichen Zellreihen. Man muss sich das so denken, dass im Vegetationspunkt eine unregelmässige Teilung stattfindet. Die so gebildeten regellos geordneten Zellen geraten bei dem fortschreitenden Wachstum entweder in die Kalyptra oder in den Wurzelkörper. In diesen Regionen waltet eine vorherrschend einseitige Zellteilung ob, die einzelnen Zellen entwickeln sich so zu lang ausgezogenen Zellfäden.

Es kann aber eine so vorherrschende Querteilung die einmal 
eingetretene regellose Anordnung natürlich nur scheinbar beseitigen; bei genauerer Untersuchung kommt diese immer dadurch wieder zum Ausdruck, dass die einzelnen Zellreihen an bestimmten Stellen aufhören, und andere sich unregelmässig an diese ansetzen. Bei den regelmässigen Wurzeln war das nicht der Fall, weil dort eine allseitige Zellteilung in der Spitze nicht stattfand oder wenigstens in so untergeordnetem Masse, dass es sich nicht bemerkbar machte. Die Zellreihen waren dort bis in dem Vegetationspunkt zu verfolgen; sie wuchsen dort mit einer Art von Initialzellen weiter. Bei einer solchen regellosen Anordnung, wie sie bei Ficaria vorherrscht, besteht natürlich eine bestimmte Grenze zwischen Rinde und Centralcylinder in dem Vegetationspunkte nicht.

\section{B. Untersuchungen an Stengelin.}

1. Methodisches. Weitaus der wichtigste Unterschied zwischen den Vegetationspunkten der Wurzel und des Stengels ist das Auftreten der Blätter. Durch diesen Umstand wird der ganze Bau der Stengelspitze beeinflusst, was wiederum für die Methodik eine wesentliche Änderung bedingt. Diese Anderung besteht darin, dass die Querschnittserie nicht bloss bis etwa $1 \mathrm{~mm}$ unterhalb des Vegetationspunktes fortgesetzt werden muss, sondern viel weiter, bis oberhalb der grössten Blätter, sodass für den Längsschnitt etwa $100 \mu$ oder noch weniger übrig bleibt.

Diese Anderung ist hier unbedingt notwendig. Denn von einer Längsschnitt-Serie eignen sich nur ein oder wenige Schnitte, die Medianen, zur Beobachtung. Von dem ganzen Umkreis des Stengels sind also nur zwei gegenüberliegende 
Punkte zu sehen, während auf Querschnitten das Ganze sich zeigt. Wenn nun durch die Entwicklung der Blätter der Querschnitt des Stengels sich in sehr verschiedene Teile gliedert, muss man von allen diesen eine Übersicht haben, und nicht bloss von zwei durch die Schnittführung bestimmten Stellen. Es wird also notwendjg, die Querschnitte soweit fortzusetzen, bis der noch übrige Stengelteil walzenförmig, also an seinen verschiedenen Seiten ganz homogen beschaffen ist.

Da bei der Wurzel der Querschnitt schon homogen war, war das andere Verfahren geboten, weil die Untersuchung an Längsschnitten, wenn sie möglich ist, viel schneller und leichter vor sich geht.

Selbstverständlich wird hierdurch auch die Technik etwas schwieriger; es kommt sehr leicht vor, dass man mit den Querschnitten etwas zu weit geht und so sein Ziel überschreitet; auch ist es nicht leicht, einen Paraffinklotz mit einem Objekt von $100 \mu$ entsprechend $\mathrm{zu}$ orientieren, und bei der weiteren Behandlung der Schnitte kann leicht das winzige Band auf die eine oder die andere Weise zu Grunde gehen.

Wenn man aber für einen genügenden Vorrat von Spitzen sorgt, ist auch diese Schwierigkeit zu überwinden.

Mehr Schwierigkeiten bot mir eine andere Sache. Bei den Vegetationskegeln der Stengel habe ich stets das Bedürfnis empfunden, den protoplasmatischen Inhalt der Zellen grössenteils zu beseitigen, um das Zellnetz besser hervorheben zu können. Bei den Wurzeln war das nicht nötig, weshalb weiss ich eigentlich nicht; aber in den Stengeln gelang es mir mit keiner Färbung, die Zellnetze entsprechend deutlich zu bekommen.

Wenn man aber von einer Schnittserie den Zellinhalt durch Eau de Javelle oder ein anderes Lösungsmittel beseitigen will, 
so kann man die Schnitte nicht mit Eiweiss aufkleben, weil dieses sich ebenfalls löst; ebensowenig kann man sie nach der Wasser-Methode aufkleben, weil sie sich auch dann in Eau de Javelle von dem Glase ablösen. Nur ein Klebemittel wie Collodion lässt sich dann verwenden.

Als ich nun meine Schnitte mit Collodion aufklebte, machte sich ein anderer Übelstand bemerkbar; denn diese Methode lässt sich nicht vereinigen mit dem Ausbreiten der Schnitte auf warmes Wasser. Eine solche Methode besteht wenigstens nach Bolles-LeE nicht; über SchäLliBAums Collodion-Methode sagt er (106 S. 213): "Its great defect is that it does not readily lend itself to any device for the flattening out of folded sections."

Dennoch war das Ausbreiten der Schnitte auf Wasser hier unumgänglich nötig. Denn wenn man wie hier, nicht einen Schnitt der Serie, sondern alle Schnitte braucht, weil das Fehlen eines Schnittes die ganze Serie wertlos machen kann, so ist eine einzige Falte in einem Präparat schon im stande, alles zu verderben.

Ich musste also versuchen, diese Methoden zu kombinieren. Nach vielen vergeblichen Versuchen war ich endlich so glücklich, ein Verfahren zu finden, das diesem Zweck entsprach.

Ich nahm dazu Deckgläser, welche - wie ich sie sonst immer zum Aufkleben der Schnitte gebrauche - durch vorheriges Kochen in Königswasser ganz sauber gemacht wurden. Diese Deckgläser wurden in Alkohol aufbewahrt, und vor dem Gebrauch auf ein reinem Filtrierpapier an der Luft getrocknet. So behandelte Gläser werden sehr leicht durch Wasser benetzt; ein darauf gelegter Tropfen breitet sich von selbst aus. Auf ein solches trockenes Deckglas werden die Schnittbänder gelegt und dabei in die richtige Anordnung gebracht. Weil das 
Glas trocken ist, geht das sehr leicht. Alsdann wird neben den Schnitten etwas destilliertes Wasser auf dasselbe Deckglas gebracht, das sich unter den Schnitten ausbreitet und das ganze Glas benetzt. Ein Umschlagen der Bänder, das bei dem Auflegen der Schnitte auf Wasser so leicht vorkommt, ist so nicht zu befürchten. Nun wird das Ganze, das ich immer auf einem Objektträger liegen hatte, samt dem Objektträger über einer Spirituslampe erhitzt, bis die Streckung der Bänder erfolgt. Selbstverständlich kann man das auch auf einem Thermostaten tun, was natürlich weniger gefährlich ist, man muss dann aber ausgekochtes destilliertes Wasser nehmen, weil sich sonst bei der langsamen Erhitzung unterhalb der Schnitte kleine Luftblasen bilden, die das Präparat verderben. Weil das Deckglas so sauber ist, können die Schnitte sich ungestört ausdehnen, weil die Oberseite immer von einer Wasserschicht bedeckt bleibt.

Nun legt man das Ganze beiseite, nimmt ein anderes ebenfalls sauberes Deckglas, und bestreicht es mittelst eines feinen Pinsels möglichst dünn mit einer Lösung von Collodion in 3-4 Volumina Nelkenöl. Dieses Deckglas legt man dann auf einen anderen Objektträger, mit der Schichtseite nach oben, und bedeckt es sofort mit einer Wasserschicht. Weil das Collodion sich nicht so leicht befeuchtet, ist hier allerdings mehr Wasser nötig, um das ganze Viereck zu benetzen wie oben. Hat man das Collodion zu dick aufgetragen, so wird dieses sich unterhalb des Wassers in Tropfen sammeln und sich nicht wieder beseitigen lassen.

Nun nimmt man das erste Deckglas wieder auf, auf dem die Schnitte noch schwimmen, lässt, indem man mit einer Nadel die Schnitte zurückhält, das Wasser von dem Glas ablaufen, und hält das Glas mit den Schnitten nach oben in 
geneigter Lage so über das andere, mit Collodion bestrichene, dass es an einer Seite das sich darauf befindliche Wasser berührt. Es ist nun leicht, die Schnitte mit einer Nadel von dem Glase auf das Wasser zu schieben. Das einzige, was man dabei zu beachten hat, ist, dass das Wasser sich nicht auf den unterliegenden Objektträger ausbreitet, was bei einer ungeschickten Bewegung des ersten Deckglases leicht geschehen kann. Man hat dann nur noch das Collodion-Glas mit den Schnitten aufzunehmen und das Wasser ablaufen zu lassen, wobei man wie zuvor die Schnitte mit der Nadel zurückhält; dann legt man das Objektglas mit den Schnitten zum Trocknen auf einen Thermostaten. Nach einigen Stunden ist es trocken, und die Schnitte sind sehr fest auf das Deckglas aufgeklebt.

Sie können nun in gewöhnlicher Weise mit Xylol und mit Alkohol behandelt und dann in Eau de Javelle gelegt werden. Hierin lasse ich die Schnitte meist eine halbe Stunde liegen. Der Protoplasma-Inhalt der Zellen ist dann zwar noch lange nicht aufgelöst, aber doch hinreichend korrodiert, um das Zellnetz deutlich hervortreten zu lassen, während dabei die Zahl und Lagerung der Kerne noch Anhaltspunkte für die Erkennung der genetischen Beziehungen der Zellen geben können.

Dass die Schnitte auf diese Weise genügend fest aufgeklebt sind, geht wohl daraus hervor, dass sie nach Behandlung mit Xylol und mit Alkohol ein Abspülen unter dem Wasserhahn vertragen; ein $5 \mathrm{~mm}$ dicker Wasserstrahl, der direkt auf die Schnitte floss, hat mir niemals auch nur das kleinste Stückchen entfernt.

2. Hippuris vulgaris L. Weitaus die eingehendste Untersuchung wurde an der Stengelspitze von Hippuris angestellt. Die Wahl dieser Pflanze konnte nach dem vorhin (S. 27) Be- 
sprochenen nicht mehr fraglich sein. Ist Hippuris doch neben Cuscuta die einzige Pflanze, von der die auf eine genauere Untersuchung gestützte Behauptung ausgesprochen worden ist, dass die Endodermis sich aus der innersten Periblemschicht entwickelt (Sanio 3 S. 224). Den Stengel von Cuscuta (136) durfte ich aber nicht wählen, weil ein so reduzierter Parasit zu sehr von den normalen Verhältnissen abweicht. Für Hippuris sprach auch noch der Umstand, dass es die einzige Pflanze ist, bei der ein unzweifelhaftes Plerom im Stengel scharf und deutlich abgegrenzt ist. $\mathrm{Zu}$ diesen Umständen, deren jeder an sich schon von entscheidender Bedeutung war, kam noch hinzu, dass die Blätter der Hippuris sehr klein sind im Verhältnis zum Stengel, wie man es nur bei wenigen Angiospermen findet; dies rührt auch zum Teil daher, dass die Blätter hier in 8- bis 12-gliederigen Wirteln stehen. Die Blätter üben durch ihre Kleinheit also eine weniger störende Wirkung auf den Stammscheitel aus als bei andern Pflanzen.

Ungeachtet all dieser Vorteile, welche die Stammspitze der Hippuris besitzt, war es dennoch eine sehr langwierige und zeitraubende Untersuchung. Ich werde mich hier darauf beschränken, den Hauptgang der Untersuchung zu beschreiben und einige wenige Details zur Veranschaulichung etwas näher entwickeln. Es wird sich dabei ergeben, dass SANio sich ungeachtet seiner genauen Untersuchung geirrt hat. Die Endodermis entsteht nicht aus dem Periblem, sondern mit einigen Rindenschichten, wenigstens auf dem grössten Teil der Peripherie, aus dem Plerom. Es wird sich aber auch ergeben, dass SANIo mit der in seiner Zeit zu Gebot stehenden Methode wohl nicht anders hätte schliessen können.

Gehen wir nun zu der eigentlichen Untersuchung über. Das Material entnahm ich einer Kultur von Hippuris in einem 
steinernen Bassin im hiesigen botanischen Garten, im Juni 1901.

Ich werde hier den umgekehrten Weg folgen als bei der Untersuchung der Wurzeln. Dort ging ich von dem ausgewachsenen Zustande aus und schritt in der Vergleichung nach oben fort. Hier, wo die Querschnittserie sich viel weiter ausdehnte, weiter als die Vergleichung nach oben zu direkt durchzuführen war, ist es besser, erst von oben her anzufangen, zumal weil hier eine äusserst scharfe Trennung zwischen Periblem und Plerom besteht, die sich eine Strecke lang sehr gut verfolgen lässt.

Betrachten wir die Längsschnitte also zuerst.

Der längsgeschnittene Stengelteil war $140 \mu$ hoch, die Schnittdicke $5 \mu$. Zur Bestimmung des Medianen war ein sehr geeignetes Merkmal in den regelmässigen Periblemkappen gegeben. Von diesen Kappen waren zu unterscheiden in: Präparat $N^{0} .11$ die äussere ziemlich scharf

$N^{0} \cdot 12 \quad 2$ scharf

$\mathrm{N}^{0} .132 \%$, die $3^{\text {e }}$ kommt

$\mathrm{N}^{0} \cdot 143 n$, die $4^{\mathrm{e}} n$

$\mathrm{N}^{0} .154 n$, (Fig. 1).

$\mathrm{N}^{0} \cdot 164 \%$

$N^{0} .173 n$, die $4^{e}$ nicht mehr so scharf

$\mathrm{N}^{0} .182 "$, die $3^{\mathrm{e}}, " n "$ "

$N^{0} .191 \ldots$, die $2^{\mathrm{e}}$ ziemlich scharf

$\mathrm{N}^{0} \cdot 20 \quad 1 \quad \ldots$.

Das Symmetrische dieser Tabelle zeigt, dass die Schnittführung wohl die richtige war, die medianen Schnitte waren 15 und 16. In diesen waren (Fig. 3) zwischen Epidermis und Plerom 4 deutlich getrennte Periblemkappen vorhanden. Das Plerom endete nach oben, wie schon SANio angibt (5 S. 184), in einer einzigen Zelle. 
Die Vergleichung mit dem obersten Querschnitt, den ich wieder No. 1 nannte (Fig. 4), war sehr einfach. Die 4 Periblem-

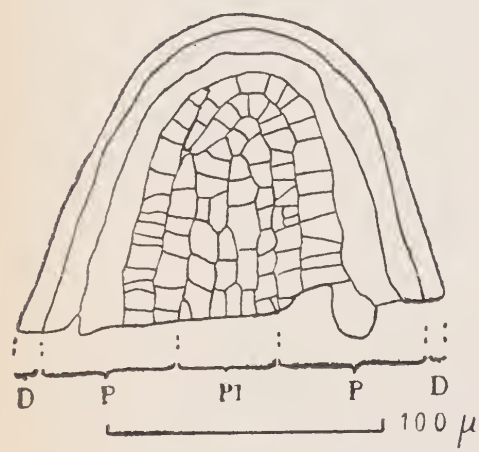

Fig. 3. Längsschnitt No. 15. Pl. Plerom, P. Periblem, D. Dermatogen. In dem Plerom und in den zwei innersten Periblemschichten sind die Zellen eingetragen. In diesen Periblemschichten links oben eine unregelmässige Stelle.

schichten waren sehr deutlich zu erkennen, innerhalb des einfachen Dermatogens (Fig. 4). Die äussere Periblemschicht hatte sich ebenfalls einfach erhalten, nur in den hier schon als unbedeutende Ausbuchtungen sich bemerkbar machenden Blattanlagen war diese Schicht einigermassen tangential geteilt. Die $2^{\text {e }}$ Periblemschicht hatte von der Blattbildung keinen sichtlichen Einfluss empfunden, sie teilte sich radial, weniger tangential; die zwei inneren dagegen gleichmässig radial und tangential, obwohl sehr spärlich. Zwischen allen vier Periblemlagen hatten sich schon Intercellulärräume gebildet, meistens viereckige.

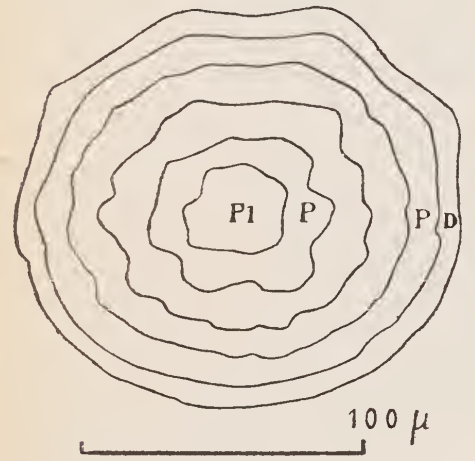

Fig. 4. Querschnitt No. 1. Pl. Plerom. P. Periblem, D. Dermatogen. Die Blätter werden angelegt.

Diese werden uns später noch ausgezeichnete Anhaltspunkte darbieten. Das Plerom bestand aus kleineren Zellen als das Periblem und war somit sehr deutlich abgegrenzt. Auch in diesem waren die Zellen in Gruppen zu ordnen, welche aus einer Zelle entstanden waren; etwa 8 solcher Gruppen fanden sich in dem Querschnitt.

Die so in $\mathrm{N}^{0} .1$ gefundene Grenze. zwischen Periblem und Plerom musste nun nach unten hin verfolgt werden. Dies war anfangs sehr leicht; die 4 Periblemschichten und das deutlich 
gesonderte Plerom liessen sich sofort erkennen (Fig. 5). Die Verschiedenheiten, welche sich in den Bildern ergaben, waren hauptsächlich das stärkere Wachstum der Blätter, wodurch die Epidermis in diesen immer schief durchschnitten wurde, die ansehnlichere Grösse der Intercellulären, welche sich zu Luft-

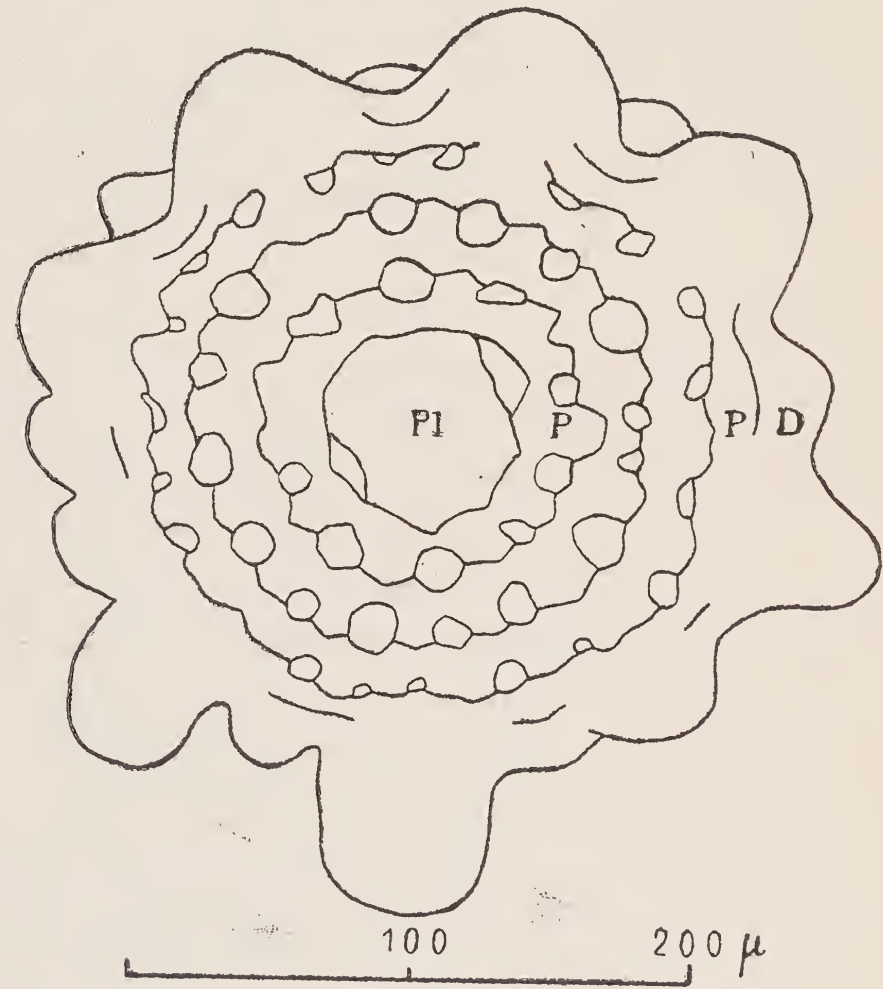

Fig. 5. Querschnitt No ${ }^{0}$ 35. $315 \mu$ von der Spitze. Pl. Plerom. P. Periblem,

D. Dermatogen. Im Periblem drei Luftgangkreise. In den Blättern sind die Zellschichten schief durchschnitten, dadurch also nicht deutlich.

gängen ausbilden., und die ausgiebigere Teilung in allen Zellschichten. Die äussere Periblemschicht blieb zwischen den Blättern noch immer einfach.

Über diese Luftgangbildung muss ich hier noch einiges anführen. Dieselbe fand dadurch statt, dass von den Komplexen, die aus 
den einzelnen ursprünglichen Periblemzellen der drei inneren Schichten hervorgegangenen sind, die äussere Hälfte in ihrem tangentialen Wachstum zurückblieb (Fig. 6). Auf diese Weise

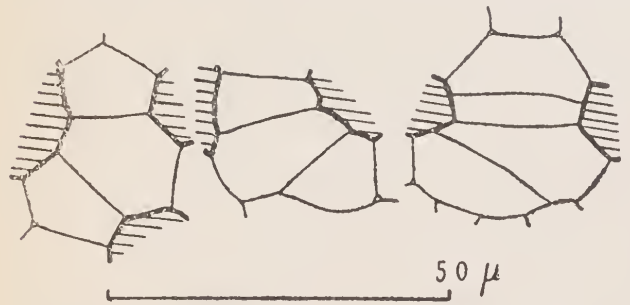

Fig. 6. Drei ursprüngliche Periblem-Zellkomplexe aus Querschnitt No. 35. Derjenige links aus der dritten die 2 andern aus der vierten Periblemschicht. Die Luftgänge sind schraftiert.

bildeten sich also drei Kreise von Luftgängen, ein Verhalten, das ich hier besonders betonen muss, weil später noch wiederholt von diesen Luftgangkreisen die Rede sein wird. War einmal der Gang gebildet so fand das Wachstum in diesen Zellkomplexen in den senkrecht zu den Gängen stehenden Pichtungen fast nicht mehr statt; und bei den neu hinzukommenden Teilungen waren die Wände ausnahmslos senkrecht auf die Gänge gerichtet. Auf diese Weise entstanden später die eine Zelle breiten Mauern zwischen den benachbarten Luftgängen.

Die ersten Prokambiumbündelchen erschienen in den 3 äusseren Periblemschichten in Präparat 22-24, also $140+22 \times 5=$ $250 \mu$ unterhalb der Spitze. In diesen Präparaten haben wir also einen künftigen Knoten. Von den 9 Bündelchen, welche später in jedem Knoten sichtbar waren, waren hier erst ś entwickelt, als protoplasma-reichere durch radiale Teilung ausgezeichnete radiale Bänder. Jedes Bündel entstand in allen drei äusseren Periblemschichten zugleich, die Teile, welche von jeder Schicht gebildet wurden, waren noch sehr scharf zu unterscheiden.

Auf diese Weise liess sich bis an Präparat 35, also $315 \mu$ von der Spitze, die Grenze Pleriblem-Plerom gut unterscheiden (Fig. 5). Hier fanden sich zum ersten Male zwei Zellgruppen (rechts oben und links unten, siehe Figur), deren Herkunft 
fraglich war. Es waren auf der Grenze gelagerte Zellen, welche ebensogut zum Periblem als zum Plerom gehören konnten. Von nun an war dies jedesmal der Fall; die Untersuchung wurde dadurch erheblich schwieriger. Eine erste Methode, die ich befolgte, war, die schwierige Stelle in einigen z. B. vier Präparaten möglichst genau zu zeichnen. Dazu benutzte ich meistens $\mathrm{D}+4$ von ZeIss, während ich mit einer Öl-Immersion das Präparat immer nachprüfte um auch die feinsten eben gebildeten Wändchen sehen zu können.

In diesen Zeichnungen wurden dann diejenigen Wände, welche nur mit höherer, oder diejenigen, welcher nur mit niedriger Einstellung zu beobachten waren, mit zwei Arten von punktierten Linien eingetragen. Aus diesen Zeichnungen konnte ich mir dann ein Bild der räumlichen Verhältnisse machen. Über diese Methode siehe: Über Zellteilungsvorgänge in Cambium (150 S. 31 ff.). Eine sehr wesentliche Unterstützung dabei war der Gebrauch von dünnem Pauspapier, auf das ich die Zeichnungen roh übernahm, dieses legte ich dann auf die Zeichnung des folgenden Präparates, um die Übereinstimmung oder Abweichung von Zelllinien um so sicherer feststellen zu können. Wenn nun von einer fraglichen Zellgruppe festgestellt wurde, dass sie mit einer Zellgruppe im Periblem oder im Plerom radial angeordnet war — sowohl auf dem Querschnitt wie auf dem idealen Längsschnitt - so war es wohl sicher, dass diese fragliche Zellgruppe denselben Ursprung hatte, wie die mit ihr übereinstimmende Periblem- oder Pleromgruppe.

Wirklich hat mir das in zwei Fällen nähere Auskunft über eine Zellgruppe gegeben. In der Mehrzahl der Fälle aber konnte ich mit dieser Methode nicht weiter kommen.

Denn alle die Zellen in dieser Region waren bloss 5 bis $10 \mu$ hoch, so dass bei einer Schnittdicke von $5 \mu$ die Höhen- 
unterschiede der Querwände der benachbarten Zellkomplexe nur wenig grösser waren als die Beobachtungsfehler. Ich konnte also auf diese Weise nur wenig erreichen. Ich versuchte deshalb zuerst, wie weit ich von unten her mit der Trennung Rinde-Centralcylinder kommen würde. Ich betrachtete dazu zuerst eines der untersten Präparate, dem ich keine Nummer mehr beigelegt hatte, das aber etwa Präparat 380 war, also $2 \mathrm{~mm}$ von der Spitze entfernt gewesen sein musste. Dieser Schnitt war durch ein Internodium geführt. Hier war die Trennung zwischen Rinde und Centralcylinder mit aller wünschenswerten Schärfe ausgebildet; die Zellen des Centralcylinders waren erheblich kleiner als die der Rinde $(1 / 2-1 / 5$ des Durchmessers der innersten Rindenzellen). In dieser Rinde hatten sich die Luftgänge sehr stark ausgebildet, es waren aber nicht mehr 3 Kreise von Luftgängen vorhanden, sondern es hatte sich an der Innenseite der Rinde noch ein vierter kleinerer Kreis gebildet. Etwas ganz Ähnliches hatte Sanio gefunden, der einen Stengel mit 5 Periblemkappen untersuchte. Er fand in dieser in der Spitze 4 Luftgangkreise, im ausgebildeten Teil dagegen 5. Seine Erklärung dieser Tatsache lautete wie folgt: "Die innerste von den 4 kegelmantelförmigen, für die Bildung der Intercellulärcanäle bestimmten Zelllagen, also, von Aussen gerechnet, die sechste”, (d. h. die Epidermis mitgerechnet) „theilt sich noch einige Male durch tangentiale Scheidewände, zwischen den beiden durch die erste Theilung entstandenen Tochterzelllagen entsteht nun der fünfte innere Kreis der Intercellulärcanäle. Die innere von diesen Tochterzelllagen theilt sich noch einige Male (zweimal) tangential weiter, die innerste von den dabei gebildeten Zelllagen, wẹlche unmittelbar dem centralen Gefässstrange anliegt, entwickelt sich dann zu der CASPARY'schen Schutzscheide, ausgezeichnet durch den dunklen Punkt." 
Gerade in dieser Erklärung steckt der Irrtum Sanios. Dass diejenigen Intercellulären, welche sich schon im Anfang zwischen den Periblemschichten bemerkbar machen, sich zu den äusseren Luftgängen entwickeln, ist leicht nachzuweisen. Dass aber der zuletzt hinzugekommene innere Kreis sich auf der von ihm beschriebenen Weise aus der innersten Periblemschicht bildet, ist nicht richtig. Betrachten wir deshalb diesen Luftgangkreis etwas näher.

In Präparat 380 - wie ich das Präparat nur nennen will bestand die Rinde aus: $1^{0}$. einer subepidermalen, einfachen Zellschicht, welche offenbar aus der äussersten Periblemkappe hervorgegangen war, $2^{0}$. den drei äusseren Luftgangkreisen, mit deren einschichtigen Zellmauern, welche offenbar aus den drei weiteren Periblemkreisen hervorgegangen waren. Innerhalb des $3^{\text {en }}$ Kreises fanden sich nun 3 bis 4 Zellschichten, deren innerste die Endodermis war, während zwischen der äussersten und der zweiten Schicht der vierte Luftgangkreis sich ausgebildet hatte. Die Verhältnisse waren also der SANioschen Beschreibung völlig entsprechend. Wenn ich nun diese Anordnung in den aufeinanderfolgenden Internodien nach oben zu verfolgte, so blieb sie bis an Präparat 109 unverändert. Weiter nach oben nahm die Zahl der Rindenschichten innerhalb des $4^{\text {en }}$ Kreises ab, bis in 73 nur noch eine Rindenschicht vorhanden war. Die Luftgänge des $4^{\text {en }}$ Kreises waren erheblich kleiner geworden.

Zwei Internodien höher, in 45 , war der $4^{\mathrm{e}}$ Kreis noch an der linken Seite des Präparates zu beobachten, in dem nächsthöheren Internodium, in $N^{0}$. 36, gar nicht mehr. Nun waren wohl in 36 an zwei Stellen zwei rindenartige Zellschichten innerhalb des dritten Luftgangkreises zu beobachten, zwischen denen nach Analogie des vorigen sich der $4^{e}$ Kreis entwickeln 
sollte; den inneren dieser rindenartigen Schichten hatte ich aber nach der vorigen Untersuchung, welche bis Präparat 35 gelangt war, als zum Plerom und nicht zum Periblem gehörig erkannt. Wenn diesern Ergebnis zu trauen war — was sich später auch herausstellte - so war es erwiesen, dass die äusseren Pleromzellen sich an dem Aufbau der Rinde beteiligten. Ohne weiteres war solches aber noch nicht genügend festgestellt, weil es keine kontinuierliche Untersuchung gewesen war, sondern nur ein Vergleich der aufeinanderfolgenden Internodien, ohne auf die Knoten zu achten. Das Vorbild von SANio hatte mich schon zu grosser Vorsichtigkeit gebracht, weil es zeigte, wie leicht man sich in diesen Sachen irren kann. Dazu kam noch, dass in den Internodien diejenigen Rindenzellen, welche nach den oben genannten Verhältnissen aus dem Plerom hervorgegangen sein müssten, sich dennoch mit den nach aussen angrenzenden Rindenzellen in radialer Anordnung (Fig. 7, A) befanden, was entschieden auf periblematische Herkunft hindeutete. Ich habe deshalb die Strecke zwischen Schnitt 35 und Schnitt 54 genauer studiert. In 35 fanden sich noch deutlich die Verhältnisse des Vegetationskegels wieder, in 54 schon die des ausgewachsenen Stengels. Diese $100 \mu$ des Stengels habe ich deshalb zum Studium gewählt, und ich habe nicht geruht, bis ich mit dem ganzen Bau dieser Strecke völlig bekannt war und nichts Rätselhaftes mehr darin für mich übrig blieb. Diese Untersuchung war sehr langwierig und kompliziert, weil die Verhältnisse nicht einfach waren.

Dies rührte nun hauptsachlich von zwei verschiedenen Umständen, die ich erst später kennen lernte, her. Zuerst waren die Zellen der äussersten Pleromschicht in den Internodien (nicht in den Knoten) in dieser Gegend an vielen Stellen ausgewachsen; die Zellen wurden grösser als 
die inneren Pleromzellen und drängten sich bei ihrem Wachstum in das Periblem hinein. Dies geschah nicht regelmässig sondern in der einen Zellgruppe stärker als in der andern. Diese Zellen des Pleroms bekamen hierdurch ein rindenartiges Aussehen. Das Resultat war, dass solshe nach aussen aus dem Plerom hervorragenden Zellgruppen bei der Betrachtung nicht sofort unter einem von beiden Geweben unterzubringen waren. Ein zweiter Umstand, der leicht irre führen kann, war die schon erwähnte radiale Anordnung der inneren Periblemzellen mit den Pleromzellen. Diese Anordnung, die sehr täuschend ist, hat Sanio gewiss zu seinem Schluss veranlasst, dass die Endodermis die innerste Periblemschicht sei. Diese Anordnung beweist hier aber nichts für eine genetische Zusammengehörigkeit der Zellen, weil sie erst nachträglich auftritt. Diese so sonderbare Erscheinung steht wohl in Beziehung zu dem Auftreten des vierten Luftgangkreises. Wir sahen oben schon (S. 73), dass die neuen Zellwände sich stets rechtwinkelig. an etwaige Luftgänge ansetzten. Dieses trat nun auch hier ein, und zwar schon als Einleitung zu der Luftgangbildung. An denjenigen Stellen, wo in den Internodien eine Wand sich im Periblem an der Aussenseite der Grenze von Periblem und Plerom ansetzte, bildete sich an der Innenseite der Grenze in den Pleromzellen ebenfalls eine radiale Wand, die sich genau in die Verlän. gerung von der äussern Wand stellte. Die so gebildete Kreuzstelle in den Wänden war dann die Ursprungsstelle eines Luftganges.

Wenn man diese Verhältnisse noch nicht kennt, ist es anfangs sehr schwierig, hierin den Weg zu finden, und es ist auch nicht befremdend, dass SANIo, obwohl er einer der ge-nauesten Untersucher war, den wir kennen, durch diesen Umstand irre geführt worden ist, weil er nicht über lücken-. lose Schnittserien verfügte. 
Als ersten Versuch, um in diesen Partien Klarheit zu bekommen, habe ich von Präparat 30 ab bis an 56 die Grenzen, welche ich zwischen Periblem und Plerom annehmen musste, mit Hilfe des Zeichenapparates kontrolliert. Dazu zeichnete ich mit dem grossen Zeichenapparat nach ABBE von C. Zeiss, um von aller Verzerrung freibleiben zu können, die Umrisslinie. des Pleroms in Tusche nach. Diese Zeichnung liess ich dann wiederum vermittelst des Prismas mit dem folgenden Präparat zusammenfallen und kontrollierte so, ob die im folgenden Präparate angenommene Form mit der im vorigen Präparat hinreichend genau übereinstimmte. War die Übereinstimmung wie öfters der Fall war, an einer Stelle nicht genau genug, so wurde die Stelle für eine nähere Untersuchung notiert. Indem so im folgenden Schnitt dieselbe Grenzlinie festgestellt war, konnte dessen Zeichnung wieder mit einem dritten Präparat verglichen werden, usw.

Indessen auch so würde ich noch nicht fertig gekommen. sein, weil, wie schon oben bemerkt wurde, eine weitere Untersuchung durch Serienzeichnungen meistens nicht direkt möglich war, sobald die Grenzen an einer Stelle nicht übereinstimmten. Ein sehr glücklicher Umstand war es daher, dass die Entwicklung in den Knoten und in den Internodien auf verschiedene Weise von statten ging. Während in den Internodien im Periblem sich schon die Luftgänge bildeten, war solches in den Knoten noch nicht der Fall. In diesen Knoten nun waren, zumal 5 oder $10 \mu$ oberhalb der horizontalen Prokambiumbündel, die Periblemzellgruppen noch deutlich in 4 Kreise geordnet und die ursprünglichen Periblemzellen den Umrissen nach noch zu erkennen. Solches war sogar bis an $54 \mathrm{der}$ Fall, allerdings dort nicht mehr so deutlich, wie höher nach. oben. Während also in den Internodien die Sache nicht direkt deutlich mehr war, gaben die Knoten neue Anhaltspunkte. 
Von denjenigen Zellgruppen, welche entweder durch ihre radiale Anordnung mit den Periblemzellen, oder durch ihre Grösse und ihr rindenartiges Äusseres oder auch durch ihr Auftreten auf der Grenze zwischen Periblem und Plerom als verdächtig notiert waren, konnte ich durch diesen Umstand die Herkunft bestimmen. Denn wenn ich die Serienzeichnungen bis an einen Knoten fortsetzte, konnte ich die ursprünglichen Verhältnisse in diesem Knoten wieder erkennen. Fast ausnahmslos gehörten solche fraglichen Zellen dem Plerom an, was nach dem oben (S. 77, 78) Gesagten wohl nicht anders konnte. Die Untersuchung solcher Zellgruppen geschah in einfachen Fällen nur durch die Zeichnung der aufeinanderfolgenden Plerom-Umrisse, in den komplizierteren aber durch Anfertigung von Serienzeichnungen.

Es wäre wohl nicht gut möglich, von dieser Untersuchung eine detaillierte Übersicht zu geben. Ich will hier deshalb nur eine der Zeichnungenserien reproduzieren, und wähle dazu die ausführlichste, die von Präparat 41 bis 48 läuft (Fig. 7).

Dass ich diese Serie hier wiedergebe, geschieht nicht, um den Beweis für die gewonnenen Resultate zu liefern; diesen Beweis kann man nur für sich mit Gewissheit bekommen, wenn man nicht nur die Zeichnungen vergleicht, sondern stets wieder alles an den Schnitten selbst kontrolliert, wo die Beschaffenheit der Wände selbst und andere untergeordnete Merkmale, wie die Form eines Kernes oder Ähnliches, mit in Betracht gezogen werden können. Dass ich sie hier gebe, geschieht nur, weil an dieser Serie einige der angegebenen Verhältnisse gut zu beobachten sind. In Präp. 41 sind wir mitten im Knoten, rechts und oben links geben die langgezogenen Kerne und Zellen zwei Prokambiumbündelchen an (bei B). Luftgänge sind 


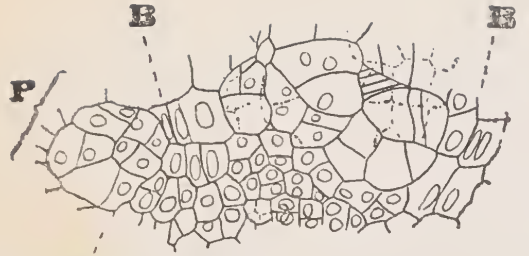

41
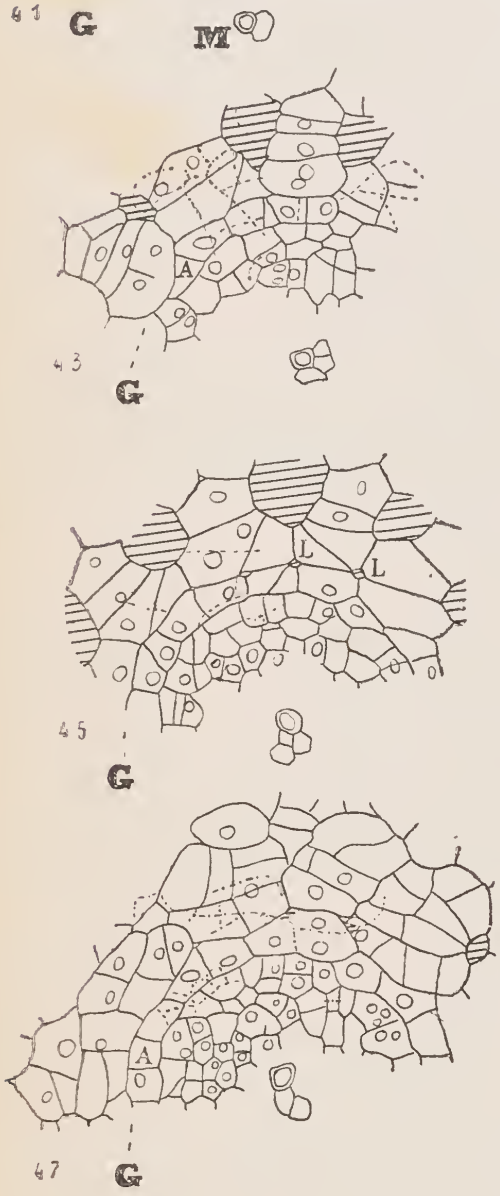

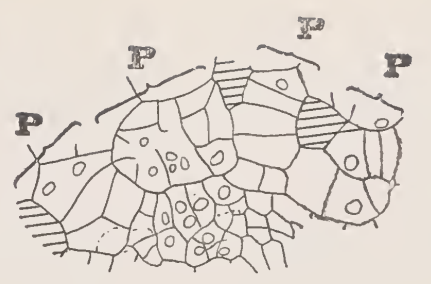

42
'

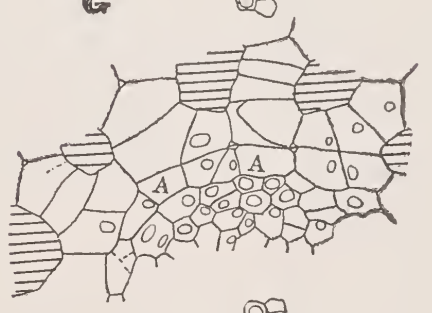

44

09

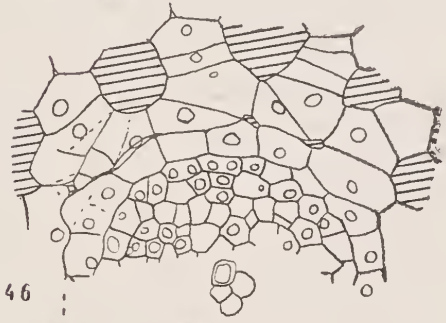

G

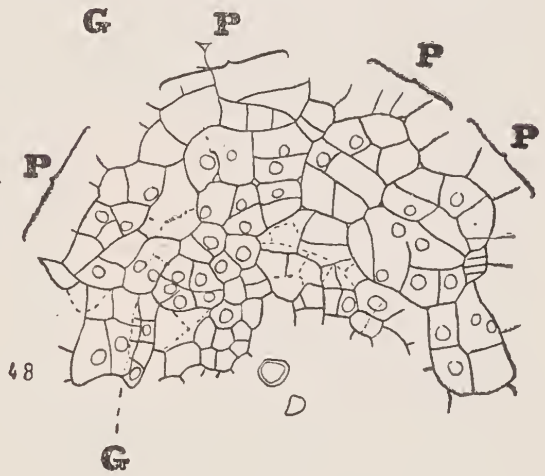

100

$200 \mu$

Fig. 7. Hippuris vulgaris. Die nämliche Gewebepartie in 8 aufeinanderfolgenden Querschnitten, No . 41-48 des Präparats. G. Grenze zwischen Periblem und Plerom. P. Zellkomplexe, welche aus den ursprünglichen Zellen der vierten Periblemschicht entstanden sind. B. Prokambiumbündel (nur in 41). A. Rindenartige Pleromschicht. M. Mittleres Xylemgefäss (in den Zeichnungen zur leichteren Orientierung bei meiner Untersuchung hinzugefügt). L. (in 45) Luftgänge des vierten Kreises. Grössere Luftgänge sind schraffiert. 
nicht ausgebildet; die Periblemzellgruppen sind wohl einigermassen deutlich, so z. B. diejenige, die sich ganz links befindet. In 42 treten schon einige Luftgänge auf (die schraffierten Teile), die Periblemzellgruppen sind vielleicht noch deutlicher. In 43 findet sich an der Innenseite der zwei mittleren abgebildeten Periblemzellgruppen eine Pleromschicht, die anfängt sich rindenartig auszubilden (A.), und die in den folgenden Präparaten anfängt, eine radiale Anordnung mit den Periblemzellen zu zeigen. In $N^{0} .44$ bis 46 würde man ohne nähere Kenntnis der Verhältnisse diese Zellen (A.) als zum Periblem gehörig betrachten; in 47 fängt der nächstuntere Knoten an sich bemerkbar zu machen, und die Periblemzellgruppen treten wieder deutlicher auf. In 48 sind diese wieder sehr gut zu erkennen und zeigen bei genauerem Vergleich deutlich, dass die fraglichen Zellen wirklich dem Plerom angehören.

Das Resultat der in dieser Weise angestellten Untersuchungen war nun, dass von den Zellen am äusseren Pleromrande im Internodium sich im Laufe der Entwicklung immer mehrere zu Rindenzellen ausbildeten. Während dies im ersten Internodium, wo es vorkam, (34-39) nur an zwei Stellen der Peripherie der Fall war (nicht die zwei fraglichen Zellgruppen in Fig. 5, sondern 2 andere), fand es sich im folgenden (43-47) nur an zwei Stellen nicht, im darauffolgenden (52-56) sogar nur an einer schmalen Stelle nicht. Es lag also nahe, zu vermuten, dass in noch älteren Stadien ringsum die Bildung der innersten Rindenschichten aus dem Plerom erfolgen sollte. Eine weitere Untersuchung war nicht möglich, weil im darunterliegenden Knoten (№.57-60) die Schwierigkeiten, welche von der fortschreitenden Gefässbündelbildung und der sonstigen Ausbildung herrührten, hier ein weiteres Vordringen nicht erlaubten. Nach dem Gefundenen war es aber nicht 
wahischeinlich, dass im Internodium der Schnitte $N^{0} .52-56$, wenn es älter geworden wäre, auch noch an der letzten Stelle die Pleromzellen sich zu Rindenzellen entwickelt haben würden. Denn die fragliche Stelle sah ganz wie die andern aus: es fanden sich hier ebensogut wie an den andern Stellen zwei Rindenschichten innerhalb des dritten Luftgangkreises; diese aber waren hier beide aus Periblemzellen gebildet, und nicht wie sonst nur die äussere aus Periblem, die innere aus Plerom.

Im Knoten fand ganz derselbe Vorgang statt wie in den Internodien, nur später. Auch hier entwickelten sich äussere Pleromzellen zu Rindenzellen, wie im Knoten 57-60 zuerst ersichtlich war. Wieweit sich dieser Vorgang auf den Umkreis ausdehnte, habe ich nicht ermitteln können.

Res umi e rend können wir somit sagen, dass im untersuchten Stengel von Hippuris aus dem Plerom sich ausser der Centralcylinder a ch noch ein Teil der Rinde bildet. Dieser Teil besteht im ausgewachsenen Zustande aus etwa drei Zelllagen, deren innerste sich durch den Besitz der schwarzen Punkte als Schutzscheide kennzeichnet. An einer Stelle der Peripherie des Pleroms hatte sich aber im untersuchten Teil keine Rindenzelle aus dem Plerom entwickelt, sondern die Bildung dieser Rindenzone war vom Periblem aus erfolgt.

Weil das gewonnene Resultat für unsere Anschauungen über die Stelärtheorie von grosser Bedeutung ist, und weil bei den andern untersuchten Stengeln, wie sich zeigen wird, nirgends eine ebenso genaue Untersuchung möglich war, so habe ich noch einen zweiten Stengel von Hippuris ebenfalls der Untersuchung unterzogen, um sicher zu sein, dass nicht eine individuelle Eigentümlichkeit dieses einen Stengels eine irrige Schlussfolgerung veranlassen könnte. Das Material holte ich deshalb am 28. Juni '02 von anderer Stelle, aus einem Graben bei 
Noordwolde, $1 \frac{1}{4}$ Stunde von Groningen entfernt, wo die Pflanze üppig wuchs.

Eine Stengelspitze wurde in ganz ähnlicher Weise untersucht, nur bei weitem nicht so eingehend. Dennoch konnte ich feststellen, dass die oben gefundenen Verhältnisse auch hier zutrafen; im allgemeinen waren diese Präparate denjenigen des vorigen Stengels zum Verwechseln ähnlich. Ebenso wie dort liessen sich die vier Periblemschichten anfangs sehr scharf angeben, während sie später undeutlich wurden, zuerst in den Internodien, später in den Knoten. Innerhalb der $4^{\text {en }}$ Periblemschicht entwickelte sich eine Zellschicht aus dem Plerom zu Rinde, wobei zwischen diesen Zellen und den Periblemzellen sich ein vierter Luftgangkreis bildete, auch hier stellte sich die radiale Anordnung dieser pleromatischen Rindenzellen mit den Periblemzellen ein.

Wir werden also wohl kaum fehlgehen, wenn wir diese Verhältnisse als der Hippuris eigentümlich betrachten.

3. Aesculus Hippocastanum L. Weil Hippuris als Wasserpflanze mit axilem Gefässstrang gewiss einen modifizierten Typus darstellt, so war es erwünscht, einige Landpflanzen zu untersuchen. Die Wahl war aber nicht sehr leicht, weil mir weder aus eigener Beobachtung, noch aus der Literatur auch nur eine einzige Landpflanze bekannt war, bei der ein Periblem und Plerom mit genügender Schärfe zu unterscheiden war.

Das einzige, was ich also tun konnte, war, einige Pflanzen zu wählen, von denen in der Literatur angegeben wird, dass bei ihnen ein Periblem und Plerom unterschieden worden ist, wenn auch diese Unterscheidung nach dem im I. Kap. Besprochenen sehr mangelhaft sein musste. Am liebsten waren die Pflanzen Hansteins zu wählen, weil die ganze Einteilung an diesen aufgestellt worden war, und zwar nur diejenigen, 
von denen in Abbildungen die Einteilung angegeben worden war; denn ausführliche Beschreibungen fehlen bei diesen Pflanzen ganz.

Aus diesen Gründen wurde auch Aesculus Hippocastanum gewählt. Das Material entnahm ich den ruhenden Winterknospen (Blattknospen, nicht die gemischten). Schon das Betrachten einer Längsschnittserie zeigte mir aber, dass ich mit dieser Pflanze nicht weiter kommen würde. Die Figur 3 aus Hansteins Arbeit ist sehr genau; auf dieser ist schon ersichtlich, dass man in der Spitze keine Trennung findet. Man darf das nun nicht so auffassen, dass diese Trennung vielleicht dennoch besteht, aber durch die Gleichartigkeit der Zellen wenig ins Auge springt; vielmehr konnte ich nachweisen, dass tatsächlich eine Trennung nicht besteht. Denn wirklich finden wir hier ganz ähnliche Verhältnisse, wie ich sie oben für die Wurzel von Ficaria beschrieben habe. Ganz wie dort hören die einzelne Zellreihen an bestimmten Stellen auf, während andere an ihre Stelle treten. Nur finden sich diese Verhältnisse hier nicht so deutlich ausgeprägt wie bei Ficaria, weil die ganze Anordnung der Zellen in den äiteren Teilen noch unregelmässiger wird. Die grössten Unregelmässigkeiten werden durch das Auftreten der Blätter bedingt. Die sehr grossen Blätter geben Veranlassung zu ganz anderen Wachstumsrichtungen als die longitudinale; die Zellen strecken sich in den Stengelknoten nicht mehr longitudinal, sondern in der Richtung der Blatt-Längsachsen, sodass die genetischen Beziehungen in diesen Knoten alle undeutlich werden. Dazu kommt, dass bei der geringen Anzahl der Blätter alle Übergangsstufen fehlen, was die Sache wieder erheblich schwieriger macht. Ich glaube deshalb auch, dass dieser Blätter wegen eine genaue Untersuchung fast unmöglich sein würde. 
Weil aber in denjenigen Teilen des Vegetationskegels, wo die Blätter noch nicht aufgetreten sind, die Verhältnisse ebenfalls unregelmässig sind, da die Zellreihen nicht alle bis in den Vegetationspunkt $\mathrm{zu}$ verfolgen sind, so ist eine solche Untersuchung auch nicht nötig.

4. Lysimachia Ephemerum L. und

כ. Evonymus europaeus L. (Hanstein hat E. Japonica untersucht, es gelang mir aber nicht, die Spitzen dieser Pflanze gehörig in Paraffin einzubetten).

Bei diesen beiden Pflanzen hatte die Untersuchung denselben Erfolg als bei Aesculus Hippocastanum; das Fehlen einer scharfen Grenze in der Spitze konnte festgestellt werden.

6. Ajuga reptans $\mathrm{L}$. Auch mit dieser, von H. Douliot (83 S. 344) untersuchten Pflanze habe ich es noch versucht. Hier ist zwar die Zellanordnung im Vegetationspunkt viel regelinässiger, sodass dort wohl 3 bis 4 Kappenschichten unterschieden werden können; $100 \mu$ niedriger ist aber die Zellanordnung schon wieder ganz unregelmässig, so dass ein Plerom dort nicht besteht; auch auf den Querschnitten kann man keine zuverlässige Grenze bestimmen, bevor diejenige in Rinde und Centralcylinder auftritt, was erst viel später der Fall ist.

7. Elodea canadensis Michx. Material im Spätsommer 1901 unweit Groningens gesammelt. Über diese Pflanze ist, was das Scheitelwachstum angeht, schon sehr viel untersucht worden; nach DouLiot gab es 1890 schon 11 verschiedene, einander widersprechende Arbeiten ( 83 S. 314) über Elodea. Die Kontroversen beziehen sich hauptsächlich auf die Selbständigkeit von Periblem und Plerom, welche zuerst von SANio angegeben worden war (5 S. 187). Bei meiner eigenen Untersuchung versuchte ich daher zuerst in den Längsschnitten 
der letzten $300 \mu$ langen Spitze des Stengels ein Periblem und Plerom aufzufinden. In Vegetationspunkt gelang mir das nicht, weil in den letzten $100 \mu$ des Stengels die Färbung nicht gelungen war. Die Zellwände waren hierdurch bei der geringen Schnittdicke $-4 \mu-$ nicht deutlich. Weil aber in den weiteren $200 \mu$ die Zellwände wohl zu sehen waren, war es nicht nötig, ein neues Präparat anzufertigen. Denn in dieser Gegend war deutlich $\mathrm{zu}$ sehen, dass Periblem und Plerom nicht scharf abgegrenzt waren; es war also um so wahrscheinlicher, dass auch im Vegetationspunkt eine solche Trennung nicht vorhanden war. Der mediane Schnitt hatte, durch die kurzen vertikalen Zellreihen, die grösste Ähnlichkeit mit einem der äussersten Schnitte eines Bandes. Dennoch war der Schnitt auch in dieser Strecke wohl median, wie durch Zählen der äussersten Enden zu ermitteln war. Selbstverständlich war bei einer solchen Anordnung von einer scharfen Trennung eines Periblems und eines Pleroms nicht die Rede. Weil aber der Vegetationskegel so schlank war, und nur aus wenigen Zellen bestand, liessen șich Periblem und Plerom doch einigermassen angeben.

Natürlich konnte man deren Trennung nicht scharf fassen, und nicht nach oben oder nach unten hin verfolgen, weil sie nicht kontinuierlich verlief; um die Grenze festzustellen musste man auf die ungefähre Zahl der Zellschichten achten.

Von allen Autoren, welche bei Elodea ein Periblem angegeben haben, ist dasselbe als ein anfangs zweischichtiges beschrieben worden, (SANio 5 S. 187) auch in den Abbildungen erscheint es immer so (Douliot 83 Pl. 15 Fig. 10, Groom 50 Pl. 16 Fig. 10).

Dies stimmte sehr gut mit der Struktur meines Präparates 
überein. Es war hier ebenfalls ein derartiges Periblem entwickelt, das aus zwei periphere Schichten gebildet war, die sich von dem schmalen Plerom hervorhoben. Dieses Plerombestand im allgemeinen aus einer Zellschicht und einer zentralen Reihe, was auf den genannten Figuren auch der Fall war.

Die oben erwähnten Kontroversen sind nach vorstehendem leicht verständlich; man kann hier ein Periblem und ein Plerom annehmen oder nicht, je nach den Anforderungen, die man an die Schärfe der Trennung zwischen diesen beiden stellt.

Auf dem obersten Querschnitt war diese Differenzierung auch zu erkennen; die zwei Periblemschichten hatten sich schon wieder geteilt, waren aber doch noch sehr gut zu erkennen, im Innern war das Plerom zu beobachten, wie oben zusammengesetzt aus einem Kreis von Zellen um eine zentrale grössere Zelle herum. Diese Anordnung liess sich nun nach unten wohl verfolgen; dabei stellten sich die Verhältnisse auch wieder als nicht sehr konstant heraus. Statt der zwei peripheren Schichten fand ich bisweilen drei, auch der innere Komplex war nicht immer gleichgeartet.

Ich habe deshalb hier bei weitem nicht mit einer solchen Gewissheit arbeiten können wie bei Hippuris. Trotzdem glaube ich mit grosser Wahrscheinlichkeit festgestellt zu haben dass die spätere Endodermis mit den CAsparyschen Punkten aus der äusseren Schicht des Pleroms hervorgeht.

Betrachten wir dazu zuerst einen älteren Querschnitt, etwa $2 \mathrm{~mm}$ von der Spitze, wo ein deutlicher Centralcylinder zu beobachten ist. Hier fand sich eine nicht scharf abgetrennte Epidermis. Die Rinde bestand aus etwa 5 Zellschichten, zwischen der $2^{\text {en }}$ und $3^{\text {en }}$ Schicht fand sich ein Kreis von Luftgängen. Durch die Rinde gingen noch 6 kleine Bündelchen aufwärts, welche Phloembündeln nicht unähnlich waren, sie 
befanden sich in der äussersten oder in der nächstäussersten Zellschicht. Auf den Schnittserien war zu beobachten, wie diese in den Knoten mit den Blattspuren anastomosierten: je zwei dieser Bündelchen standen durch Seitenäste mit einer Blattspur in Verbindung.

Die innerste Rindenschicht zeigte sich durch ihren besonderen Amylumgehalt aus, das Amylum fand sich stets im physikalisch unteren Ende der Zellen. Wir können diese Schicht somit als Stärkescheide betrachten, wenn auch die sonstige Rinde hier ziemlich viel Stärke führte; aber diese Stärke war in den Zellen zerstreut.

Ganz merkwürdig war hier aber, dass diese Schicht nicht identisch ist mit der Schutzscheide: denn die Schutzscheide lag unmittelbar innerhalb der Stärkescheide. Während die Zellen der Stärkescheide ebensogross waren wie diejenigen der sonstigen Rinde, hatten die der Schutzscheide nur $1 / 2$ bis $1 / 3$ ihrer Dimensionen; die Zellen der Schutzscheide schlossen sich ganz denjenigen des Centralcylinders an.

Verfolgte man nun diese Unterscheidung nach oben, so ergab sich, dass die Rinde mit der Stärkescheide höchstwahrscheinlich aus den zwei Periblemschichten hervorging, dass aber der Centralcylinder mit der Schutzscheide aus dem Plerom entstand. Wenn dem so war, so erfolgte die Trennung zwischen Schutzscheide und Centralcylinder sehr spät, die Zellen von Schutzscheide und Pericykel wurden erst durch eine der am spätesten auftretenden Zellwände von einander getremnt.

Mit Gewissheit kann man solches nie beweisen. Dies rührt daher, dass die Zellanordnung, welche einmal in der Spitze unregelmässig ist, später nie wieder regelmässig werden kann. Bei Hippuris war die Anordnung im Vegetationskegel äusserst regelmässig, daher die Möglichkeit der genauen Untersuchung. 
Wenn man aber auch von der Spitze von Elodea ein vollständiges räumliches Bild erhalten hat, so kann man doch die genetischen Beziehungen der Zellen nicht alle mehr erkennen. Es kommt mir aber sehr wahrscheinlich vor, dass die gegebene Beschreibung den Verhältnissen tatsächlich entspricht.

Nehmen wir einmal die Genauigkeit dieser Angaben an, was ergibt sich dann für unsere Frage? Man kann die Verhältnisse dann noch immer auf zweierlei Weise auffassen. Wir haben hier zwei Scheiden, die Stärkescheide und die Schutzscheide.

Nimmt man an, dass die Stärkescheide die eigentliche Endodermis ist, so haben wir hier einen Fall, wo die Rinde aus dem Periblem, der Centralcylinder aus dem Plerom gebildet wird.

Nimmt man dagegen an, dass die Schutzscheide die echte Endodermis ist - was man bis jetzt allgemein getan hat so geht hier wie bei Hippuris die Endodermis aus dem Plerom hervor. Eine vergleichend-anatomische Untersuchung soll natürlich darüber entscheiden.

Mir kommt es aber nicht unwahrscheinlich vor, dass die letztere Mutmassung die richtige ist.

§ 3. Zusammenfassung und Diskussion der Ergebnisse der UNTERSUCHUNGeN ÜBER DAS SPITZENWACHStum.

Bei diesen Untersuchungen hat sich ergeben, dass bei denjenigen untersuchten Wurzeln wo die Trennung von Periblem und Plerom in der Spitze eine scharfe ist, wo somit die ganze Zellanordnung regelmässig ist, die Rinde aus dem Periblem hervorgeht, der Centralcylinder aus dem Plerom.

Bei den Stengeln fand sich dagegen, dass eine solche Über- 
einstimmung in dem einzigen regelmässigen Fall nicht besteht, weil bei Hippuris die Schutzscheide mit einigen Rindenschichten aus dem Plerom hervorgeht.

Die Verhältnisse bei Elodea, wo die Schutzscheide ebenfalls aus dem Plerom hervorgeht, werde ich der eben entwickelten Unsicherheit wegen (S. 90) hier ganz ausser acht lassen.

Bei denjenigen Wurzeln, wo die Zellteilungen nicht so regelmässig vorsichgehen, findet sich ganz wie bei der überaus grossen Mehrzahl der Stengel, im Vegetationskegel gar keine Gewebesonderung, mit der die Van Tieghemsche Einteilung verglichen werden kann.

Das Ergebnis fällt also für eine Übereinstimmung zwischen den Hansteinschen und den Van Tieghemschen Geweben ungünstig aus. In der grossen Mehrzahl der Fälle trifft die Hansteinsche Einteilung nicht zu, so dass eine Vergleichung unmöglich wird; in denjenigen Fällen aber, wo sie wirklich besteht, findet sich nicht einmal immer ein vollständiges Korrespondieren mit den VaN Tieghemschen Geweben.

Dieser Widerspruch löst sich aber leicht. Im ersten Kapitel, über die Hansteinsche Gewebesonderung sind wir schon zu dem Ergebnis gekommen, dass diese Differenzierung anatomisch äusserst mangelhaft begründet ist. Eigentlich würde man aus den mannigfach schwankenden Verhältnissen dort schon $\mathrm{zu}$ der Folgerung berechtigt gewesen sein, dass diese Einteilung ganz bedeutungslos ist, wenn nicht der Gedanke an die Möglichkeit einer hohen phylogenetischen Bedeutung sie aufrecht gehalten hatte. Und wenn wirklich eine Übereinstimmung von Dermatogen, Periblem und Plerom mit Epidermis, Rinde und Centralcylinder nachgewiesen worden wäre, so würde die Hansteinsche Einteilung für uns erheblich an Bedeutung gewonnen haben. Jetzt aber, wo eine Übereinstimmung der 
beiden Gewebearten nicht überall festgestellt worden ist, kann man völlig von der Hansteinschen Einteilung absehen.

Man würde hiergegen vielleicht vorbringen, dass es doch nicht angeht, auf Grund eines einzigen Beispiels, (Hippuris) die ganze Hansteinsche Lehre zu verwerfen. Tatsächlich würde das auch nicht erlaubt sein, wenn die Hansteinsche Lehre auch nur etwas besser begründet wäre. Weil aber die HANsteINsche Gewebedifferenzierung nur in einigen Wurzeln und in einem Stengel hervortritt, so muss man die Sache vielmehr umkehren und fragen, ob man berechtigt ist, diese Lehre auf Grund der wenigen Fälle, in denen sie zutrifft, aufzustellen und zu verallgemeinern? Wenn wir die Frage so stellen, muss die Antwort bestimmt verneinend sein. Die Unterscheidung von Periblem und Plerom in den regelmässig gebauten Wurzeln ist immer noch eine unsichere Sache, ein Unterschied zwischen den beiden findet sich eigentlich nicht. In den meisten Fällen kann man ebensogut andere Grenzen angeben. Eine solche Unterscheidung kann deshalb nicht den Ausgangspunkt für eine so wichtige Verallgemeinerung bilden, zumal nicht für eine Verallgemeinerung, gegen die sich nach den oben gewonnenen Resultaten auch wichtige Tatsachen erheben. Man kann also wohl nicht anders, als anerkennen, dass die Unterscheidung von Periblem und Plerom keine höhere Bedeutung besitzt.

Wie steht es nun aber mit der Bedeutung des Dermatogens?

Hier würde man die Hanstinssche Lehre noch am leichtesten aufrecht halten können. Denn die Epidermis entsteht ja wohl immer aus dem Dermatogen. Es konnte somit dem Dermatogen doch eine phylogenetische Bedeutung zukommen. An sich wäre das nicht so befremdend, weil doch auch phylogenetisch die Epidermis zweifellos älter ist als die Trennung von Rinde 
und Centralcylinder. Letzterer findet sich ja ausser bei einigen wenigen Moosstämmchen nur bei den Gefässpflanzen, während die Sonderung der Epidermis bei den Moosen viel allgemeiner ist und ebenfalls z. B. bei Marchantia ausgebildet ist.

Es lassen sich aber gegen eine solche Auffassung ebenfalls Bedenken vorbringen. Wenn wirklich die Sonderung des Dermatogens eine ontogenetische Wiederholung der phylogenetischen Ausbildung einer Epidermis war, so wären erstens die verschiedenen Beziehungen im Vegetationspunkt zu der Kalyptra schwer verständlich; es wäre dann nicht einzusehen, wie die Epidermis bald aus der innersten Kalyptrazelllage, bald aus der äussersten Schicht des Wurzelkörpers hervorgehen könnte. Weiter wären die Fälle, in denen das Dermatogen durch tangentiale Teilungen solche Rindengewebe angibt, die in anderen Pflanzen immer aus dem Periblem hervorgehen, wie z. B. das Mesophyll und die Gefässbündel des Gramineenblattes (Vergl. S. 33), als schwere Entstellungen der verkürzten Phylogenie aufzufassen. Wahrscheinlich ist also die phylogenetische Bedeutung des Dermatogens nicht grösser als die des Periblems und des Pleroms. 


\section{ZWEITER TEIL.}

DIE STELÄR-THEORIE UND DIE VERGLEICHENDE ANATOMIE.

\section{KAPITEL.}

Die Grenze zwischen Rinde und Centralcylinder in den Stengeln.

Im ersten Teil dieser Arbeit haben wir gesehen, dass von einer Begründung der Stelär-Theorie auf entwicklungsgeschichtliche Tatsachen wohl nicht die Rede sein kann. Tatsächlich ist die Theorie auch auf vergleichend-anatomischem Gebiete aufgestellt worden. Es wird sich nun auch ergeben, dass hier die Verhältnisse ganz anders liegen; wir werden hier finden, dass der Einteilung Van Tigghems eine hohe morphologische Bedeutung zukommt.

Es giebt aber einige Forscher, welche die Stelär-Theorie auf vergleichend-anatomischem Gebiete bekämpfen, indem sie das Vorkommen einer inneren Rindengrenze leugnen. Von diesen Angriffen müssen wir hier in erster Linie zwei betrachten, die von Fischer (131) und von Belli (112) geliefert worden. 
sind. Sie beziehen sich beide nur auf den Stengel, nicht auf die Wurzel; tatsächlich ist auch die Sonderung in Epidermis, Rinde und Centralcylinder in der Wurzel so scharf und so geringen Ausnahmen unterworfen, dass man hier wohl keine Bestreitung der Theorie Van Tieghems zu erwarten braucht.

Fischer spricht ausschliesslich vom Pericykel; seine Schlüsse sind aber für die ganze Theorie Van Tieghems von Bedeutung. Er hat untersucht, inwiefern der Pericykel in den Stengeln praktisch anzugeben ist.

Von den Monokotylen betrachtet er zuerst die Familien mit "rippenlosem Bastring” Schwendeners, d. h. einem mechanischen Gewebering, der nicht durch aussen angesetzte "Rippen” an bestimmten Stellen mit der Epidermis in Kontakt steht. Bei diesen ist zwar die Rinde deutlich abgegrenzt, der Pericykel kann somit angegeben werden, wenn auch die Endodermis hier nicht als solche ausgebildet ist; bei den Familien mit "geripptem Bastring" dagegen kann man keine Grenze ziehen. Rechnet man den Bastring zum Centralcylinder, so fehlt an vielen Stellen die Rinde, rechnet man ihn zur Rinde, so ist kein scharf begrenzter Centralcylinder mehr anzugeben, weil die äusseren Gefässbündel vielfach in diesem Ringe liegen.

Bei den Dikotylen ist zwar bisweilen der Pericykel recht gut abgegrenzt, wenn die Endodermis deutlich ausgebildet ist; dieses ist nach Fischer aber der seltenere Fall. Eine Schutzscheide mit Casparyschen Punkten kommt nach ihm nur in Rhizomen vor, nicht in freien Stengeln, und auch die Stärkeund Parenchymscheiden sind verhältnismässig selten. Bei 100 untersuchten Pflanzen fand Fischer nur bei 32 eine Endodermis ausgebildet. Die Übereinstimmung zwischen Pericykel in Stengel und Wurzel dehnt sich nach ihm, wenn ein Pericykel im 
Stengel überhaupt ausgebildet ist, bloss auf die Lage aus, nicht auf die Histologie, oder Funktion.

Bei den Koniferen endlich fand Fischer gar keine Trennung zwischen Rinde und Pericykel ausgebildet, bei 8 untersuchten Arten.

Wenn wirklich, wie Fischer beschreibt, bei der grossen Mehrzahl der Pflanzen eine Grenze zwischen Rinde und Pericykel nicht bestände, so würde die ganze Stelär-Theorie damit geradezu hinfällig. Wir werden aber im folgenden sehen, dass dem nicht so ist, und dass sich bei der grossen Mehrzahl der Pflanzen eine solche Grenze sehr genau angeben lässt. Nur muss man die geeigneten Stadien dafür in der geeigneten Jahreszeit aufsuchen.

Eine zweite ausführliche Bestreitung der Ansichten VAN Tieghems hat S. Belui in seiner Arbeit: „Endoderma e periciclo nel G. Trifolium in rapporta co.la teoria della stelia di V. Tieghem et Douliot" gegeben.

In der Einleitung schon behauptet Belli: „V. Tieghem und seine Schule, das Gebiet der Anatomie verlassend und das der Theorie betretend, nehmen im Stengel immer eine Endodermis als topographisch bestehend, an" (112 S. 6). Diese Behauptung rührt wohl daher, dass BeLuI als einseitig physiologischer Anatom nur physiologische Charaktere als Merkmale anerkennt, und von einer morphologischen Betrachtung nichts wissen will. Weil nun VAN TIEghem die Endodermis als eine Region betrachtet, die entweder als Schutzscheide oder als Stärkescheide oder noch anders ausgebildet sein kann, und nicht durch eine bestimmte Gewebeart charakterisiert wird, so erklärt BELLI dies für graue Theorie, die sich mit der Wirklichkeit nicht verträgt.

Auch noch von anderen Gesichtspunkten aus bestreitet 
BELLI die Stelär-Theorie, und zwar auf Grund der von DelPino aufgestellten Theorie (45), nach der die Blätter statt periphere oder Anhangsorgane zentrale Organe sind, während das, was bis jetzt als Stengel betrachtet wird, einfach eine durch Verwachsen von Blattbasen entstandene Region ist. Die höheren Pflanzen sind somit keine Kormophyten, sondern Phyllophyten, und der Stengel wäre am besten Phyllopodium oder Phyllopodial-Gegend genannt.

"Aus dieser Theorie" sagt BeLLI (112 S. 18) „ergibt sich ein direktes Korollarium, nämlich, dass die Unterscheidung zwischen Rinde und Centralcylinder im Stengel theoretisch unmöglich ist, sowie sie in der Praxis unausführbar ist."

Es dürfte hier nicht am Platze sein, näher auf diese Theorie DeLpinos einzugehen; wir können jedoch wohl bemerken, dass diese Theorie sich noch nicht über den Rang eines genialen Gedankens erhoben hat, und dass von einer wissenschaftlichen Begründung derselben auch nicht die leisesten Spuren vorhanden sind; deshalb ist von dieser Seite auch kaum ein ernsthafter Angriff auf die Stelär-Theorie zu befürchten.

Aus Beldis weiterer Bekämpfung der Stelär-Theorie sei noch bemerkt, dass er als Tatsache, welche sich nicht mit VAN Tieghems Theorie verträgt, nur ermittelt, dass bei den verschiedenen Arten von Trifolium ausserhalb des hypokotylen Gliedes keine Gesamtendodermis vorkommt, sondern dass hier nur Partial-Endodermen an der Aussenseite der einzelnen Gefässbündel vorhanden sind.

Weil also die praktische Durchführbarkeit der Einteilung für den Stengel von einigen Autoren bezweifelt wird, habe ich selbst untersucht, inwiefern eine solche Einteilung bei den Phanerogamen tatsächlich besteht. $\mathrm{Zu}$ diesem Zwecke 
habe ich hauptsächlich die allgemeine, kontinuierliche Schutzscheide oder Stärkescheide bei vielen Pflanzen aufgesucht. Wenn man eine solche findet, so hat man selbstverständlich eine vollkommen scharfe Grenze zwischen Rinde und Centralcylinder, und das ist's gerade, was man braucht. Ohne die Möglichkeit, eine scharfe Grenze zu ziehen, wird die StelärTheorie an praktischer Bedeutung erheblich einbüssen. ES gibt natürlich auch in solchen Fällen, wo eine besonders ausgebildete Endodermis fehlt, mehrmals eine sehr scharfe Grenze zwischen Rinde und Centralcylinder, diese aber ist nicht so leicht mit objektiver Gewissheit festzustellen; wo der eine eine deutliche Sonderung erkennt, kann der andere eine solche von untergeordneter Bedeutung oder gar keine Grenze erblicken. Wenn man aber eine Schutzscheide oder eine Stärkescheide findet, hat man eine zuverlässige Grenze. Ausserdem sind diese Scheiden in grosser Zahl in der Literatur erwähnt, weshalb ich meine Untersuchung sehr wesentlich habe beschränken können.

Eine solche Untersuchung über das Vorkommen einer scharfen Grenze zwischen Rinde und Centralcylinder durch das Auftreten einer besonders ausgebildeten Endodermis habe ich nur für die Phanerogamen ausgeführt, und nicht für die Gefässkryptogamen - obwohl die Stelär-Theorie sich auch auf diese bezieht - weil die Gefässkryptogamen hinreichend untersucht worden sind. Das Ergebnis dieser Untersuchungen der Gefässkryptogamen ist, dass eine scharfe, zuverlässige Grenze in den noch zu nennenden Scheiden wohl zu finden ist. Dennoch sind die Verhältnisse ziemlich kompliziert durch das häufige Auftreten von Polystelie, Astelie und noch andere Strukturen. Auf diese Verhältnisse komme ich unten noch zurück, zumal auf den Wert, den man diesen Strukturen zuerkennen muss; hier betrachte ich aber nur die Schärfe der Grenzen. 
Bei den Farnen findet sich fast allgemein um die Stele oder um die Stelen im Stengel eine Schutzscheide (DE BARY 28 S. 431); diese Verhältnisse sind von den später zu nennenden englischen und amerikanischen Forschern näher bestätigt worden.

Bei den Equiseten treten ebenfalls deutliche Schutzscheiden auf, die hier vorkommenden Verhältnisse sind nach den Untersuchungen Pfitzers (6) und VaN Tieghems (85) zu sehr bekannt, um dieselben hier noch näher anzuführen. Auch bei den Lycopodinae finden wir für die zwei wichtigsten Repräsentanten, Lycopodium und Selaginella eine Endodermis angegeben, für Lycopocium in PRITzeL, Lycopodiaceae (134 S. 580), von Selaginella in LECLERC DU SABLON, Sur l'endoderme de la tige des Sélaginelles (80 S. 208). Auch bei Psilotum triquetrum findet sich eine deutliche Schutzscheide (nach mündlicher Mitteilung des Herren R. van Munster, stud. bot.)

Bei den Phanerogamen ist aber im Stengel eine scharfe Sonderung zwischen Rinde und Centralcylinder in genügendem Masse bis jetzt nicht nachgewiesen; man findet auch z. B. in der neuesten dänischen Ausgabe von Warmings Lehrbuch angegeben, dass diese Gewebe im Stengel nur selten so scharf getrennt sind wie in der Wurzel (144 S. 285). Ich habe deshalb diese Untersuchungen einigermassen systematisch getrieben, indem ich, wenigstens für die Angiospermen, für alle bekanntere Familien, von denen aus der Literatur eine Endodermis nicht schon bekannt war, eine Art daraufhin untersuchte.

\section{Gymnospermen.}

Die Gymnospermen haben keine besonders ausgebildete Endodermis. Diese Behauptung ist schon von FIscher ausgesprochen (S. 96), und ich kann sie nur bestätigen. Meine eigene Untersuchung beschränkt sich auf nur 5 Arten: 
Abies pectinata DC.

Cupressus Lawsoniana Andr. intertexta.

Pinus Laricio Poir.

P. leiophylla Schlecht. et Cham. pendula.

Taxus baccata L. var. cuspidato.

Bei keiner dieser Pflanzen war in den neuen Trieben zwischen Anfang Mai und Anfang Juli 1900 in irgend einer Zone eine Schutzscheide oder eine Stärkescheide zu beobachten. Und doch sind diese Monate die beste Zeit für das Auftreten einer Stärkescheide, weil sonst der ganze Querschnitt mehr oder weniger stärkeführend ist; im Frühsommer beschränkt diese sich auf die innersten Teile der Rinde. Auch aus der Literatur ist mir nur eine einzige Erwähnung einer Stärkescheide bei einem Gymnospermen bekannt, nämlich bei Ephedra fragilis, nach Strasburger (98 S. 143).

Nach dem vorhergehenden konnte man also für die Gymnospermen die praktische Durchführbarheit der Einteilung VAN Tieghems bezweifeln. Dennoch glaube ich nicht, dass dazu ein Grund vorliegt. Denn auch ohne besonders ausgebildete Endodermis ist hier in vielen Fällen eine hinreichend scharfe Grenze zwischen Rinde und Centralcylinder vorhanden.

Die Gymnospermen reihen sich bekanntlich in dem Bau ihres Stammes den Dikotylen an; alle haben von Anfang an einen Vaskularcylinder mit einem eingeschlossenen Mark, der von einer Rinde umgeben ist. Diese Rinde grenzt sich in vielen Fällen scharf vom Pericykel ab. So fand ich bei Taxus baccata L. var. cuspidata die Rinde stärkeführend, zumal in den 2-3 inneren Zellschichten.

Der Pericykel dagegen war völlig stärkefrei, was eine scharfe Trennung andeutete. Bei Pinus leiophylla pendula beschränkte sich die Stärke auf die 1-2 innersten Rindenschichten, so dass hier fast eine Stärkescheide ausgebildet war. 
Eine genaue morphologische Untersuchung der Gymnospermenstengel würde hier zu weit führen; wahrscheinlich würde aber eine solche wohl überall die Trennung von Rinde und Centralcylinder in genügender Schärfe ergeben.

\section{MONOKOTYLEDONEN.}

Ganz anders gestaltet sich die Sache bei den Monokotyledonen. Dass hier mehrmals eine scharfe innere Rindengrenze $\mathrm{zu}$ beobachten ist, geht wohl hervor aus der folgenden Liste.

In dieser Liste habe ich alle diejenigen Pflanzen angeführt, bei denen mir eine scharfe Endodermis entweder aus der Literatur oder aus eigener Beobachtung bekannt ist. Dabei bezeichnet Schutzsch. oder Sch. Schutzscheide, Stärkesch. oder St. Stärkescheide, zug. zugleich, Einz. Einzel-, Ges. Gesamt-, Ast. Astelie und Pol. Polystelie. Die Anordnung ist systematisch nach den Familien, innerhalb der Familien alphabetisch. Die systematische Anordnung ist die nach der ersten deutschen Auflage von WARMING Lehrbuch der Botanik (88). Bei den Angaben aus der Literatur habe ich, wenn keine Autorennamen beigefügt waren, diese selbstverständlich auch nicht mehr hinzugefügt.

Das Material zu den eigenen Beobachtungen war meistens in den Monaten Mai und Juni gesammelt worden.'

\section{Ordnung Helobiae.}

Fam. Alismaceae.

Alisma plantago L. (Rhiz.) Schutzsch. Eigene Untersuchung. Alisma plantago (Kugel-

förmiger Stengelteil der

jungen Pflanze 
Hydrocleis Humboldti

Fam. Juncaginaceae.

Triglochin maritimum

(Rhiz.)
Einz.sch. Ast. DE BARY 28 S. 129, [MOROT 52 S. 261.

Schutzsch.

Fam. Potamogetonaceae.

Cymodocea aequorea Kön

Potamogeton

Zostera marina I.

Z. nana Roth.

Fam. Hydrocharitae.

Elodea canadensis Michx.

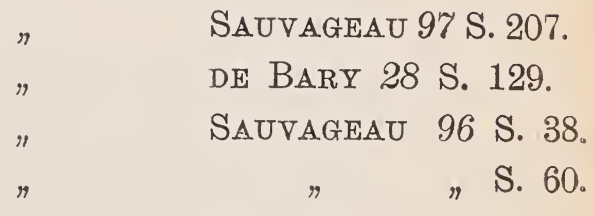

2. Ordnung Glumiflorae.

Fam. Juncacecie.

Juncaceae (Stengel)

Luzula campestris (Rhiz.)

Fam. Cyperaceac.

Carex hirta (Rhiz.)

Cyperaceae (Stengel)

Fam. Gramineae.

Agropyron repens Beauv.

(Rhiz.)

Hordeum vulgare L.

Zea Mays L.
Einz.sch. Ast. DREYer 102 S. 9.

schutzsch. GuIllaud 36 S. 63.

(ebenfalls innere

Schutzsch.)
Schutzsch. DE BARY 28 S. 129.

Einz.sch. Ast. DreYer 102 S. 9.

3. Ordnung Spadiciflorae.

Fam. Araceae.

Acorus calamus (Rhiz.) Schutzsch. Guillaud 36 S. 47.

A. gramineus

Schutzsch.

Eigene Untersuchung.

Stärkesch.

Scindapsus pictus Hassk. Sch.zug. St. Eigene Untersuchung. Symplocarpus foetidus

(Knolle) Einzelsch. Ast. JeFFrey 127 S. 624.

" (Stengel) Ges.schutzsch. 
4. Ordnung Enantioblastae.

Fam. Commelinaceae

Einige Commelinaceae, im

Stengelknoten

Tradescantia virginiana L
Stärkesch. $"$

Commelina sp.

\section{(Rhiz.) Schutzsch. G
(nicht kontinuierlich). \\ (Rhiz.) Schutzsch. G
(nicht kontinuierlich).}

$"$
HABERLANDT 157 S. 264.

Eigene Untersuchung.

GuILlaud 36 S. 72.

S. 77

Fam. Colchicaceae

ว. Ordnung Liliiflorae.

[Narthecium ossifragum(Rhiz.) ${ }^{1}$ ) Schutzsch. GUILLAUd 36 S. 61.] (1 bis 3 Zellen dick).

[Tofieldia paniculata " $\begin{aligned} & \text { Schutzsch. } \\ & \text { (1 bis } 2 \text { Zellen dick). }\end{aligned} \quad$ " S. 59.]
[Uvularia flava
" Schutzsch.
S. 60.]
(1 bis 2 Zellen dick.)

Fam. Liliaceae

Allium odorum

Asparagus officinalis L.

Funkia ovata

Hemerocallis graminea (Rhiz.)

[Lloydia serotina (Rhiz.)

Muscari comosum

(Blütenstiel)

Ornithogalum pyrenaicum

Ruscus hypoglossum L.

Fam. Convallariaceae

Stärkesch.

"

Schutzsch.
HABERLANDT 157 S. 264.

Eigene Untersuchung. Guillaud 36 s. 62.

$"$

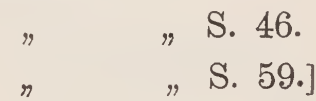

(3 Zellen dick).

Convallaria maialis L.

(Jahresspross für das künftige Jahr.)

a. in seinem basalen Teil. Schutzsch. Eigene Untersuchung.

b. in seinem apicalen Teil Stärkesch.

HABERLANDT 157 S. 263.

Stärkesch.

S. 264.

Eigene Untersuchung.

1) In Klammern gestellt weit die Endodermis nicht einfach ist. 
Convallaria maialis (Rhiz.) Schutzsch. Guillaud 36 S. õ2.

Smilacina stellata (1-2" Zellen dick).

Paris quadrifolia " $\quad$ Schutzsch. " 69. Fam. Pontederiaceae.

Pontederia azurea Sch. zug. St. Eigene Untersuchung. Fam. Iridaceae.

Iris amoena

I. sibirica

I. variegata $\mathrm{L}$.
(Rhiz.)
"
Guillaud 36 S. 62.
$" \quad "$
"S. 62.
$n$
$n$
Eigene Untersuchung. (nur an der Unterseite ausgebildet.)

Fam. Dioscoreaceae.

Tamus communis $\mathrm{L}$.

Stärkesch.

6. Ordnung Scitamineae.

Scitamineae (Rhiz.)

Schutzsch.

DE BARY 28 S. 129.

Fam. Zingiberaceae

Zingiber officinale Roscoe Stärkesch. Eigene Untersuchung. $" \quad$ "(Rhiz.) Schutzsch.

Zingiberaceen

Fam. Cannaceae.

Canna indica $\mathrm{L}$. $" \quad "$ TSCHIRCH 81 S. 375. Guillaud 36 S. 56.

7. Ordnung Gynandrae.

Fam. Orchidaceae.

Epipactis palustris (Rhiz.) Schutzsch. GuILLAND 36 S. 45. Epipogon

Corallorhiza Endod. REINEE 14

Vanilla planifolia $" \quad$ Endod. DE BARY 28 S. 129. $n \quad n$ REINKE 14

V. Pompona Stärkesch. MoRot 52 S. PI. 10, Fig. 10. 
Das Resultat ist, dass die Monostelie mit ausgebildeter Endodermis bei den Monokotyledonen sehr häufig vorkommt. Von den 36 monokotylen Familien, die Warmivg angibt, sind oben 18 angeführt worden, bei denen solches der Fall was, und diese sind über alle sieben Ordnungen verteilt. Die Polystelie findet sich hier gar nicht, die Astelie nur in 4 Familien aus 3 Ordnungen; in allen diesen 4 Familien kommt ebensogut die Monostelie vor.

Gibt es nun keine Ausnahmen bei den Monokotylen, Fälie, in denen eine Grenze in keinem Teil der Pflanze anzugeben ist? Tatsächlich sind solche vorhanden.

Bei einigen unten angegebenen Pflanzen gelang es mir nicht, eine solche Grenze aufzufinden. Natürlich ist damit nicht gesagt, dass nicht in einer andern Jahreszeit oder in anderen Stengelteilen der Pflanze eine Grenze zu finden gewesen wäre; denn eine so genaue Untersuchung dieser Pflanzen, dass ich alle Stadien derselben gesehen hätte, habe ich nicht ausgeführt.

Dennoch glaube ich sie hier anführen zu müssen.

Es waren:

Cyperus gracilis $\mathrm{R}$. Br.

Koeleria cristata Pers.

Triticum vulgare Vil. (Keimpflanze.)

Galanthus nivalis Linn. (Zwiebelkuchen.)

Epipremnum mirabile Schott.

Dendrobium nobile Lindl.

Bei anderen Pflanzen konnte ich zwar eine Grenze zwischen Rinde und Centralcylinder angeben, eine besondere Scheide war aber nicht ausgebildet. Solches war der Fall bei :

Bambusa arundinacea Willd.

Calla palustris L. 
Hedychium Gartnerianum

Lilium bulbiferum L.

Uvularia grandiflora Sm.

Zingiber officinale Rosc.

Auch aus der Literatur sind derartige Fälle bekannt. Weil es aber bei den stets mehr oder weniger incidentellen Angaben aus der Literatur sehr gut möglich sein kann, dass von jemand das Fehlen einer Scheide angegeben wird bloss deshalb, weil er seine Untersuchungen nicht zur rechten Zeit argestellt hat, um eine solche $\mathrm{zu}$ finden, so muss man dabei sehr kritisch verfahren.

Ich führe deshalb von diesen Angaben nur die folgenden an, welche mir zuverlässig erscheinen.

Das grossartigste Beispiel liefern uns die Palmen. Unter dieser Familie findet sich, soweit mir aus der Literatur bekannt, nirgends eine scharfe Rindengrenze angegeben. EICHLER schreibt: "Dadurch wird eine Art Rinde gebildet, von MoHL „Faserschicht” genannt, welche allerdings gegen den inneren Theil, der Holzkörper heissen möge, nichts weniger als scharf abgegrenzt ist." (59 S. 505). Auch Strasburger (98 S. 378) gibt an, dass bei Cocos flexuosa die Rinde nicht scharf vom Centralcylinder abgegrenzt ist.

Andere Fälle finden wir bei den Orchideen, nach L. Hering, in seiner "Anatomie der monopodialen Orchideen" (133). Hering, der - es sei nebenbei bemerkt, unter Endodermis etwas ganz Ungewöhnliches versteht, nämlich die Exodermis, auch wo eine solche sich nur durch ihre Zellformen auszeichnet gibt an, dass er bei den folgenden Arten eine scharfe Trennung zwischen Rinde und Centralcylinder nicht gefunden hat, dagegen wohl einen allmählichen Übergang zwischen beiden (133 S. 49): 
Acampe papillosa Lindl.

Saccolabium Witteanum Reichb.

Sarcochilus Calceolus Lindl.

Bei anderer Arten findet er dagegen Rinde und Centralcylinder scharf gegen einander abgegrenzt (S. 49):

Plialaenopsis grandiflora Lindl.

Renanthera coccinea Lour.

R. moschifera Reichb.

Saccolabium ampullaceum Lindl.

S. giganteum Lindl.

Sarcanthus rostratus Lindl.

S. sarcophyllus H. B. G.

S. tricolor Reichb.

Vandopsis gigantea Pfitz.

Alle diese Fälle können aber unsere Auffassung von der Struktur der monokotylen Stengel nicht beeinflussen. Alle diese Stengel schliessen sich in ihrem Bau den übrigen monostelen Stengeln aufs engste an. Nur die Endodermis ist nicht scharf ausgebildet.

Eine Beeinträchtigung der praktischen Durchführbarheit der Einteilung VAN Treghems ist hier also auch nicht zu befürchten. Die Fälle beziehen sich auf 9 Familien aus 5 Ordnungen, in 8 dieser 9 Familien sind aber auch die normalen Fälle bekannt, nämlich Monostelie mit ausgebildeter Endodermis, während die 9. Familie - die Palmen - sich in ihrem Bau ebensogut an die Monostelie anschliesst als die anderen. Wir haben also auf 19 untersuchte Familien, (die Palmen mitgerechnet), 18, bei denen die Monostelie mit Endodermis bekannt ist, gegen eine, bei der eine Endodermis nicht gefunden ist. Von diesen 18 Familien sind 10, bei denen, soweit bis jetzt bekannt ist, immer eine Scheide vorkommt, und 8 , bei denen diese 
gelegentlich fehlt. Ausserdem kommt in 4 dieser 18 Familien die Astelie gelegentlich vor.

3. DiKotyledonen.

Die hier folgende Liste ist ganz wie oben bei den Monokotylen aus Literatur und eigener Beobachtung zusammengestellt. Wenn bei letzterer keine besonderen Angaben darüber gemacht sind, so ist immer von krautigen Pflanzen der Hauptspross oder ein starker Ast untersucht worden, bei holzigen Pflanzen die neu gebildeten Triebe, von einer Länge von einigen $\mathrm{mm}$ bis mehrere $\mathrm{cm}$. Wenn bei einer untersuchten Pflanze die Stärkescheide die einzige Stärke des Querschnittes innehatte - die Stärke in den Schliesszellen der Stomata natürlich nicht mitgerechnet, so habe ich diese Pflanze mit einem Stern * angedeutet. Das Material war wieder in den meisten Fällen Alkoholmaterial, das Mai bis Juni gesammelt worden war.

Fam. Salicaceae.

1. Ordnung Saliciflorae.

${ }^{*}$ Salix viminalis L.

Stärkesch.

Eigene Untersuchung.

Fam. Betulaceae.

2. Ordnung Querciflorae.

Betula alba L.

Stärkesch.

Fam. Corylaceae.

*Corylus avellana L. atropurpurea

Fam. Cupuliferae.

Quercus robur L.

n (Hypokotyles

Glied)

Fam. Juglandaceae.

3. Ordnung Juglandiflorae.

"Juglans regia L. laciniata Stärkesch.

Eigene Untersuchung. 
4. Ordnung Urticiflorae.

Fam. Ulmacede.

*Ulmus pyramidalis L. Stärkesch. Eigene Untersuchung. Fam. Urticaceae.

Urtica dioica L.

Fam. Cannabinae.

"Humulus Lupulus L.

Fam. Casuarinae.

Casuarina

${ }^{*}$ C. equisetifolia Frst.
Schutzsch.

BOodLE und WORSDELL 110 s. 236.

Stärkesch. Eigene Untersuchung.

5. Ordnung Polygoniflorae.

Fam. Polygonaceae.

Einige Polygonaceen, im

Stengelknoten

Stärkesch. HABERLANDT 157 S.164.

Fam. Piperaceae.

Arthanthe ampla

Macropiper excelsum

Peperomia incana

$P$. obtusifolia

P. rubella

Piper Cubeba

$P$. nigrum L.

Pipereen

Saururus cernuus

Sch. zug. St. Мовот 52 S. 268.

Einz. st. Ast. Eigene Untersuchung. $" \quad " \quad$ WEISS 26.

" " " "

Sch. zug. St. Mовот 52 S. 268.

Eigene Untersuchung.

Schutzsch. Werss 26.

SANIO 5 S. 176.

6. Ordnung Curvembryeae.

Fam. Caryophyllaceae.

Einige Caryophyllaceae, im

Stengelknoten

Stärkesch. HABERLANDT 157 S. 264.

Achyronychia Cooperi, A. Gray

Schutzsch. Joesting 149 S. 150.

A. Parryi Hemsl. 
Anychia dichotoma Michx. Schutzsch.

Jonsting 149 S. 150.

Cerdia congestiflora Hemsl.

S. 154.

Cometes abyssinica R. Br.

S. 150.

Corrigiola capensis Willd.

S. 154.

Dicheranthus ploeamoides

Webb.

Drymaria cordata Willd.

Gymnocarpus fruticosus

Pers.

Habrosia spinuliflora Fenzl.

Herniaria glabra L.

Honckeneja peploides

Illecebrum verticellatum L.

Löfflingia hispanica L.

Pollichia campestris Ait.

Polycarpaea candida Webb.

et Berth.

$P$. Teneriffae Lam

Polycarpon peploides DC.

P. tetraphyllum L.

Pteranthes echinatus

Pycnophyllum Lechleria-

num Rohrb.

Scleranthus perennis L.

Sclerocephalus arabicus

Boiss.

Siphonychia americana

Torr. et Gray.

Spergula arvensis L.

S. Morisonii Boreau.

Spergularia rubra Presl.

S. salina Presl.

Sphaeronychia Hookeri

T. Anders.

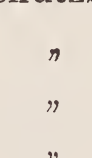

\section{0}


Stipulicida setacea Michx. Schutzsch.

Telephium Imperati L.

Fam. Chenopodiaceae.

Atriplex patula

A. hastata (im Hypokoty. len Glied)

A. hortense

A. nitens

Boussingaultia baselloides

Salicornia herbacea

Chenopodium album

Obione portulacoides

Beta maritima

Camphorosma monspelia-

num.

Fam. Phytolaccaceae.

Phytolacca dioica

Fam. Nyctixiniaceae.

Bougainvillea fastuosa

Oxybaphus nyctagineus Sw.

Fam. Aizoaceae.

Mesembryanthemeen

* Mesembryanthemum blan.

dum Haw
JoESTING 149 S. 145.

" $\quad$ S. 142.

DE BARY 28 S. 432.

Fron 125 Pl. 9 , Fig. 2. Fischer 131 S. 16.

Morot 52 S. 277.

Morot $52 \mathrm{Pl} .10$

Fig. 14.

Schutzsch. Fron 125 Pl. 6 Fig. 3,

Pl. 8 Fig. 5.

Endoderm. $\quad$ ग $125 \mathrm{Pl} .7$ Fig. 5.

Stärkesch. FIscher 131 S. 16.

Endoderm. FroN 125 Pl. 8 Fig.1,2.

" "Pl. 8 Fig. 4.

" $\quad$ Fig. 9 im

Text.

Stärkesch. MoRot 52 S. 275.

Fig. 43.

Eigene Untersuchung.

HAGEN 13.

Eigene Untersuchung.

7. Ordnung Cactiflorae.

Fam. Cactaceae

Cereus flagelliformis $\mathrm{Hw}$. grandiflora

Stärkesch. Eigene Untersuchung 


\section{Ordnung Polycarpicae.}

Fam. Ranunculaceae. Die Ranunculaceae sind schon mehrmals in der Literatur über die Stelär-Theorie besprochen worden, seitdem von Marié die Struktur des Stammes eingehend untersucht worden war (51), wobei sich ergeben hat, dass sich unter den $R a$ nunculaceae verschiedene Formen finden, bei denen statt der gewöhnlichen allgemeinen Endodermis Einzelendodermen um die einzelnen Gefässbündel vorkommen: wir haben hier somit die astele Struktur Van TIEghems. Dieser Arbeit Marí́s entnehme ich die folgenden Angaben.

Einzelendodermen sind beobachtet bei den folgenden Arten:

Anemone nemorosa

Einz.schutzsch.

S. 58 .

A. pavonina

Caltha dionaefolia

C. palustris

Eranthis hyemalis

Ficaria avenonensis

F. grandiflora

F. ranunculoides

Oxygraphis Scheftoana

Ranunculus acris (Rhiz.)

Einz.stärkesch.

S. 90 .

Einz schutzsch.

S. 91 .

Einz.endocerm.

S. 92 .

S. 87.

S. 87 .

S. 87 .

Einz.schutzsch.

S. 88 .

Einz.end.,

S. 80 . um diese herum Einz.st.sch.

R. auricomus (Stengel) Einz.endoderm.

S. 81 .

R. flammula

S. 81 .

$R$. hederaceus

"

S. 73 .

R. lanuginosus

(Rhiz.)

S. 80 .

R. multifidus

"

S. 81 .

R. peucedanifolius (Stengel)

S. 73 .

R. polyanthemos

(Rhiz.)

S. 80 .

$R$. repens

"

S. 80 .

$R$ tuberosus

S. 80 . 
Bei einer grösseren Zahl von Ranunculaceen fand MarIÉ aber eine Gesamtendodermis, auch bei zahlreichen Ranunculus-Arten. Diese sind :

Aquilegia 8 sp.

Aconitum Napellus

A. Anthora

A. Iycoctonum

Actaee spicata

Adonis vernatis (Rhiz.)

(Stengel)

Anemone nemorosa

A. pensylvanica

A. Pulsatilla

A. ranunculoides

A. vernalis

Anemonopsis macrophylla

(Rhiz. und Stengel)

Atragene alpina

Callianthemum rutaefolium

(Rhiz.) Stärkescheide. rutaefolium

(Stengel) Parenchymsch.

Cimicifuga foetida (Rhiz.)

" (Stengel) Stärkescheide.

Clematis recta

Coptis trifolia (Rhiz.)

Delphinium albiflorum

D. Ajacis

D. Consolida

D. grandifolium

D. Staphisagria

D. vitifolium

Hamadryas magellanica Helleborus foetidus

Stärkescheide.
Endodermis.

Parenchymsch.

Endodermis.

Parenchymsch.

Schutzscheide.

Parenchymsch.

Schutzscheide.

Parenchymscheide.

Endodermis.
Endodermis.

S. 114 .

S. 147.

S. 133 .

S. 138 .

S. 45 .

S. 68 .

S. 68 .

S. 57.

S. 61.

S. 54.

S. 57.

S. 54 .

S. 50 .

S. 30 .

S. 66.

S. 67.

S. 47.

S. 48 .

S. 16 .

S. 104.

S. 128.

S. 117 .

S. 117 .

S. 127.

S. 119 .

S. 128 .

S. 89 .

Stärkescheide.

S. 99. 
Helleborus niger

Hepatica triloba (Rhiz.)

Hydrastis canadensis

Isopyrum thalictroides

Knowltonia rigida

Myosurus minimus

Nigella Garidella

Paeonia Moutan

P. officinalis

P. papaveracea

Ranunculus abortivus

R. aconitifolius

$R$. acris

$R$. amplexicaulis

$R$. arvensis

R. choerophyllos

R. multifidus

R. parnassifolius

R. polyanthemos

$R$. sceleratus

R. Thora

Thalictrum anemonoides

Th. aquilegifolium

Th. foetidum

Th. maius

Trautvetteria palmata

Trollius europaeus

Xanthorrhiza apiifolia
Stärkescheide

Endodermis

S. 95.

S. 63.

S. $6 \check{\text {. }}$

S. 107.

S. 42.

S. 71 .

S. 110 .

S. 152 .

Stärkescheide

S. 156 .

Endodermis

S. 152.

S. 82 .

S. $\varepsilon 0$.

S. 82.

S. 81.

S. 8อั.

S. 76.

S. 82 .

S. 80 .

S. 82.

S. 82 .

S. 77.

S. 40.

S. 34 .

S. 38 .

S. 38 .

S. 88 .

S. 102 .

S. 150 .

Wie man also aus der Vergleichung dieser Angaben sehen wird, finden sich die Astelie und Monostelie bei sehr nahe verwandten Arten, und sogar in derselben Pflanze, oftmals in verschiedenen Gliedern: so finden sich die Namen Anemone nemorosa, Ranunculus acris, R. multifidus, R. polyanthemos in beiden Listen. Ausserdem 'gibt MarIÉ von einigen astelen Arten noch an, dass in den Blü- 
tenstielen sich wieder eine Gesamtendodermis findet: so gibt er hier bei Anemone nemorosa und A. pavonina eine Gesamtstärkescheide an, (51 S. 59) und ebenso eine Gesamtendodermis bei den Ranunculi der sectio IV Hecatonia, zu der $u$. a. auch $R$. acris, $R$. flammula, $R$. lanuginosus, $R$. multifidus, $R$. polyanthemos, R. repens, $R$. tuberosus, gehören, d. h. also fast alle astele Ranunkel.

Von anderen Autoren gehören noch hierhin:

Atragene alpina

Clematis montana
Stärkesch.

"
DE BARY 28 S. 432.

Morot 52 Pl. 12 Fig. 33.

Fam. Nymphaeaceae. Auch unter den Nymphaeaceen finden sich viele astele Formen. Die Familie wird von VAN Treghem in vier Unterfamilien geteilt (65).

Cabombées (Brasenia, Cabomba).

Nupharées (Nuphar, Barclaya).

Nymphéees (Euryalo, Victoria).

Nelumbees (Nelumbo).

Die Astelie findet sich nun bei den drei ersten allgemein im Rhizom. (54 S. 380 und 65). Bei dem Nelumbées dagegen finden wir eine Gesamtendodermis um den Centralcylinder herum. Nach GWYNNE-VAUGHAN (113 S. 289 und 114 S. 624) finden wir in den Ausläufern von Nymphaea flava, $N$. tuberosa und Victoria deutliche Polystelie.

Fam. Ceratophyllaceae.
Ceratophyllum
Schutzsch.
DE BARY 28 S. 129.

Fam. Magnoliaceae.

Liriodendron tulipifera L. Stärkesch. Eigene Untersuchung. Fam. Berberidaceae.

Berberis vulgaris L.

(einjährige Zweige) Stärkesch.

\author{
H. H. JANSSONIUS \\ mündliche Mitteilung.
}


Fam. Menispermaceae.

Menispermum canadense L. Stärkesch. Eigene Untersuchung: (nur in den interfas. cikulären Teilen.)

Fam. Lauracecue.

Cinnamomum Zeylanicum Rees Stärkesch.

9. Ordnung Rhoeadinae.

Fam. Papaveraceae.

Chelidonium maius L.

Einz.st.Ast. Fam. Cruciferae.

Brassica

Stärkesch.

Fischer 131 S. 16.

Brassica oleracea

Camelina

Capsella

$$
"
$$
DE BARY 28

S. 432.

Schutzsch.

"

Stärkesch.

Schutzsch.

Stärkesch.

Cochlearia officinalis L.

Iberis amara (Hypok. Glied)

Kernera

Nasturtium amphibium

(Wasserstengel) Schutzsch.

Nasturtium amphibium R.Br. Stärkesch.

N. officinale R. Br.

Stärkesch.

Sinapis

Rhaphanus sativus

(Hypok. Glied)

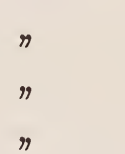

"

”
Constantin 46 S. 313 . DENNERT 47.

Dennert 47 .

DENNERT 47.

SANio 5 S. 175 ff.

DenNeRT $4 \%$.

Eigene Untersuchung.

SACHS 154 S. 186.

Dennert $4 \%$.

10. Ordnung Cistiflorae.

Fam. Resedaceae.

* Reseda luteola L.

Stärkesch.

Eigene Untersuchung. 
Fam. Droseraceae.

Byblis gigantea

Stärkesch. LANG 142 S. 45.

"

(Blütenstiel) Einz.st.Ast. \# \# S. 44.

Drosera intermedia Hayne

(Stengelfuss) Schutzsch.

Eigene Untersuchung.

Fam. Nepenthaceae.

Nepenthes intermedia hort Stärkesch.

Fam. Hypericineae.

Hypericum perforatum L.

Fam. Clusiaceae.

Clusia Liboniana

"

HABERLANDT $15 \%$ S.263.

St. zug. Sch.

Morot 52 S. 263.

11. Ordnung Gruinales.

Fam. Linaceae.

Linum perenne

${ }^{*}$ L. usitatissimum L.

Fam. Geraniaceae.

Einige Geraniaceae

(Stengelknoten)

Fam. Tropaeolaceae.

Tropaeolum maius L.

Fam. Balsaminaceae.

Impatiens Balsamina

(Hypok. Glied)

1. noli-tangere $\mathrm{L}$.

I. parviflora
Stärkesch. Morot $52 \mathrm{Pl}$. 10. Fig. 9.

Eigene Untersuchung.

HABERLANDT 157 S.264.

Eigene Untersuchung.

SACHS 154 S. 186.

Eigene Untersuchung.

Morot 52 S. 267.

12. Ordnung Columniferae.

Fam. Tiliaceae.

Sparmannia africana

Stärkesch. Morot 52 Pl.11 Fig. 19. 
Fam. Malvaceae.

Abutilon striatum

A. vexillatum

Lavatera

Malva
Stärkesch.

$\eta$

$n$

,
Dumont 73 S. 158.

Fischer 131 S. 16.

Dumont 73 S. 140.

13. Ordnung Tricoccae.

Fam. Euphorbiacede.

Euphorbia

Mercurialis

Ricinus communis (Hyp. Gl.) Stärkesch.

Fam. Buxaceae. (Stengel)

Schutzsch.

"

»
Buxus sempervirens L.

Fam. Callitrichaceue.

Callitriche

Schutzsch.
DE BARY 28 S. 432.

SACHS $154 "$ S. 180.

n 18 Fig. 93 S. 113 .

Eigene Untersuchung.

14. Ordnung Terebinthinae.

Fam. Rutaceae.

*Ruta graveolens L.

Stärkesch.

Eigene Untersuchung.

Fam. Anacardiaceae.

${ }^{*}$ Rhus toxicodendron L.

15. Ordnung Aesculinae.

Fam. Aceraceie.

Acer (Hypok. Glied)

A. campestre L.

A. pensylvanicum L.

A. platanoides

Fam. Erythoxylacede.

* Erythroxylum Coca Lam.
Stärkesch.

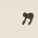

"9

n

$"$
DE BARY 28 S. 129. 
Fam. Aquifoliaceae.

Ilex Aquifolium L.

Fam. Ampelidaceae.

"Vitis Labrusca L.

Fam. Rhamnaceae.

Rhamnus Frangula L.

Stärkesch.

Eigene Untersuchung.

17. Ordnung Thymelaeinae.

Fam. Thymelaeaceae.

Daphne Mezereum L.

Daphnobryon Spp.

Drapetes Spp.

Kelleria Spp.

Octolepis Spp.

Elaeagnus multiflora Thunb.

\section{Fam. Elaeagnaceae.}

Stärkesch. Eigene Untersuchung.

Schutzsch. VAN TIEGHEM 108S.209.

$n$

S. 208.

"

Stärkesch.

S. 209.

» S.237. 
Heuchera

Hoteia japonica (Rhiz.)

Mitella

Parnassia palustris (Rhiz.) Endoderm.

Endoderm.

Schutzsch.
Schutzsch.

"

Roussea

Saxifraga (Rhiz.)

(Stengel)

Tellima

Vahlia

\section{(im Knoten). Einz.sch.Pol.} Schutzsch.

Endoderm.

Schutzsch.

$\eta$
THOUVEnIN 84 S. 55.

S. ว็5.

S. ว̃5.

S. วั5.

Fam. Ribesiaceae.

Ribes sanguineum Pursh. Stärkesch. Eigene Untersuchung. Fam. Hydrangeaceae.

Philadelphus coronarius L. aurea

19. Ordnung Rosiflora.

Fam. Rosaceae.

Alchemilla vulgaris L.

Spiraea semperflorens

Fam. Amygdalaceae.

Amygdalus communis

(Hypok. Glied)

Prunus Cerasus (Hyp. Glied)

Fam. Pomaceae.

Cydonia vulgaris Pers.
Parenchymsch. Fischer 131 S. 13. Stärkesch.
JEFFREY 127 S. 612. Thouvenin 84 S. $10 \%$.

S. 14.

S. 15 . Thouvenin 84 S. 5 j. S. 64. 
Cytisus laburnum

C. racemosus Hort.

Lupinus sulfuricus

Phaseolus (Hypok. Glied)

Trifolium ( ",$)$

(Stengel)
Stärkesch.

"

$"$

" DE BARY 28 S. 432.

Schutzsch. BELLI 112 S. 22.

Einz.st. Ast.
Fischer 131 S. 16.

Eigene Untersuchung.

Fischer 131 S. 16.

S. 23.

21. Ordnung Passiflorinae.

Fam. Passifloraceae.

* Passiflora racemosa coccinea

Brot.

Stärkesch.

Eigene Untersuchung.

Fam. Begoniaceae.

Begonia nitida

$" \quad$ Morot 52 S. 268.

Fam. Cucurbitaceae.

Cucurbita Pepo

(Hypok. Glied) Stärkesch. SACHS 154 S. 186.

Cucurbitaceae

Echinocystis fabacea

Van 'Tieghem 44

Morot 52 Pl. 10 Fig. 11.

22. Ordnung Myrtiflorae.

Fam. Melastomaceae. Diese Familie ist anatomisch am besten untersucht von Van Tieghem (100); weil die Zahl der Genera, bei denen er eine Schutzscheide angibt, mehr als hundert beträgt, werde ich hier dieselben nicht anführen, und nur bemerken, dass bei den meisten Melastomaceae (es gibt bis jetzt 138 Genera) eine Schutzscheide vorkommt.

Fam. Oenotheraceae.

Epilobium hirsutum

Oenothera biennis L.

Trapa

Fam. Haloragidaceae.

Gunnera bracteata

$G$. chilensis
Stärkesch. Fischer 131 S. 16. Eigene Untersuchung. Schutzsch. Morot 52 S. 251.

Einz.sch.Pol. VAN Tieghem 68 S. 309. 
Gunnera commutata

G. cordifolia

G. insignis

G. integrifolia

G. lobata

G. macrophylla

G. magellanica

G. manicata

G. monoica

G. perpens $\alpha$

G. petaloidea

G. prorepens

Hippuris vulgaris L.

Myriophyllum

Fam. Myrtaceae.

"Metrosideros robusta A.

Cunn.

Punica Granatum L.
Einz.sch. Pol. VAN Tieghem 68S.309. Schutzsch. Mon. S. 308. Einz.sch. Pol. S. 309.

Schutzsch. Mon. Einz.sch. Pol. S. 308. S. 309.

Schutzsch. Mon. Schutzsch. "S. 308. , SANIO 3 S. 224. Morot 52 S. 251. Eigene Untersuchung.

23. Ordnung Umbelliflorae.

Fam. Cornaceae

Cornus sanguinea L. Stärkesch. Eigene Untersuchung. Fam. Umbelliferae.

Bupleurum graminifolium Parenschymsch. David 135 S. 28.

B. junceum

B. longifolium

B. Ripoi

B. tenuissimum

Daucus Carota Heracleum Spondylium

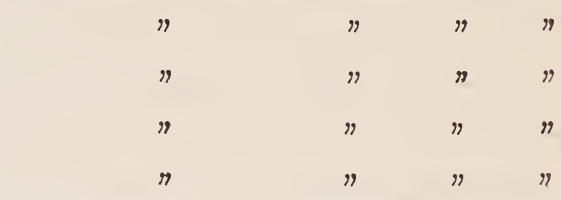

Stärkesch. Fischer $131 \mathrm{~S} 16$.

24. Ordnung Hysterophyta.

Fam. Aristolochiaceae. Aristolochia Sipho A. tricaudata Lem.

Stärkesch.
Strasburger 98 S. 263.

Eigene Untersuchung. 


\section{Dicotyledones Sympetalae.}

1. Ordnung Bicornes.

Fam. Ericaceae.

Erica Tetralix L.

Stärkesch.

Eigene Untersuchung.

Fam. Rodoraceae.

"Rododendron Nudiflorum

Torr.

Fam. Vacciniaceae.

*Vaccinium Vitis-Idaea L.

2. Ordnung Diospyrinae.

3. Ordnung Primulinae.

Fam. Primulaceae. Unter den Primulaceen ist das Geschlecht Primula L. hier am merkwürdigsten. Von TourneforT wurde das Geschlecht in zwei verschiedene Geschlechter zerlegt: nämlich Primula. Tourn. und Auricula Tourn. Von diesen findet sich nun, wie Van Tieghem gezeigt hat (66 und 68 S. 276) die normale, monostele Struktur bei Auricula Tourn., während die Arten der Gattung Primula Tourn. fast alle im Stengel polystel gebaut sind. Eine Gesamtschutzscheide findet sich bei den monostelen Arten sowohl, wie auch Einzelschutzscheiden bei den polystelen.

Lychimachia clethroides Duby. Stärkesch. Eigene Untersuchung.

Fam. Myrsinaceae.

Jacquinea ruscifolia

Fam. Plumbaginaceae.
Limoniastrum
Parench.sch. MAURY 61 S. 143.
Plumbago Spp.
Endoderm.
S. 16.
Statice Spp.
Stärkesch.
S. 30.

4. Ordnung. Tubiflorae.

Fam. Polemonaceae. 
Fam. Convolvulacece.

Calystegia

Stärkesch.

Eigene Untersuchung.

Convolvulus tricolor (Hypok.

Glied) Sch. zug. St.

SACHS 154 S. 186

Ipomaea leucantha

Stärkesch.

Morot 52 Pl. 10,Fig. 1 .

I. versicolor Meissn.

Schutzsch. Sсотт 92 Pl. 12, Fig. 4.

5. Ordnung Personatae.

Fam. Solanaceae.

Atropa Belladonna L.

Hyoscyamus niger L.

Solanum tuberosum

(Stolones)

Fam. Scrophulariaceae.

Antirrhinum orontium

Linaria

L. minor

L. vulgaris

Pedicularis

Fam. Utriculariaceae.

Pinguicula

Polypompholyx

Utricularia vulgaris $\mathrm{L}$.

Fam. Gesneraceae.

Nematanthus longipes DC. Stärkesch.

Sciadocalyx Luciani

Fam. Acanthaceae.

Hexacentris coccinea

Cyrtanthera magnifica Nees
Stärkesch.

Endod.

Schutzsch.

Endod.

Schutzsch.

Polystelie

Schutzsch.
Stärkesch.
Eigene Untersuchung.

$\eta$

DE BARY 28 S. 432. 
Fam. Verbenaceae.

Clerodendron Thomsonae Balf. Stärkesch. Eigene Untersuchung. Fam. Labiatae.

Calamintha clinopodium

Galeopsis Spp.

G. Tetrahit L.

G. versicolor Curt.

Origanum vulgare L.

Stachys betonica
Endod.

Schutzsch.

Endod.

Stärkesch.
FISCher 131 S. 13.

BRIQUET 105 S. 49 und

51, Fig. 11 und 12.

Fischer 131 S. 13.

7. Ordnung Contortae.

Fam. Gentianacecie.

Erythraea Centaurium Pers. Sch. zug. St. H. H. JANssonius mündliche Mitteilung.

Gentianoideae (Rhiz.) Endod. Perrot 121 S. 130.

Menyanthes trifoliata hat nach DE BARY (28 S. 129) eine astele Struktur: Gefässbündel mit Einzelschutzscheiden. Nach Morot aber (52 S. 261) und Dutalluy (33) sind diese nur sich nach den Blättern begebende Stränge; der Centralcylinder ist durch eine Gesamtschutzscheide scharf abgetrennt.

Fam. Apocynaceae.

Allamanda Hendersoni

Bull.

A. Schottii

Vinca maior

Fam. Asclepiadaceae.

Asclepias curassavica

Cynanchum monspelianum

Fam. Loganiaceae.

Strychnos nux-vomica L.

Fam. Oleaceae.

Syringa chinensis Willd.
Stärkesch.

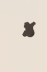

$n$

"

$n$
Eigene Untersuchung. Morot 52 S. 255.

$n$

, S. 254. 
Fam. Jasminaceae.

Jasminum officinale

Stärkesch. MоRот 52 S. 257.

8. Ordnung Rubiales.

Fam. Rubiaceae.

* Cinchona succirubra Pavon Stärkesch.

Galium mollugo

Pentas carnea Benth

Einige Rubiaceae

(Stengelknoten)

Fam. Caprifoliaceae.

Lonicera Xylosteum

Sambucus nigra L.

* Symphoricarpus racemosus

Michx.

Fam. Valerianaceae.

Vateriana sambucifolia
Endod.

Stärkesch.

$n$

HABERLANDT 157 S.264.

FISCHER 131 S. 16.

Eigene Untersuchung.

Fam. Campanulaceae.

Mikan

9. Ordnung Campanulinae.

Campanula rapunculoides Endod. FIscher 131 S. 13.

Phyteuma limonifolium Schutzsch. Morot 52 S. 251.

Fam. Lobeliaceae.

Lobelia inflata Linn.

Stärkesch.

Eigene Untersuchung a

L. syphilitica

Schutzsch.

DE BARY 28 S. 129.

Fam. Stylidiaceae.

Coleostylis Preisii

Stylidium adnatum.

9

$n$
Van Tieghem et Morot 48 S. 284.

VAN TIEghem et

Morot 48 S. 282.

10. Ordnung Aggregatae.

Fam. Dipsaceae.

Stärkesch. Morot 52 S. 259. 
Scabiosa maritima

Fam. Compositae.

Achillea millefolium

A. Ptarmica

Aster Drumondi

Artemisia vulgaris

Cnicus benedictus L.

Dahlia

Helianthus annuus

(Hypok. Glied)

Lactuca virosa

Picridium vulgare

Senecio Cineraria

Tagetes patula

"(Hypok. Glied)

Xanthium Strumarium
Schutzsch.

Morot 52 S. 250.

Endod.

FisCHer 131 S. 13.

Stärkesch.

Eigene Untersuchung. DE BARY 28 S 432.

(Hypok. Glied) Stärkesch. SAcHs 154 S. 185.

Das Ergebnis dieser Untersuchung ist also für die StelärTheorie noch weit günstiger als bei den Monokotyledonen. Die Angaben beziehen sich hier auf 69 von den 120 Familien, die WARMing anführt, aus allen 24 Ordnungen der Choripetalae; und auf 30 von den 49 Familien der Sympetalae, aus 9 von den 10 Ordnungen; zusammen also auf 99 von den 169 Familien aus 33 van den 34 Ordnungen. In allen diesen 99 Familien war die Monostelie mit deutlich gesonderter Endodermis nachzuweisen. In einzelnen dieser 99 Familien war neben der Monostelie auch noch die Astelie oder Polystelie vertreten, nämlich Astelie in fünf, und Polystelie in fünf, zusammen in neun Familien. Gegenüber 90 "normalen" Familien gibt es also nur neun, bei denen ausser der Monostelie ebenfalls die Astelie oder Polystelie bekannt ist. 
Gibt es hier nun auch Fälle, wo eine Trennung gar nicht aufzufinden ist? Tatsächlich gibt es solche, aber nur in verschwindend kleiner Zahl. Bei all den untersuchten Pflanzen ist es mir nur bei 7 nicht gelungen, eine deutliche Scheide aufzufinden. Diese Pflanzen waren:

Aesculus flava Ait.

Drosera intermedia Hayne.

Fumaria officinalis L.

Myristica verrucosa

Plantago media L.

Rhipsalis pentaptera Pfeiff.

Camellia Thea Link.

Bei einzelnen dieser Pflanzen, nämlich bei Aesculus, Myristica, Rhipsalis und Thea, war zwar die Grenze zwischen Rinde und Centralcylinder deutlich ausgebildet, eine Scheide war aber nicht zu finden. Bei den übrigen war gar keine scharfe Trennung angegeben.

Natürlich kann man aus diesen Angaben nicht folgern, dass nie eine Endodermis bei diesen Pflanzen ausgebildet ist. Erstens habe ich stets nur die blatttragenden Stengelorgane untersucht, nicht die Blütenachsen usw. Zweitens aber ist es sehr gut möglich, dass entweder in andern Jahreszeiten eine deutliche Stärkescheide $\mathrm{zu}$ finden ist, oder auch in dem hypokotylen oder epikotylen Gliede. Denn bei zahlreichen anderen der von mir untersuchten Pflanzen fand ich ebensogut anfangs keine Scheide, während ich diese bei weiterer Untersuchung dennoch ausfindig machte; die 7 angeführten Ausnahmen sind nun eben die Fälle, in denen diese weitere Untersuchung, so weit sie angestellt wurde, nicht zum Ziele führte.

Soll man also bei seiner eigenen Untersuchung schon recht vorsichtig sein, und nicht sofort die Existenz einer Endodermis 
leugnen, in noch stärkerem Grade ist das natürlich nötig bei Angaben aus der Literatur, welche fast immer incidentell sind. Wenn man findet, dass keine Endodermis genannt wird, so sagt das natürlich nichts. Wird angegeben, dass eine Scheide fehlt, so sagt das aber nur wenig mehr, denn meistens hat man die Sache nicht speziell untersucht.

Dass dem so ist, folgt wohl daraus, dass ich von mehreren Pflanzen, von denen in der Literatur angegeben war, dass eine Endodermis fehlte, gefunden habe, dass sie eine solche in typischer Ausbildung besassen.

Ich führe hier als Beispiel nur an, dass von Thouvenis angegeben wird (84 S. 88), bei den Arten der Gattung Philadelphus sei keine Endodermis ausgebildet, nur bei P. Zeyheri finde man eine Schutzscheide. Dagegen fand ich selbst bei $P$. coronarius eine Stärkescheide, die aber nur im Frühsommer deutlich ist, und somit leicht von Thouvenis übersehen werden konnte.

Es würden sich noch viele andere derartige Fälle angeben lassen, es würde aber keinen Zweck haben, das zu tun. Nur einen Fall muss ich noch anführen, nämlich die Untersuchung Fischers. Oben haben wir schon gesehen, dass Fischer die Durchführbarkeit der Stelär-Theorie deshalb bezweifelt, weil bei den meisten höheren Pflanzen sich keine Grenze zwischen Rinde und Centralcylinder findet.

Eine solche Grenze konnte Fischer wenigstens nur bei den Dikotylen finden, nicht bei anderen Phanerogamen, und bei den Dikotylen auch nur in 32 von den 100 untersuchten Pflanzen. Diese 32 habe ich natürlich alle in obige Liste aufgenommen. Wie steht "es aber mit den 68 anderen? Wenn wir diese mit unserer Liste vergleichen, so finden wir bei 11 dort schon aus meinen Beobachtungen oder aus der übrigen Literatur eine Schutzscheide oder eine Stärkescheide 
in den freien Stengelorganen angegeben (Cornus sanguinea, Corylus avellana, Echium vulgare, Helleborus foetidus, Hyperi. cum perforatum, Ilex aquifolium, Impatiens noli-en tangere, Ranunculus acris, Sambucus nigra, Symphoricarpus racemosus, Urtica dioica). Seine Prozentsätze ändern sich dadurch schon von 68 und 32 in 57 und 43. Von den anderen 57 Pflanzen habe ich keine Angaben gefunden. Wohl finden sich einige Pflanzen in meiner Liste, die zu der nämlichen Gattung gehören wie diejenigen Pflanzen, von denen Fischer angibt, dass sie keine Endodermis haben. Diese Pflanzen Fischers sind Cytisus sagitalis, Helianthus tuberosus, Lonicera caprifolium, Malva Alcea, Mercurialis annua, Paeonia, Raphanus raphanistrum, Reseda odorata, Sambucus Ebulus, Sedum purpureum, Senecio Jacobea, S. vulgaris, Spiraea ulmaria, Trifolium incarnatum. Von allen diesen Gattungen finden sich oben in der Liste eine oder mehrere Arten mit deutlicher Endociermis, wahrscheinlich würde bei vielen dieser 15 Pflanzen also auch wohl eine solche zu finden sein.

Aus obigem geht also deutlich hervor, dass Fischer die Endodermen nicht hinreichend aufgesucht hat; wenn er in einem Pflanzenteil keine Endodermis fand, so wurde daraus geschlossen, dass sie bei dieser Pflanze fehlte. Ein solches Verfahren ist natürlich nicht richtig. Am besten geht das noch aus dem folgenden hervor. Von den 68 von Fischer untersuchten Pflanzen, bei denen er keine Endodermis findet, habe ich selbst nur 8 untersucht. Bei allen diesen 8 Pflanzen habe ich nun eine deutliche Endodermis aufgefunden. Diese 8 Pflanzen waren die 11 eben genannten Pflanzen ausser Helleborus foetidus, Hypericum perforatum und Ranunculus acris.

Der Prozentsatz von Dikotylen mit deutlicher Scheide und solche ohne dieselbe wird somit ganz anders als 32 und 68 . 
Nach obigen Angaben findet sich eine deutliche Endodermis bei etwa 400 Arten, dagegen nur bei 7 nicht, von denen bei 4 noch wieder eine andere scharfe Grenze zu beobachten war. Es wird somit nur noch bei 3 auf 400 , d. i. noch nicht einmal $1 \%$, keine scharfe Rindengrenze gefunden.

In diesem Kapitel haben wir also gefunden, dass die Trennung in Rinde und Centralcylinder den tatsächlichen Verhältnissen sehr gut entspricht. Bei den Phanerogamen finden wir diese Trennung überall wieder. Bei den Gymnospermen sind zwar keine Endodermen vorhanden, um die Grenze scharf zu markieren; eine Sonderung in Rinde und Centralcylinder ist aber dennoch zu beobachten. Bei den Monokotyledonen war in der Mehrzahl der Fälle eine ausgebildete Endodermis zu erkennen, während bei den Dikotyledonen eine solche Endodermis eigentlich nie fehlt.

Nun könnte man aber noch fragen: Wenn schon bei allen diesen monostelen Pflanzen eine analoge Struktur vorkommt, ist noch keineswegs erwiesen, dass wir hier immer mit Homologien zu tun haben. Ist die Rinde z. B. bei allen diesen Pflanzen eine homologe Gewebeschicht?

Das ist natürlich nicht sofort mit Bestimmtheit zu beweisen. Ich glaube aber wohl, dass es kaum bezweifelt werden kann. Dass Epidermis, Rinde und Centralcylinder bei allen dikotylen Pflanzen die nämlichen Gewebe sind, steht wohl ganz fest, die Übereinstimmung zwischen den verschiedenen Stengelstrukturen ist so gross, dass man das wohl ganz sicher behaupten kann. Auch die Gymnospermen schliessen sich diesen so vollkommen an, dass auch deren Gewebe wohl mit denen der Dikotylen homolog sind. Anders steht es mit den Monokotyledonen. Hier ist der Stengelbau nicht unerheblich modifiziert; die Rinde ist in vielen Stengeln verschwindend klein 
gegenüber dem starken, mit vielen Gefässbündelkreisen versehenen Centralcylinder.

Hier wird aber die Einheit im Bau mit den anderen Phanerogamen in überraschender Weise zu Tage gefördert durch die von Von MoHL gegebene Erklärung (1) der monokotylen Gefässbündelanordnung, welche ich in meinem Aufsatze über "Die Stammesbildung der Monokotyledonen" besprochen habe (153 S. 34-37.) Aus dieser Erklärung ergibt sich, dass die Gefässbündel sich hier ganz wie bei den Dikotylen alle in einem einzigen Kreise innerhalb der Rinde im äusseren Centralcylinderrande bilden; durch das fortschreitende kambiale Dickenwachstum geraten diese Bündel aber ins Innere des Centralcylinders.

Die Homologie der Strukturen aller monostelen Phanerogamenstengel dürfen wir somit wohl annehmen. Nicht so leicht ist die Sache bei den Gefässkryptogamen, wo Polystelie vielfach vorherrscht. Dennoch werden wir im folgenden Kapitel sehen, dass auch die abweichenden Gefässkryptogamen alle nur Abänderungen des monostelen Typus zeigen.

IV. KAPITEL.

\section{Vergleichende Anatomie des Stengels der jungen Pflanze.}

Im vorigen Kapitel haben wir gesehen, dass bei den höheren Pflanzen aus allen Abteilungen hauptsächlich die monostele Struktur mit scharfer Trennung zwischen Rinde und Centralcylinder vorkommt.

Es ist dies aber nicht das einzige, was für die Beurteilung 
der Stelär-Theorie vom vergleichend-anatomischen Standpunkt aus geschehen kann.

Denn man kann nicht nur den Bau des Stengels bei den verschiedenen Familien der höheren Pflanzen vergleichen, sondern auch den Bau des Stengels in den verschiedenen Teilen einer und derselben Pflanze, wobei besonders Gewicht zu legen ist auf den Bau der zuerstgebildeten Internodien des Keimlings, des hypokotylen und epikotylen Gliedes und der nächstfolgenden Glieder. Nach dieser Richtung hin sind in neuerer Zeit von amerikanischen und englischen Forschern sehr bemerkenswerte Untersuchungen angestellt worden, die für die Morphologie des Centralcylinders wesentlich neue Gesichtspunkte bieten. Diese Arbeiten werde ich hier kurz besprechen.

Es sind:

D. T. Gwynne-Vaughan. On Polystely in the Genus Primula. 1897 (117).

E. C. Jefrerey. The Morphology of the Central Cylinder in Vascular Plants 1897 (118).

JEFFREY. The Development, Structure and Affinities of the Genus Equisetum. 1899 (126).

Jeffrey. The Morphology of the Central Cylinder in the Angiosperms. 1899 (127).

L. A. Boodle. Comparative Anatomy of the Hymenophyllaceae, Schizeaceae and Gleicheniaceae. 1900-1901 (158).

Gwynne-Vaughan. Observations on the Anatomy of solenostelic Ferns. 1901 (140).

J. H. FAulu. The Anatomy of the Osmundaceae. 1901 (139).

JEFrRey. The Structure and Development of the Stem in the Pteridophyta and Gymnosperms. 1902 (148).

W. C. Worsdelu. The Evolution of the Vascular Tissue of Plants. 1902 (152). 
J. Bretland Farmer and T. G. Hill. On the Arrangement and Structure of the Vascular Strands in Angiopteris evecta, and some other Marattiaceae. 1902 (146).

Miss S. O. Ford. The Anatomy of Ceratopteris thalictroides L. 1902 (147).

A. G. Tansley and R. B. Lulham. On a new Type of Fern-stele, and its probable phylogenetic Relations. 1902 (151).

G. Brebner. On the Anatomy of Danaea and other Marattiaceae. 1902 (145).

Ausserdem ist mir nur aus Citat bekannt:

JEFFREY. A Theory of the Morphology of Stelar Structures. 1896 (156).

In diesen Arbeiten wird diese Forschungsmethode mehrmals als "developmental study” bezeichnet; man spricht von Ontogenie. Tatsächlich ist ein entwicklungsgeschichtliches Element in diesen Forschungen nicht zu leugnen. Ich habe sie dennoch nicht in den ersten Teil, über die Entwicklungsgeschichte, gestellt, weil ich glaube dass man unter Entwicklungsgeschichte, Ontogenie, besser nur die Entwicklung aus Meristemen versteht. Diese ist ja ein ganz besonderer, einheitlicher Zweig der Biologie, während wir hier mit dem Studium a usgewachs ener, wenn auch früh gebildeter Organe $\mathrm{zu}$ tun haben. Mit der vergleichenden Anatomie hat aber diese Forschungsmethode die grösste Ähnlichkeit, so dass wir sie am zweckmässigsten dort unterbringen: es ist dann derjenige Zweig der vergleichenden Anatomie, der nicht die verschiedenen Pflanzen untereinander, sondern die verschiedenen Teile einer und derselben Pflanze vergleicht.

Schon Van Tieghem hatte für diese Forschung Wesentliches geleistet, indem er in seinem Traité (101 S. 764) und in seiner Arbeit „Sur la polystelie” (68 S. 281) angibt, dass bei den 
polystelen und den astelen Stengeln sich die monostele Struktur in den zuerst gebildeten Internodien der jungen Pflanze findet; durch allmähliche Veränderungen in den aufeinanderfolgenden Internodien stellt sich der Übergang zu der definitiven Form dar. Dabei entsteht die Polystelie nach Van Tieghem durch Verästelung der primitiven Stele; die Astelie entsteht, indem Endodermis und Pericykel zerbrechen („se rompent”) und sich um die einzelnen Gefässbündel falten („se reploient”.) Diese Tatsachen sind selbstverständlich für die Morphologie von grosser Bedeutung. War die Entwicklung aus Meristemen, wie wir im ersten Teil dieser Arbeit gesehen haben, ohne grosse phylogenetische Bedeutung, so ist das offenbar mit dieser „Entwicklung” doch der Fall. Es ist ja aus der Systematik längst bekannt, dass die Form der zuerstgebildeten Blätter einer Pflanze systematisch von grosser Bedeutung ist; dies macht es schon äusserst wahrscheinlich, dass der Aufbau der mit diesen Blättern zusammenhängenden Internodien ebenfalls von gleicher Wichtigkeit sein kann.

Auf diesem Boden ist nun von den oben genannten Forschern weiter gearbeit worden. Dabei hat sich verschiedenes ergeben. Was den für uns wichtigsten Teil angeht, so hat die Meinung Van Tieghems, dass anfangs stets ein einziger Gefässcylinder zu finden ist, sich immer bewährt. Wenigstens sind immer die Gefässelemente in einem festen oder hohlen cylinder angeordnet.

In Abweichung von den VaN TIEghemschen Angaben hat sich jedoch ergeben, dass erstens diese Anfangsstruktur nicht ganz mit der gewöhnlichen Monostelie übereinstimmt, und dass zweitens die Polystelie in ganz anderer Weise sich aus den einfacheren Verhältnissen entwickelt als in der von VAN TIEGHEM vorgetragenen. 
Die Abweichung vom monostelen Typus, welche sich in den zuerst gebildeten Stengelgliedern findet, ist das Vorkommen einer Schutzscheide oder einer ähnlichen Scheide innerhalb des Bündelcylinders. Im System Van Tieghems kommt das nur in der gamodesmen Astelie oder bei der Gamostelie, nicht aber in monostelen Organen vor. Es ist jedoch nicht anzunehmen, dass wir in diesen jugendlichen Organen eine Gamodesmie oder Gamostelie vor uns haben, aus der in den meisten Fällen durch Undeutlichwerden der inneren Schutzscheide die Monostelie hervorgeht. Wenn das erste wirklich Gamostelie oder Gamodesmie ist, so ist das spätere auch nur scheinbar Monostelie; so gerät man in Widersprüche. Näheres hierüber im letzten Kapitel.

Das andere Ergebnis, das der Van Tieghemschen Theorie nicht günstig ist, ist die Weise, in der die Polystelie auftritt. Von einer Gabelung des Centralcylinders ist dabei nicht die Rede. Wo die Blattspuren sich in die Rinde ausbiegen, finden sich im Bündelcylinder Öffnungen, die sich nach oben mehr oder weniger weit ausdehnen. Wenn diese Öffnungen sich über mehr als ein Internodium ausdehnen, so ist der Bündelcylinder stets in einige Stücke zerlegt, was auf dem Querschnitt zu sehen ist. Wo diese Partien nun weit auseinander liegen, findet man, dass die Endodermis nicht mehr um den ganzen Centralcylinder herum gebildet wird, wie in den zuerst gebildeten Internodien, sondern jedes Stück des Bündelcylinders wird von einer besonderen Endodermis umgeben; zwischen dem Bündel und der Endodermis findet man dann einen ebenfalls geschlossenen Pericykel. Die Polystelie hat in ihrer En stehung also die grösste Ähnlichkeit mit der Astelie. Währenc aber die Astelie durch die bilaterale Gefässbündelstruktur der einzelnen Teile des Vaskulärgewebes charakterisiert ist, findet 
man in den polystelen Stengeln dagegen, dass die von den Einzelendodermen umgebenen Abschnitte des Centralcylinders konzentrisch angeordnet sind, in ihrer Struktur also ganz die Gestalt des ursprünglichen Centralcylinders wiedergeben. Diese "Stelen" vermehren sich dann nach oben in ähnlicher Weise, indem jedesmal oberhalb der Stellen, wo eine Blattspur austritt, nicht eine, sondern zwei Partieen Gefässgewebe fortgebildet werden, welche beide Stelärstruktur erhalten.

Wenn also auch in einigen Punkten eine Revision der Ansichten Van Tieghems notwendig ist, so ist das allgemeine Ergebniss dieser Forschungen doch eine sehr gute Bestätigung seiner Theorie, weil die Monostelie nunmehr bei allen Pflanzen, auch bei den später abweichenden, in den zuerstgebildeten Stengelgliedern nachgewiesen ist.

Hatten wir oben aus der vergleichenden Anatomie der verschiedenen Familien schon gesehen, dass bei allen monostelen Phanerogamen eine homologe Stengelstruktur anzunehmen war, so ergibt sich nun, dass auch die astelen und polystelen Phanerogamen und alle Gefässkryptogamen, monostele und andere, sich ganz naturgemäss anschliessen. Die morphologische Bedeutung der Trennung von Rinde und Centralcylinder ist dadurch natürlich um so fester begründet.

\section{KAPITEL.}

\section{Allgemeine Betrachtungen und Folgerungen.}

Im ersten Teil dieser Arbeit haben wir gesehen, dass auf entwicklungsgeschichtlichem Gebiete eine Grundlage für die 
Stelär-Theorie nicht gefunden werden kann. Denjenigen Einteilungen, welche in den Meristemen angegeben worden sind, kommt weder eine historische, phylogenetische Bedeutung, noch eine Bedeutung für den weiteren Aufbau der Pflanze aus diesen Meristemen zu. Im allgemeinen darf uns das nicht Wunder nehmen. Nach dem Vorgang der Zoologen legt man den embryologischen Tatsachen allerdings eine sehr grosse Bedeutung bei; wirklich hat ja die Entwicklungsgeschichte in der Zoologie vorzügliches geleistet. Vergleichen wir aber das Tatsachenmaterial der zoologischen Entwicklungsgeschichte mit demjenigen der botanischen, so ergibt sich ein fundamentaler Unterschied. In der Zoologie ist dabei hauptsächlich von 'Falten, Umschlagen, Einstülpen usw. die Rede und in geringerem Masse auch von histologischer Differenzierung, nicht aber von verschiedener Lagerung der einzelnen Zellen. In der botanischen Embryologie aber ist das anders, man hat sich hier mit verschiedenen Weisen von Zellanordnungen in übrigens vollkommen homogenen Meristemen begnügen müssen. $\mathrm{Ob}$ das biogenetische Grundgezetz sich auch auf eine solche Entwicklungsgeschichte übertragen lassen wird, ist von vornherein nicht zu sagen. Dasjenige, was in der Botanik mit der tierischen Embryologie am besten übereinstimmen würde, ist die Untersuchung der Anlage der Nebenorgane, der Höckerbildung - aber nur von aussen betrachtet, ohne auf die Anordnung der Zellen zu achten, weiter das Studium der nacheinander an der jungen Pflanze gebildeten, gleichwertigen Organe, wie z. B. der ersten Blätter. Auch solche Studien, wie die der englischen und amerikanischen Forscher, über welche ich im vorigen Kapitel berichtet habe, gehören dazu, weil dort nicht auf die Zellanordnung, sondern nur auf die grob-histologische Differenzierung geachtet wird. 
Wirklich haben alle diese Forschungsmethoden, soweit sie angewandt worden sind, sich als weit bessere Hilfsmittel erwiesen, um die Phylogenie kennen zu lernen, als die Zellanordnung im Meristem.

Dass wirklich in den Meristemen die Zellteilungen mit der morphologischen Differenzierung überhaupt nur in entfernter Beziehung stehen, ist nach dem vorhergehenden schon sehr wahrscheinlich. Tatsächlich beruhen aber auch alle diejenigen Fälle, in denen man in irgend einem pflanzlichen Meristem den ersten Teilungen eine grundlegende Bedeutung für die spätere morphologische Ausbildung zuerkannt hat, auf starken Verallgemeinerungen, die sich bei näherer Untersuchung, soweit mir bekannt ist, stets als unrichtig herausgestellt haben.

So hat Hanstein die erste Meridianwand im Dikotylen-Keimling als die Trennung zwischen den beiden Kotyledonen betrachtet. Dies hat er jedoch nie beobachtet, sondern nur angenommen, weil es sehr plausibel erschien. Von WesterMAIER wurde später gezeigt (124 S. 17-20), dass die Richtung der ersten Kreuzteilung und die Lage der Kotyledonen durchaus unabhängig von einander sind.

Ebenso hatte Hanstein angenommen (8 S. 67, Satz 35), die Differenzierung der Stamm-Anlage erfolge „in einem Punct derjenigen Zone, in der die Descendenzen der beiden HauptMutterzellen aneinander grenzen." Auch von diesem Satz ist später gezeigt worden, dass solches höchstwahrscheinlich nicht immer der Fall ist (Fleischer 15 S. 441).

Oftmals ist auch die Identität der Segmente der Scheitelzelle im Kryptogamen-Stammscheitel mit den Blattanlagen ausgesprochen; jedes Segment sollte nämlich ein Blatt bilden. Von Schwendener ist aber dargetan (53 S. 927), dass solches nicht bewiesen ist und dass die Tatsachen der Behauptung 
sogar direkt widersprechen. Die Blätter entstehen vielmehr ganz unabhängig von diesen Segmenten, oft aus benachbarten Stücken von zwei oder mehreren Segmenten.

Die Zahl dieser Fälle liesse sich bei einer speziellen Untersuchung noch wohl vermehren; hier können wir aber wohl daraus schliessen, dass höchstwahrscheinlich die in den pflanzlichen Meristemen zuerst auftretenden Zellwände in keiner Hinsicht wichtiger sind als die später auftretenden.

Es ergibt sich somit, dass Van Tieghem bei der Aufstellung seiner Theorie einen glücklichen Griff tat, die als er die Entwicklungsgeschichte von der Betrachtung ausgeschlossen hat, indem er nicht versuchte, eine Übereinstimmung seiner Theorie mit der Hansteinschen zu begründen. Dass er sich im Gegenteil von diesen Einflüssen stets frei zu halten versucht hat, hat er gelegentlich einer Erwiderung an J. D'ARBEAUMONT in einer Sitzung der Société botanique de France (64) scharf zum Ausdruck gebracht. Er sagte dabei u. a.: „en exposant la définition du péricycle, j'ai pris grand soin de ne considérer que l'état adulte, de manière à la placer en dehors et audessus de la question d'origine qui fait l'objet de la discussion présente".

Auch Strasburger stellt sich auf diesen Standpunkt. In seinen „Leitungsbahnen” (98, S. 338) schreibt er: „Eine andere Frage ist, ob in der That nach? ",rein entwickelungsgeschichtlichen Principien"'" eine Gewebseintheilung möglich sei. Das ist entschieden zu verneinen. Eine morphologische Behandlung der Gewebe, wie sonst jede andere Morphologie, stützt sich vornehmlich auf den Vergleich und sucht ihre objective Begründung im phylogenetischen Gesichtspunkte. Die Entwicklungsgeschichte verhilft unter Umständen auf den richtigen Weg der Deutung, wie seit Carl Ernst v. Bär's Arbeiten (Ueber 
Entwicklungsgeschichte der Thiere, Beobachtung und Reflexion, 1828), allgemein annerkannt wurde. Sie thut es freilich nicht unter allen Umständen, und ist daher auch nichts leichter, als derartige Fälle ausfindig zu machen."

Die vorliegenden Untersuchungen haben nun für diese Auffassungen eine bessere Grundlage ergeben, indem dasjenige, was früher nur vermutet werden konnte, jetzt als sicher betrachtet werden muss.

Wenı wir nun von solchem Standpunkt, aus der VAN Tieghemschen Einteilung näher treten; so müssen wir an derselben allerdings einige kleine Änderungen vornehmen, auf deren Notwendigkeit ich zum Teil schon früher hingewiesen habe; wir müssen nämlich zwei sich darin befindliche entwicklungsgeschichtliche Elemente nicht mehr aufnehmen. Das erste ist die Auffassung, dass der Monokotylen-wurzel keine Epidermis zukommen soll, weil die Epidermis schon im Vegetationspunkt für die Kalyptrabildung verbraucht wird. Eine solche Auffissung ist nach dem vorhergehenden keineswegśs erlaubt; solches könnte nur dann mit einigem Recht behauptet werden, wenn die hohe Bedeutung der Histogene unerschütterlich fest stände, jetzt aber wird diese Folgerung hinfällig. Aber auch ohne die Ergebnisse des zweiten Kapitels über den geringen Wert der Meristemeinteilungen war doch schon auf andere Weise festzustellen, dass diese Auffassung nicht zutraf; ich habe oben (S. 19) schon dargetan, dass wir die Epidermis der Monokotylen- und der Dikotylenwurzel als homolog betrachten müssen. Aus ganz ähnlichen Gründen können wir auch derjenigen Auffassung VAN Tieghems, nach der die Gefässkryptogamen einer Epidermis gänzlich entbehren, nicht beipflichten; auch hier sind die entwicklungsgeschichtlichen Tatsachen ohne weitere Bedeutung und auch hier steht 
die Homologie der Kryptogamen- und Phanerogamen-Epidermis einer solchen Auffassung entgegen.

Eine zweite entwicklungsgeschichtliche Tatsache in VAN Tieghems Theorie ist, dass er im Stengel von Azolla und Salvinia und in der Wurzel der Equiseten ein Pericykel nicht anerkennt.

Denn in diesen Fällen findet sich innerhalb der Endodermis eine parenchymatische Zellschicht, welche aber mit der Endodermis aus einer Zellschicht entstanden ist. (77, 101 S. 681, 753). Deshalb rechnet Van Tieghem sie zur Endodermis und sagt, der Pericykel fehlt. Auch diesen Ansichten kann ich nach den oben gewonnenen Einsichten nicht ohne weiteres beipflichten. Es würde einer vergleichend-anatomischen Untersuchung der Homologie des Pericykels dieser Pflanzen und ihrer Verwandten bedürfen; diese würde höchstwahrscheinlich die Homologie ergeben. So lange darüber nähere Tatsachen noch nicht bekannt sind, wird man also am zweckmässigsten die nach innen abgegebene Zellschicht einfach als Pericykel auffassen.

Im zweiten Teil dieser Arbeit haben wir dann die Sache vom vergleichend-anatomischen Standpunkt betrachtet, und es hat sich herausgestellt, dass wirklich die Auffassung Van TiEghems eine sehr glückliche ist. Zwar bedarf die Stelär-Theorie in einigen Punkten einiger Abänderung, der Hauptsache nach gibt sie aber eine gute Ubersicht über die tatsächlichen Verhältnisse. Das Hauptergebnis dieser Untersuchung war, dass bei der überaus grossen Mehrzahl der Pflanzen die Monostelie im Stengel vorkommt, und dass dabei sehr häufig eine besonders ausgebildete Endodermis aufzufinden ist, was eine scharfe Trennung von Rinde und Centralcylinder ermöglicht. Die abweichenden Verhältnisse der Polystelie und Astelie sind dabei 
selten, und sowohl aus der systematischen Verteilung als aus der Verteilung dieser Erscheinungen im Pflanzenindividuum ergibt sich, dass sie ohne grosse Bedeutung sind. Das häufige Auftreten dieser Schutz- und Stärkescheiden ist für die StelärTheorie von besonderem Gewicht. Für die Wurzel war die Allgemeingültigkeit der Auffassung VAN TIEGHems wohl längst anerkannt; nicht aber für den Stengel. Hier wurde die Unterscheidung in Rinde und Centralcylinder von einigen Autoren geleugnet. Nachdem nun aber die Allgemeinheit einer besonders ausgebildeten Endodermis. in genügendem Masse feststeht, können auch von dieser Seite keine Einwände mehr gegen die Stelär-Theorie erhoben werden.

Fast noch wichtiger für die Stelär-Theorie sind die Ergebnisse der amerikanischen und englischen Forscher über die Struktur der zuerstgebildeten Internodien der jungen Pflanze. Es hat sich hier gezeigt, dass die junge Pflanze bei Gefässkryptogamen und Phanerogamen, welche später die "Astelie" oder "Polystelie" Van Treghems zeigen, immer monostel ist, während die folgenden Internodien stets mehr abweichen, bis die definitive Struktur erreicht ist. Diese Tatsache wirft ein helles Licht auf die hohe phylogenetische und somit morphologische Bedeutung der von VaN Tieghem angenommenen Einteilung.

Wenn die Theorie Van Tieghems von dieser Seite also eine glänzende Bestätigung erfahren hat, so sind doch gerade von diesen englischen und amerikanischen Forschern verschiedene Auffassungen vorgetragen, die mit den VAN TiEgheuschen mehr oder weniger in Widerspruch stehen. $\mathrm{Zu}$ einer Einheit in diesen Ansichten ist man bis jetzt noch nicht gelangt. Weitans die wichtigsten Ansichten sind die von E. C. JefFrey entwickelten, von denen wir hier also zunächst handeln wer- 
den. JeFFrEy stützt sich dabei auf die oben (S. 136) schon erwähnte Erscheinung, dass bei vielen Pflanzen in den jugendlichen Organen eine „innere Endodermis”, wie er es nennt, vorkommt, und auch auf die Tatsachen, dass das Mark in vielen Centralcylindern nicht sofort in der jungen Pflanze vorkommt, sondern erst später ausgebildet wird, und dass das Mark, wo es vorkommt, vielfach durch die "Blattlücken” (foliar gaps, siehe in der untenstehenden Notiz, auf S. 145) mit der Rinde ununterbrochen zusammenhängt. Aus diesen Verhältnissen und auch aus der systematischen Verteilung der verschiedenen Centralcylinder-Formen folgert JEFFREY erstens, dass nicht die medullate Monostelie phylogenetisch die älteste Stufe bildet, sondern vielmehr die marklose Monostelie, und dass aus dieser der medullate Centralcylinder mit zwei Scheiden hervorgegangen ist. Erst durch Degeneration dieser inneren Scheide entstand dann die Monostelie. ${ }^{1}$ )

1) JefrRey hat dabei die verschiedenen Formen, in denen die Centralcylinder vorkommen, mit verschiedenen Namen belegt. Weil aber, zum Teil unabhängig von Jefrrey, zum Teil im Anschluss an seine Werke, noch eine Menge andere derartige Bezeichnungen eingeführt worden sind, so werde ich für denjenigen, der sich weiter mit dieser Literatur beschäftigen will, zur bequemeren Übersicht diese alle hier aufnehmen.

Von VaN Tieghem hatten wir also schon (S. 5) folgende Namen:

Monostelie.

Polystelie in zwei Formen Dialystelie und Gamostelie.

Astelie " "Dialydesmie und Gamodesmie.

Später hat Strasburger für die Astelie den Namen Schizostelie vorgeschlagen (98 S. 312).

1897 gab Jefreey folgende Namen an:

Protostelie (Monostelie ohne Mark) 118 S. 869.

Siphonostelie (Monostelie mit Mark und mit innerer Scheide) 118 S. 869. Die Siphonostelie kommt noch wieder in den vier folgenden Formen vor, die je zwei und zwei einander gegenüber stehen: 
Bis soweit beziehen seine Ansichten sich nur auf die phylogenetische Entwicklung des Centralcylinders, diese kön-

A mphiphloische Siphonostelie (mit äusserem und innerem Phloem) $118 \mathrm{~S} .869$ und

Ectophloische Siphonostelie (nur mit äusserem Phloem) 118 S. 869.

Phyllosiphonische Siphonostelie und

Kladosiphonische Siphonostelie, jenachdem im Centralcylinder "foliar gaps" oder "ramular gaps" vorkommen. Unter diesem Namen versteht Jeffrey die Lücken, welche sich im vaskulären Gewebe bemerkbar machen, oberhalb der Stelle, wo ein Gefässbündel ausgetreten ist. Wenn diese Gefässbündel Blattspuren sind, so haben wir "foliar gaps" und somit die phyllosiphonische Siphonostelie, wenn diese Gefässbündel sich nach Seitenknospen begeben, haben wir „ramular gaps" und somit einen „kladosiphonischen siphonostelischen Centralcylinder." Ersteres findet sich bei Filicinae und Phanerogamen, letzteres bei Lycopodinae und Equisetinae.

Nach diesem Unterschied will JefFrey die Gefässpflanzen in zwei grosse Gruppen teilen, die der Pteropsida und Lycopsida (148 S. 114).

Die Monostelie ist nun bloss ein reduzierter Fall der ectophloischen Siphonostelie.

Gwynne Vaughan, 1897.

Meristele (Teil des Centralcylinders, der gesondert auftritt bei Astelie oder Polystelie) 117 S. 311.

Perfect stele (konzentrische Stele) 117 S. 308.

I m p e r f e c t stel e (an einer Seite fehlt das Gefässgewebe) 117 S. 308.

VAN Tieghem 1898.

Type monostélique périxyle (Struktur der Wurzelstele) 123 S. 177.

T y p e més ostéli qu e (Centrale Stele und in der Rinde Meristelen) 123 S. 178.

Boodle 1900.

Subcollaterale Stele (mit einfachem centralem Xylem, mit nur einem Protoxylem-Bündel) 158 S. 461.

Gwynee Vaughan 1901. 
nen hier somit ausser Betracht bleiben, ebenso wie die ähnlichen von anderen Autoren aufgestellten phylogenetischen Theorien

Solenostelie (amphiphloische Siphlonostelie) 140 S. 71.

JEFFREY 1902.

Adelosiphonie (Siphonostelie, wenn die Rohrform des vaskulären Gewebes nicht mehr vorhanden ist) 148 S. 144.

Tansley and Lulham 1902.

Linds a y a-Type (Monostel mit zentralem Xylem, in welchem noch ein Phloembündel an der Dorsalseite eingeschlossen ist) 151 S. 153.

BREBNER 1902.

$\mathrm{E}$ u s te le (medullater Centralcylinder mit kollateralen Gefüssbündeln) 145 S. 519.

Actinostele (Centralcylinder der Wurzel und ähnliche Strukturen) 145 S. 519.

Protostel e (hypothetischer primitiver Centralcylinder) 145 S. 519 in den zwei folgenden Formen, die Actinostele und die:

H aplostele (Phloem um ein centrales Xylem herum) 145 S. 519. Medullated haplostele (voriger mit Mark) 145 S. 519.

A tactostele (unregelmässige Bündelanordnung wie bei den Monokotyledonen), 145 S. 520. In zwei Formen:

$\mathrm{Hom}$ odesmic und

Heterodesmic Atactostele (mit einer oder mit zwei Arten von Gefüssbündeln) 145 S. 520.

Solenostele (kontinuierliches amphiphloisches Rohr mit breiten Blattlücken) 145 S. 520.

Dictyostele (vorige Form, wenn nur ein Netzwerk von Bündeln überbleibt) 145 S. 520, in zwei Formen:

Siphonic und

Adelosiphonic Dictyostele (je nachdem das Bündelnetz noch rohrförming ist oder nicht mehr) 145 S. 521.

$\mathrm{Hyster}$ ostele (reduzierter Centralcylinder vieler Wasserpflanzen).

Eumeristelie (Meristelen in der Form der Eustele) 145 S. 521.

Haplomeristelie (Meristelen in der Form der Hapostele) 145 S. 522.

Ich glaube, dass der aufmerksame Leser mit mir die Frage Brebsers: „if this attempt to simplify stelar terminology by increasing the number of terms was a wise one" mit einem herzlichen Nein beantworten wird. 
(D. H. Scott, 93 S. 517, Worsdell 152, Tansley and Lulham 151). Denn die nähere Begründung dieser Ansichten, so wichtig sie auch sein mögen, würde uns auf andere Bahnen leiten; für das hier gesteckte Ziel ist nur deren Gesamtresultat von Bedeutung. Dasselbe steht aber noch zu wenig fest; diese Theorien sind $\mathrm{zu}$ jung und noch $\mathrm{zu}$ sehr spezielle Ansichten einzelner Forscher, um sie sofort weiter verwerten zu können.

Es werden von JEFFREY und anderen aber auch bestimmte morphologische Auffassungen gegeben, die hier natürlich näher berücksichtigt werden müssen.

Betrachten wir erst, was von diesen Forschern gegen die Monostelie Van Tieghems vorgebracht wird.

Die Auffassung Van Treghems über die medullate Monostelie wird von JEFFREY als unhaltbar betrachtet (148, S. 141), weil das Mark nicht zur Stele gehört. Das Auftreten einer „inneren Endodermis", die Kontinuität von Mark und Rinde durch die Blattlücken und das Fehlen des Markes in vielen Stengeln von Keimpflanzen beweisen nach ihm die "Homologie” von Mark und Rinde; das Mark stellt nur einen eingeschlossenen Teil der Rinde dar (oder, wie Jefrrey es nennt, des Grundparenchyms.) Eine ähnliche Auffassung vertreten FAuLL (139), und auch Bretland Farmer und Hill (146). Letztere Autoren betrachten auch die Begrenzung der Stele durch die Endodermis als äusserst mangelhaft, weil die Endodermis in ihrem Auftreten so unregelmässig ist; sie schreiben: „It is the inclusion of the pith as an integral part" (of the stele) "together with a strained and artificial criterion as to the boundary of the stele, that seem to us the fatally weak points in the whole stelartheory." (S. 398.)

Noch weiter geht BrebNer (145) der sich die Frage stellt, 
ob es sich wohl verlohne, auf dem Boden der Stelär-Theorie weiter zu arbeiten. "Il would perhaps be better to abandon the stelar theory altogether", schreibt er S. 548. BREBNER stützt sich dabei auf die erwähnte Meinung von BretLand FARMer und Hill, dass der Endodermis kein morphologischer Wert zukommt, sowie auf die Ergebnisse Pitards (143), der ähnliches für den Pericykel gefunden zu haben glaubt.

Diese verschiedenen Auffassungen, die die Stelär-Theorie aufs innigste berühren, können hier natürlich nicht unberücksichtigt bleiben. Wenn wir denselben aber etwas näher treten, so ergibt sich, dass wir den Wert dieser Auffassungen erst recht beurteilen können, wenn wir zunächst zwei Punkte klargestellt haben, welche in diesen Auffassungen eine wichtige Rolle spielen. Diese zwei Punkte sind: $1^{0}$. Welchen Wert soll man dem Auftreten der Schutz- und anderen Scheiden zuschreiben? Und $2^{0}$ : Aus welchen Gründen kann man auf die Homologie zweier Gewebe schliessen?

Betrachten wir zuerst den zweiten Punkt. Wir sahen oben schon, dass JEFFrey als einen der wichtigsten Gründe für die Homologie von Mark und Rinde den kontinuierlichen Zusammenhang der beiden Gewebe durch die Blattlücken betrachtet. Ja sogar ganz allgemein nimmt .TEFFREY an, dass die Kontinuität eines Gewebes ein unverkennbares Zeichen der Homologie der verschiedenen Teile dieses Gewebes ist. Dies geht aus allen seinen Arbeiten hervor.. So beschreibt er von Ranunculus und Anemone, dass "in the young axis the stelar system possesses an internal phloeoterma which is continuous with the external phloeoterma through the foliar gaps, and is therefore of the same morphological value." (127 S. 629).

Eine solche Betrachtungsweise, nach der aus der blossen Kontinuität der Gewebe ihre Homologie zu folgern ist, finden 
wir nun keineswegs bei JeFFREY allein, sondern auch bei vielen anderen Autoren, unter denen Van Tieghem und Strasburger in erster Linie zu nennen sind.

Strasburger stellt in seinen "Leitungsbahnen" bei Zea Mays fest, „dass die aus dem Centralcylinder des Stammes kommende Gefässbündelscheide .... in fortschreitender Reduktion in den chlorophyllhaltigen, einschichtigen, parenchymatischen Scheiden der reducirten Gefässbündel ihren Abschluss fand" (98 S. 343). Er fragt dann, wie diese Teile morphologisch zu deuten sind. Ebenso wie er nun im allgemeinen bei den astelen Pflanzenorganen VAN Tinghems die Gefässbündel als „Schizostelen”, Teilstelen, bezeichnet, weil sieden Teilen der Stele entsprechen, so folgert er hier, diese parenchymatischen Scheiden seien morphologisch zu deuten als zur Stele gehörige Scheiden, für die er den Namen „Stelolem m a" vorschlägt (98 S. 343).

Dass VaN Tieghem der gleichen Meinung ist, ergibt sich aus einer schon von STrasbURGER citierten Stelle in seinern Traité (101 S. 842) „En s’incurvant horizontalement pour entrer dans la feuille, chaque faisceau libéroligneux de la tige entraîne la portion d'endoderme et la portion de péricycle qui lui est adossée. Si les faisceaux demeurent distincts dans le pétiole, séparés par de plus ou moins larges rayons de parenchyme, l'endoderme et le péricycle se replojent ordinairement autour de chacun d'eux pour l'enveloprer d'une double gaîne (Composées, Ombellifères, Graminées, Cycadées, etc.); il en est toujours ainsi quand il n'y a qu'un faisceau (Conifères, etc.). Si les faisceaux se rapprochent au contraire et s'unissent en arc ou en anneau, les portions d'endoderme et de péricycle se rejoignent de manière à recouvrir l'arc ou l'anneau dans toute son étendue (Solanées, Cucurbitacées, 
etc.). Quand les faisceaux sont enveloppés individuellement par un endoderme propre et un péricycle particulier, le pétiole n'a rien qui corresponde au cylindre central de la tige; sa structure peut être dite astélique. Quand, au contraire, les faisceaux sont disposés en un anneau entouré d'un péricycle général et d'un endoderme commun, le pétiole a, comme la tige, un cylindre central et sa structure peut être dite monostélique. La juxtaposition des faisceaux en arc réalise un état intermédiaire."

Aus dieser Stelle geht also sehr deutlich hervor, dass VAN TIEgHem ebenfalls aus der Kontinuität auf die Homologie schliesst, zumal wenn man bedenkt, dass VAN Treghex mit "Endodermis" die innere Rindenschicht, also eine morphologische Schicht versteht, die histologisch auf verschiedene Weise ausgebildet sein kann; die "Endodermis” um die Gefässbündel des Blattes ist also nach ihm homolog mit der des Stengels. ${ }^{1}$ )

1) Zugleich ergibt sich hier noch eine Eigentümlichkeit, dass nämlich VaN Treghem die verschiedenen Lagerungen der Gewebe in verschiedenen Niveaux als "Bewegungen" der einzelnen Teile beschreibt (entraîne, se reploient, se rapprochent, se rejoignent).

Dass solches keine blosse Redensart ist, ergibt sich wohl aus folgender Stelle, wo er über die Gefässbündel im Blatte und deren pericykelartige Gewebe sagt: "Il est vrai que l'assise des cellules qui sépare le liber $d u$ faisceau libéroligneux d'avec son endoderme particulier provient," (Sperrung von mir), ,pour sa partie externe, supralibérienne, du péricycle de la stèle primitive d'ou procède toujours, comme on sait, la structure astélique; mais pour ses flancs, elle provient des rayons médullaires de cette stèle et pour sa partie interne, supra-ligneuse, de la moelle... C'est seulement lorsque la stèle primitive n'a ni rajons médullaires, ni moelle, que cette assise procède toute entière du péricycle, qui se reploie autour du faisceau". (87 S. 434). 
Die nämliche Folgerung findet sich noch bei Mовот (52 S. 288), und später auch bei GwYnne-VAUGHAN wieder (117 S. 318).

Nur von einem einzigen Autor wird, soviel mir bekannt geworden ist, gegen diese Auffassungen Stellung genommen, nämlich von BOodLE. BOoduE bemerkt bei seiner Besprechung der Theorien JEFFreys: „But it must be recognized that the homology of different types of stelar structure is a difficult question, and is not at once disposed of by merely tracing the continuity of the various tissues." (159 S. 404). Die auf solche Weise gewonnenen Resultate sind also nicht gut begründet.

Die Auffassung Boodies erscheint mir als die einzig richtige. Wenn, um bei unserem Fall zu bleiben, Rinde und Mark homolog wären, so würde das bedeuten, dass dasjenige Gewebe, welches bei den Vorfahren die Rinde bildete, hier teilweise als Rinde, teilweise als Mark auftritt. Es sollte die Rinde sich dann im Laufe der phylogenetischen Entwicklung in den Centralcylinder eingestülpt haben. Nur wenn dieses nachgewiesen werden könnte, würde die Behauptung JEFFreys Sinn haben; sonst ist von Homologie, wie man dieselbe in der Wissenschaft zu definieren gewohnt ist, nicht die Rede. Eine solche Annahme wird aber kaum eine Verteidigung finden. Zweifelsohne hat sich das Mark phylogenetisch aus stelären Zellen entwickelt - wenn wenigstens der feste Gefässstrang die phylogenetisch älteste Stufe bildet - von einer Einstülpung kann dabei wohl ebensowenig die Rede gewesen sein, als es jetzt noch in der Keimpflanze der Fall ist.

Über das erste Auftreten des Markes im Stengel geben Bretrand Farmer und Hili für Angiopteris evecta noch nähere Details an: "In the centre of the xylem, certain cell-rows cease to differentiate as tracheids, but proceed to give rise to a parenchymatous pith which we regard as distinct from the 
now tubular stele" (146 S. 399, 400). Wenn sich die Sachverhältnisse also so gestalten - wie es zu erwarten war so müssen wir die Auffassung, nach der das Mark nicht zur Stele gehören sollte, als unbegründet ablehnen.

Der andere Punkt, der bei der Begründung der Theorien JEFFREYs eine wichtige Rolle spielte, war die Beurteilung des Wertes, den man dem Auftreten von Schutz- und Stärkescheiden zuerkennen muss. Dieser Wert wird meines Erachtens von JEFFREY und anderen stark überschätzt.

Denn aus der Anwesenheit einer solchen Scheide wird von ihnen ohne weiteres auf das Vorkommen einer Endodermis, einer Trennung zwischen Rinde und Centralcylinder, geschlossen. Wenn z. B. sich an der Innenseite des Gefässcylinders in einem Stengel eine innere Schutzscheide vorfindet, so wird das Mark plötzlich als Rinde betrachtet. Das ist natürlich nie erlaubt. Die Endodermis als die morphologisch innere Rindenschicht kann man meistens an ihrer histologischen Differenzierung als Schutz- oder Stärkescheide erkennen; diese histologische Differenzierung ist somit für die Beurteilung der morphologischen Verhältnisse sehr wichtig; deshalb habe ich selber von dieser Differenzierung einen ausgiebigen Gebrauch gemacht bei der Feststellung der Grenze zwischen Rinde und Centralcylinder im III. Kapitel. Damit ist aber nicht gesagt, dass eine jede histologisch als Schutzscheide ausgebildete Zellschicht sofort eine Endodermis sei. Dazu gehört noch, dass diese Schutzscheide sich um einen Centralcylinder an der Innenseite einer Rinde befindet, dass sie somit homolog ist mit der Endodermis anderer Pflanzen. Dass die Schutzscheiden sich auch an anderen Stellen im Pflanzenkörper bilden können, ist ja bekannt; so findet sich eine Schutzscheide mit CASPARYschen Punkten öfters im sekundären Korkgewebe (99 S. 166); 
ein solches Vorkommen wird doch auch niemand Anlass geben $\mathrm{zu}$ der Aufstellung eines besonderen Stelär-Typus. Aus den. selben Gründen hat Strasburger schon im Jahre 1891 Bedenken geäussert gegen eine ähnliche Auffassung VAN TiEgHeMs, nach der bei den astelen Stengeln das Mark einen Teil der Rinde bilden sollte (98 S. 311.)

Aus dem Gesagten geht also hervor, dass wenn Bretland FARMer und HILL schreiben: „For us it is a matter of absolutely subordinate importance whether there is an internal endodermis or not" (146 S. 396), man gegen einen solchen Standpunkt keine Beschwerden erheben kann; wenn dagegen BREBNER von der "unimportance of the endodermis, pericycle \&c. as morphological criterii" spricht, man ihm hierin nicht beipflichten kann. Denn nicht die histologische Ausbildung, sondern der morphologische Wert der Endodermis kommt hier in Betracht.

Tritt man nun von solchen Gesichtspunkten aus den genannten, abweichenden Ansichten JEFFREYs und anderer näher, so ergibt sich sofort, dass diese nicht durchzuführen sind. Das Mark gehört nicht zur Rinde, sondern stellt ein eigenes Gewebe dar, das sich ganz ungezwungen in die Stele unterbringen lässt. Dass man von: "a strained and artificial criterion as to the boundary of the stele" spricht, rührt nur daher, dass man die Schutzscheide, eine histologische Differenzierung, mit dem morphologischen Begriff der Endodermis vermischt. Dass der Schutzscheide an sich keine morphologische Bedeutung zukommt, wird man BReBNeR gern zugestehen, dass aber die Endodermis eine solche doch besitzt, glaube ich zur Genüge dargetan zu haben.

Von Brebner wurde noch die Arbeit Pitards ( 143) angeführt, aus welcher hervorgehen sollte, dass auch dem Peri- 
cykel morphologisch keine grosse Bedeutung beizumessen sei. Das trifft aber ebenfalls nicht zu. Die Untersuchungen Pitards beziehen sich alle auf das, was Pitard die Evolution des Pericykels nennt; diese Evolution besteht aber nur in den Veränderungen, die der Pericykel in den älteren mehrjährigen Pflanzenorganen erfährt. Hier wird der Pericykel öfters zerrissen, Zellen anderer Gewebe kommen zwischen den Pericykelzellen zu liegen. Diese Erscheinungen sind natürlich sehr merkwürdig, und ein eingehendes Studium ist wohl erwünscht; wenn man aber aus diesen Tatsachen Folgerungen auf morphologischem Gebiet ableiten will, so ist das meines Erachtens von vornherein verfehlt. Ebensowenig als man aus dem Absterben der Epidermis oder der Rinde zu folgern geneigt sein wird, dass diesen Geweben keine morphologische Bedeutung beizumessen ist, wird man auch auf Grund derjenigen Erscheinungen, die auftreten, wenn die Tätigkeit des Pericykels zum grössten Teil zu Ende ist, dasselbe nicht für den Pericykel annehmen.

Den verschiedenen Ansichten dieser Forscher über die Monostelie können wir also in keiner Hinsicht beipflichten; die Auffassung der Monostelie können wir ganz unverändert beibehalten.

Aber nicht nur auf die Monostelie, sondern auch auf die Polystelie sind mehrere Angriffe gemacht worden, und hier mit mehr Recht. Das Entstehen der Polystelie in der jungen Pflanze hatten VAN Tieghem und Douliot wie folgt beschrieben: „Le cylindre central s'aplatit et se divise par le milieu en deux moitiés, qui s'arrondissent, se ferment, s'écartent l'une de l'autre et forment deux stèles distinctes et excentriques".

Wenn dieses wirklich so wäre, so war das eine für die 
Stelär-Theorie äusserst merkwürdige Tatsache. Denn die Selbständigkeit des Centralcylinders würde dann so gross sein, dass diese wirklich Verästelungen aufweisen könnte, wenn der ganze Stengel einfach blieb. Es wäre natürlich immerhin äusserst erwünscht, diesen Vorgang nicht nur aus den ausgebildeten Stadien zu rekonstruieren, sondern ihn selber im Vegetationskegel zu beobachten. Man konnte dann aber wohl nicht anderes annehmen, als dass wirklich die zwei neuen Stelen der einen ursprünglichen Stele beide an sich homolog sein sollten, dass wir somit die echte Poly-Stelie vor uns haben sollten.

Es hat sich indess später aus den Ergebnissen JeFFREYs (127 S. 322) Gwynne-Vaughans (117 S. 613) und anderer Forscher ergeben, dass die Polystelie ganz anders auftritt, und zwar in derselben Weise wie die Astelie.

Es bilden sich über den Stellen, wo die Blattspuren sich in dem Centralcylinder ansetzen, so grosse „Blattlücken” im vaskulären Gewebe des Centralcylinders, dass dieses in mehrere Teile zerlegt erscheint; es bilden sich dann Schutzscheiden um die einzelnen Teile des vaskulären Gewebes. Es ist klar, dass also jede neue "Stele" der alten Stele nicht homolog ist, sie ist einfach die Fortbildung eines Teiles desselben; die ursprüngliche Stele ist vielmehr der Gesamtheit der späteren "Stelen" homolog. Von einer Polystelie ist somit nicht die Rede; der Stengel ist monostel wie zuvor, nur in einer etwas veränderten Form.

Aber auch von anderer Seite sind schon gegen die Polystelie Bedenken erhoben. So hat Ducrock in seiner "Anatomie des Primulacées" (138 S. 20) die Polystelie bei Primula streitig gemacht. Die „Stelen" zeigen nach seiner Untersuchung kein einziges Merkmal, dass sie von konzentrisch angeordneten 
Gefässbündeln unterscheidet; er fasst sie somit auch als solche auf.

Schliesslich hat GwYnne-VaUghín noch beobachtet, dass die Stelen der Primeln häufig an gewissen Stellen ihre konzentrische Anordnung einbüssen, oder, wie er es nennt, „imperfect" sind.

Wir können somit schliessen, dass die Tatsachen hier genügend zeigen, dass man am besten tut, die Auffassung der Polystelie ganz aufzugeben; dass vielmehr die Astelie und die Polystelie Van Tizghems in keiner Hinsicht wesentlich verschieden sind.

Wenn man den Namen Polystelie dennoch beibehalten will, so kann man diesen anwenden auf diejenigen Fälle wie die Orchideenwurzelknollen, wo durch Verwachsen mehrerer Wurzeln ein einheitlicher Körper entsteht, der wirklich mehrere Stelen führt. Bekanntlich bezeichnet aber gerade Van Tieghem diesen Fall nicht als Polystelie, weil er hier durch Verwachsen entstanden ist (68 S. 318).

Der einzige Teil der Stelär-Theorie Van Tieghems, der bis jetzt nur wenig von der Kritik berührt worden ist, ist die Astelie. Zwar ist auch gegen diese Auffassung von JEFFREY vorgebracht, dass die Astelie in der Keimpflanze meistens hervorgeht aus einem Stadium mit „innerer Endodermis”, also aus der Gamodesmie (127 S. 633); einer solchen Bekämpfung kann ich nach der vorhergegangenen Diskussion über den morphologischen Wert der Schutzscheiden natürlich nicht beipflichten. Wichtiger ist, was Strasburger im Jahre 1891 gegen diese Auffassung vorgebracht hat; wie ich schon mitgeteilt habe, hat er mit vollstem Recht hervorgehoben, dass in den astelen Stengeln ein Mark ebensogut vorhanden ist, als in den monostelen; Strasburger betrachtet die astelen Stengel als nicht prinzipiell von den monostelen verschieden. 
Um dieser Meinung einen passenden Ausdruck zu geben, schlägt er statt des Namens Astelie den der Schizostelie vor. Diesen Begriff dehnt er dann aber auch auf die Blätter aus (98 S. 312). Dieser Bezeichnung hat VAN Tieghem selbst sich neuerdings ebenfalls angeschlossen (123, S. 178), ohne aber seine Auffassung zu ändern dass in den nun "schizostelen" Stengeln kein Mark vorkommt. Auch solche Weise ist also nur der Name geändert, nicht die Auffassung.

Ein wesentlicher Unterschied besteht aber zwischen diesen Auffassungen nicht, der Unterschied liegt nur darin, dass Strasburger die Struktur der schizostelen Stengel, in denen ein Mark prinzipiell unterschieden werden muss, ebenfalls auf die Blätter ausdehnt, während VAN TIEghem von der Blattstruktur ausgeht, wo sich nur ein homogenes Mesophyll findet, und dieses nunmehr auch auf die schizostelen Stengel überträgt. Dieser Unterschied nähert sich einem nomenklatorischen. Denn von beiden Forschern werden diese zwei Strukturen, die Schizostelie im Blatte ohne Mark und die Schizostelie im Stengel mit Mark als ein einziger Stelär-Typus betrachtet.

Es fragt sich nun aber, ob solches den wirklichen Verhältnissen entspricht. Sowohl im System VAN TiEghems als in demjenigen STRASBURGERS ist es selbstverständlich, dass diese zwei Strukturen zusammengefasst werden, denn beide Forscher betrachten die Schizostelie in. Stengel und Blatt als durch Zerspaltung der ursprünglichen Stele entstanden. Beide sind somit Abänderungen der Monostelie und fallen unter einen Gesichtspunkt.

Diese Entstehung der Schizostelie aus der Monostelie kann im Stengel nicht bezweifelt werden; die Ergebnisse Jefrreys und anderer beweisen das unzweifelhaft, ausserdem geht es 
schon aus der systematischen Verteilung der Schizostelie im Stengel hervor. (Ranunkel).

Im Blatt liegen die Verhältnisse aber nicht so einfach. Betrachten wir deshalb diese hier etwas näher. In der Spreite findet man immer nur getrenntläufige Gefässbündel mit eigenen Scheiden ausgebildet. In den Nerven und zumal in dem Hauptnerv finden sich grössere Bündel, oder mehrere kleinere, die zusammen in einem Bogen geordnet sind. Je mehr man sich der Basis nähert, um so grösser ist dieser Bogen, die Struktur fängt immer mehr an, sich einem Centralcylinder zu nähern. In einigen Blättern schliesst sich sogar der Bogen oben, an der Rückenseite des Blattes, vollständig, so dass man tatsächlich ganz die Verhältnisse der Monostelie findet, denn ein Pericykel und eine Endodermis sind an der Aussenseite, ein Mark an der Innenseite ausgebildet. In dem Blattstiel endlich herrscht zwar noch meistens die schizostele Struktur des Blattes, aber in relativ vielen Fällen kann man doch auch einen vollständigen Centralcylinder finden. Als Beispiele nennt VaN Tieghem: (101 S. 841) Quercus, Pavia, Magnolia, Ricinus, Paeonia, Aquilegia, Thalictrum, Mahonia, Hedera, Tropaeolum, Geranium, Smilax.

Bei Pinus findet sich sogar die Monostelie in der ganzen. Nadel ausgebildet.

Die Monostelie ist also auch in dem Blatte an vielen Stellen entschieden nachzuweisen, wenn nur die Form des Querschnittes sich dazu eignet, finden wir sie ausgebildet. Kann man nun aus diesen Verhältnissen folgern, dass die Schizostelie hier ebenso wie die im Stengel nur eine Abänderung der Monostelie darstellt, und somit die Schizostelie in Stengel und Blatt als homolog zu betrachten ist?

Diese Frage müssen wir entschieden verneinen. Die Folge- 
rung, dass die schizostele Struktur im Blatte ebenfalls aus der Monostelie entstanden sein sollte, wäre nur erlaubt, wenn dargetan wäre, dass die Blätter der heutigen Pflanzen aus monostelen Blättern hervorgegangen sind.

Nun sind unsere Kenntnisse der Phylogenie aber leider zu dürftig, um uns über diese Frage aufklären zu können. Im Gegenteil wird völlig Raum gelassen für die Auffassung, dass die Blätter von jeher in der Spreite schizostel gewesen sind, und dass somit hier ein ganz anderer Typus vorliegt, ein eigene Struktur, die der Monostelie gleichberechtigt gegenüber steht. Wenn nämlich die Ausbildung der Gefässgewebe und der stelären Strukturen überhaupt erst stattgefunden hat, nachdem eine Differenzierung in Stengel und Blatt schon aufgetreten war, (man denke z. B. an Caulerpa und an die Moose), so ist es sehr gut denkbar, dass sich in der Spreite, der flachen Form entsprechend, von vornherein eine andere Struktur ausgebildet hat als in den runden Stengeln und Blattstielen.

Bis uns also bessere Kenntnisse der Phylogenie der höheren Pflanzen beweisen, dass auch die Schizostelie im Blatte aus der Monostelie hervorgegangen ist, glaube ich, dass wir am besten tun, diese verschiedenen Strukturen auseinanderzuhalten.

Wir können diese Strukturen nun am einfachsten so unterscheiden, dass wir für die Struktur der Blattscheibe den Namen Astelie beibehalten, während wir bei dem Stengel den Namen Schizostelie anwenden.

Letztere Bezeichnung wird also im Sinne Strasburgers gefasst, ein Mark wird dabei immer unterschieden. Es ist nur eine modifizierte Form der Monostelie.

Die Astelie ist vielleicht ebenfalls eine Abänderung der Monostelie, die dann aber von grösserer Bedeutung ist als die Schizostelie, weil sie allgemeiner verbreitet und auch mehr 
modifiziert ist; vielleicht stellt sie aber auch einen prinzipiell abweichenden Stelär-Typus dar.

Wir haben somit in der Blattspreite die Astelie, in dem Blattstiele und in den grösseren Nerven bisweilen die Monostelie. Bei denjenigen Pflanzen, wo diese Monostelie im Stengel als Schizostelie auftritt, haben wir öfters auch in dem Blattstiele und in den grösseren Nerven die Schizostelie; aber auch in anderen Pflanzen haben wir als Übergang zwischen der Monostelie des Stengels und der Astelie des Blattes manchmal die schizostele Struktur im Blattstiele oder in den Nerven.

Wo man nun die Grenze zwischen der Astelie, der Schizostelie und der Monostelie ziehen will, das ist natürlich einigermassen willkürlich; wo man ein Mark beschreiben muss, und wo man nur noch Rinde anerkennen wird, das ist nicht immer genau zu sagen.

Dasselbe würde aber mit jeder Einteilung der Fall sein; auch wenn man die Struktur der Blattspreite als schizostel betrachtete, wäre eine Grenze zwischen dieser Schizostelie und der Monostelie ebensoschwer anzugeben. Das hat übrigens diese Einteilung auch mit vielen anderen, im tiefsten Wesen der Sache begründeten Einteilungen gemein; das kann also ihre Bedeutung nicht beeinflussen.

Wir haben also die folgende Verteilung der Strukturen in den Organen:

Im Blatte:... V Vorzugsweise Astelie, weniger verbreitet Monostelie und Schizostelie.

Im Stengel: ... Monostelie, selten Schizostelie.

In der Wurzel : . Monostelie, selten Polystelie.

Über die weitere Nomenklatur noch folgendes:

Bei der Monostelie haben wir nach Van TIEghem eine Endodermis und ein Pericykel unterschieden, was wir selbst- 
verständlich gern beibehalten werden. Welche Bezeichnungen haben wir aber für die analogen Gewebeteile in den astelen und schizostelen Organen zu wählen? VAN Tieghem selbst benutzt hier Endodermis und Peridesm, Strasburger Phloeoterma und (in den Blättern) Stelolemma. Für die äussere Scheide glaube ich, dass keine von den beiden Bezeichnungen, weder Endodermis noch Phloeoterma, empfohlen werden kann. Ich habe oben schon erörtert (S. 5), weshalb ich die Bezeichnung E'ndodermis über Phloeoterma stelle; aber auch Endodermis scheint mir nicht angebracht zu sein. Wenn man nämlich unter Endodermis nur die innere Rindenschicht der monostelen Organe versteht, so wird dieser Name die Bezeichnung eines morphologisch wichtigen Gewebeteiles; wenn man dagegen auch die Scheiden um die einzelnen Gefässbündel darunter versteht, so wird der Begriff eben wieder zu einem histologischen, statt morphologisch zu bleiben. Ich glaube aber, dass der alte Name Gefässbündelscheide, den NäGELI eingeführt hat, dafür ganz passend sein wird.

Für die pericykelartigen Geweben kann man sich vorteilhaft an Vas Tieghem anschliessen und Peridesm anwenden, eine sehr glückliche, neutrale Bezeichnung.

In dieser Ausführung wird also die ursprüngliche StelärTheorie Van Tieghems in ihren wesentlichsten Punkten unverändert beibehalten, weil doch die Monostelie in Stengel und Wurzel und die Astelie in den Blättern praktisch bei weitem die Mehrzahl der Fälle bilden. Auch die Nomenklatur wird sich nur wenig ändern müssen, weil für die Monostelie Endodermis und Pericykel beibehalten sind, und Peridesm für die Astelie und Schizostelie. Nur dass letztere Bezeichnung nunmehr auch auf die frühere Polystelie ausgedehnt, und nicht mehr bei der Blattscheibe angewendet wird, und dass der 
Name Endodermis auf die Monostelie beschränkt bleibt, sind kleinere Änderungen.

Nur einen Punkt möchte ich zum Schluss noch etwas näher betrachten. Nachdem wir uns von der Auffassung einer entwicklungsgeschichtlichen Basis im Hansteinschen Sinne durch eine genaue Prüfung der Sachlage befreit haben, würde man vielleicht fragen, ob die Endodermis nicht am zweckmässigsten künftig bei dem Centralcylinder unterzubringen sei statt bei der Rinde. Denn wir haben ja gesehen, dass alle die Scheiden in ihrem Auftreten an die Vaskulärgewebe gebunden sind, und dass sie sich diesen immer anschliessen. Von diesen Gesichtspunkten aus wäre es deshalb wohl zu rechtfertigen, die Endodermis zum Centralcylinder zu rechnen.

Ich glaube aber, dass man am besten tut, hierin beim alten zu bleiben. Zwar können wir nicht mehr sagen wie Pitard es tat: "Nous savons maintenant d'une façon positive que l'écorce se termine avec l'endoderme" (143 S. 25). Nur eine Übereinstimmung der VAN TIEghemschen Gewebe mit den Hansteinschen hätte solches sicher feststellen können; nachdem dieses Hilfsmittel aber versagt, ist es eine ziemlich willkürliche Sache, wo man die Grenze ziehen will.

Eine der wichtigsten Gründe, weshalb Van Timahem sie zur Rinde gerechnet hat, wird wohl sein, dass die Endodermis meistens ein rindenartiges Äusseres aufweist, während alle Übergänge zwischen Stärkescheiden, Parenchymscheiden und gewöhnlichen Rindenzelllagen bestehen, so dass die Endodermis sich am natürlichsten an die Rinde anschliesst. 


\section{Zusammenfassung der Ergebnisse und Folgerungen.}

1. Die Übereinstimmung zwischen den Meristemschichten Hansteins und den primären Geweben VaN Tieghems ist sogar in den wenigen Fällen, wo die Hansteinschen Gewebe deutlich erkennbar sind, nicht immer vorhanden.

2. Der Hansteinschen Gewebesonderung kommt keine molphologische Bedeutung zu.

3. Durch das allgemeine Vorkommen eines besonders ausgebildeten Endodermis in Stengel und Wurzel ist die Trenrung zwischen Rinde und Centralcylinder in diesen Teilen scharf markiert.

4. In Stengel und Wurzel der Gefässpflanzen findet sich ein einziger Stelär-Typus, die Monostelie. 


\section{Verzeichnis der benutzten Literatur in chronologischer Anordnung.}

1. H. von Mohl. Ueber die Cambiumschicht des Stammes der Phanerogamen und ihr Verhältniss zum Dickenwachsthum desselben. Bot. Zg., 16. Jahrgang 1858, S. 18 õ.

2. C. A. J. A. Oudemans. Ueber den Sitz der Oberhaut bei den Luftwurzeln der Orchideen. Verhand. d. Kon. Akad. v. Wetensch., Dl. 9, 1861.

3. C. SANio. Ueber endogene Gefässbündelbildung. Bot. Zg., 22. Jahrgang, 1864, S. 193.

4. R. Caspary. Bemerkungen über die Schutzscheide und die Bildung des Stammes und der Wurzel. Pringsheims Jahrbücher, Bd. 4, 1865, S. 101.

5. C. Sanio. Einige Bemerkungen in Betreff meiner über Gefässbündelbildung geäusserten Ansichten. Bot. Zg., 23. Jahrgang, 1865, S. 165.

6. E. Pfitzen. Ueber die Schutzscheide der deutschen Equisetaceen. Pringsheims Jahrbücher, Bd. 6, 1867, S. 297.

7. J. Hanstein. Die Scheitelzellgruppe im Vegetationspunkt der Phanerogamen. Festsch. der Niederrheinischen Ges. für Naturund Heilkunde, T. 3, 1868, S. 109.

8. J. Hanstein. Die Entwicklung des Keimes der Monokotylen und Dikotylen. Hanstein's Bot. Abh., I, 1871.

9. J. Reinke. Untersuchungen über Wachsthumsgeschichte und Morphologie der Phanerogamen-Wurzel. Hanstein's Bot. Abh., I, 1871 .

10. E. Strasburger. Die Coniferen und die Gnetaceen. Jena, 1872. 
11. W. Pfefrerer. Zur Blüthenentwicklung der Primulaceen und Ampelideen. Pringsheims Jahrbücher, 8. Bd. 1872 , S. 194.

12. Ph. Van Tieghem. Mémoire sur les canaux sécréteurs des plantes. Ann. des Sc. nat., Bot. 5ième Sér., T. 16, 1872, S. 96.

13. C. HAGEN. Untersuchungen über die Entwicklung und Anatomie der Mesembryanthemeen. Inaug. Diss. Bonn, 1873.

14. J. Reinke. Zur Kenntniss des Rhizoms von Corallorhiza und Epipogon. Flora, 1873.

15. F. Fleischer. Beiträge zur Embryologie der. Monokotylen und Dikotylen. Flora, 1874, S. 369.

16. E. DE JANCZEWSKI. Recherches sur l'accroissement terminal des racines dans les phanérogames. Ann. des Sc. nat., Bot. 5ième Sér. T. 20, 1874, S. 162.

17. E. DE JANCZEWSKI. Recherches sur le développement des radicelles. Ann. des Sc. nat., Bot. 5ième Sér. T. 20, 1874, S. 208.

18. J. Sachs. Lehrbuch der Botanik. 4. Aufl. Leipzig 1874.

19. F. Schmitz. Beobachtungen über die Entwicklung der Sprossspitze der Phanerogamen, I. Habilitationsschrift, Halle-Wittenberg, 1874.

20. J. Vesque. Mémoire sur l'anatomie comparée de l'écorce. Ann. des Sc. nat., Bot., 6ième Sér., T. 2, 1875, S. S2.

21. H. Voechting. Der Bau und die Entwickelung des Stammes der Melastomeen. Hanstein's Bot. Abh., 3. Bd. 1875.

22. E. WARMing. Recherches sur la ramification des Phanérogames principalement au point de vue de la partition du point végétatif. Kongelige Danske Videnskabernes Selskabs Skrifter, Femte raekke, Tiende Bind, 1875.

23. J. ERIKsson. Ueber den Vegetationspunkt der DicotylenWurzeln. Bot. Zg., 34. Jahrgang, 1876, S. 641.

24. P. FAlKenberg. Vergleichende Untersuchungen über den Bau der Vegetationsorgane der Monocotyledonen. Stuttgart, 1876.

25. M. Treub. Le méristème primitif de la racine dans les Monocotylédones. Musée Botan. de Leide, 'T. 2, Leiden, 1876. 
26. J. E. WEIss. Wachsthumsverhältnisse und Gefässbündelverlauf der Piperaceen. Inaug. Dissert., Regensburg 1876.

27. M. Westermaier. Die ersten Zelltheilungen im Embryo von Capsella bursa pastoris M., Flora, 1876, No. 31, S. 483.

28. A. DE BARY. Vergleichende Anatomie der Vegetationsorgane der Phanerogamen und Farne. Leipzig, 1877.

29. R. Caspary. Etwas über die Schutzscheide. Bot. Zg., 35. Jahrgang, 1877, S. 185.

30. J. ERIKsson. Om Meristemet i dikotyla växters rötter. Lunds Universitets Arsskrift, Tom. 13, 1877, S. 1.

31. C. von NägeLI. Ueber das Scheitelwachsthum der Phanerogamen. Amtlicher Bericht der 50. Versammlung Deutscher Naturforscher und Aerzte in München, 1877, S. 203.

32. Nägeli und Schwendener. Das Microscop. 2. Aufl., Leipzig, 1877.

33. G. Dutailly. Observations sur le Menyanthes et l'Hydrocleis. Bull. mens. d. 1. Soc. Linnéenne de Paris, 1878.

34. J. ERIKsson. Ueber das Urmeristem der Dikotylen-Wurzeln. Pringsheims Jahrb., 11, 1878, S. 380.

35. Ch. Flahault. Recherches sur l'acroissement terminal de la racine chez les phanérogames. Ann. des Sc. nat., Bot., 6ième Sér. T. 6,1878 , S. 1.

36. A. Guilland. Recherches sur l'anatomie comparée et le développement des tissus de la tige dans les Monocotylédones. Ann. des Sc. nat., Bot., 6ième Sér., T. 5, 1878.

37. F. Hegelmaier. Vergleichende Untersuchungen über Entwicklung dikotyledoner Keime mit Berücksichtigung der pseudomonokotyledonen. Stuttgart, 1878.

38. J. SACHS. Ueber die Anordnung der Zellen in jüngsten Pflanzentheilen. Arbeiten des Bot. Instit. in Würzburg. Bd. 2, S. $46,1878$.

39. J. E. Weiss. Ueber die Schutzscheide der Polypodiaceen. Flora, 1880. 
40. L. Guignard. Recherches d'embryogénie végétale comparée. Premier mémoire: Légumineuses. Ann. des Sc. nat., Bot., 6ième Sér. T. 12, 1881, S. 5.

41. K. NörNer. Beitrag zur Embryoentwicklung der Gramineen. Flora, Bd. 64, 1881.

42. J. SAcHs. Vorlesungen über Pflanzenphysiologie. Leipzig, 1882.

43. S. Schwendener. Ueber das Scheitelwachsthum der Phanerogamen-Wurzeln. Sitzungsber. der K. Preuss. Akad. der Wissensch. zu Berlin, Jahrgang 1882, 1. Halbband, 1882, S. 183.

44. Ph. Van Tieqhem. Sur quelques points de l'anatomie des Cucurbitacées. Bull. de la Soc. Bot. de France, T. 29, 1882, S. 277.

45. F. Delpino. Teoria generale della fillotassi. Genova, 1883.

46. J. Costantin. Recherches sur la structure de la tige des plantes aquatiques. Ann. des Sc. nat., Bot., 6ième Sér., T. 19, 1884, S. 287.

47. E. Dennert. Beiträge zur vergleichenden Anatomie des Laubstengels der Cruciferen. Inaug. Diss., Marburg, 1884.

48. Ph. Van Tieghem et L. Morot. Anatomie des Stylidées. Ann. des Sc. nat., Bot., 6ième Sér. T. 19, 1884, S. 281.

49. G. Bonnier. Remarques sur le développement et la structure des rhizomes d'Anemone nemorosa. Bull. de la Soc. bot. de France, T. 32, 1885, S. 167.

50. P. Groom. Ueber den Vegetationspunkt der Phanerogamen. Ber. der d. bot. Ges., Bd. 3, 1885, S. 303.

51. P. MARIÉ. Recherches sur la structure des Renonculacées. Ann. des Sc. nat., Bot., 6ième Sér., T. 20, 1885, S. 5.

52. L. Мовот. Recherches sur le péricycle ou couche périphérique du cylindre central chez les phanérogames. Ann. des Sc. nat., Bot. 6 ième Sér., T. 20, 1885, S. 217.

53. S. ScHWENDENER. Ueber Scheitelwachsthum und Blattstellungen. Sitzungsber. der kön. Preuss. Akad. der Wissensch. zu Berlin, 1885, 2. Halbband, S. 921. 
54. Ph. Van Tieghem. Observations sur la structure des Cabombées. Bull. de la Soc. bot. de France, T. 32, 1885, S. 380.

55. P. Vuiluemin. Sur le péricycle des Caryophyllées. Bull. de la Soc. bot. de France, T. 32,1885 , S. 275.

56. J. d'Arbaumont. Note sur le péricycle. Bull. de la Soc. bot. de France, T. 33, 1886, S. 141.

58. H. Douliot. Note sur la structure des Crassulacées. Bull. de la Soc. bot. de France, T. 33, 1886.

59. A. W. Eichler. Ueber die Verdickungsweise des Palmenstammes. Sitzungsber. d. kön. Preuss. Akad. d. Wissensch. zu Berlin, 1886, S. 501.

60. G. Karsten. Ueber die Anlage seitlicher Organe bei den Pflanzen. Inaug. Diss., Rostock, 1886.

61. P. Maury. Études sur l'organisation et la distribution géographique des Plombaginacées. Ann. des Sc. nat., Bot., 7ième Sér., T. 4, 1886 , S. 1.

62. L. Моrot. Réponse à la note de M. D’Arbaumont sur le péricycle. Bull. de la Soc. bot. de France, T. 33, 1886, S. 204.

63. Ph. Van Tieghem. Sur la croissance terminale de la racine dans les Nymphéacées. Bull. de la Soc. bot. de France, T. 33, 1886, S. 264.

64. Ph. Van Tieghem. Erwiderung auf 56. (Siehe oben). Bull. de la Soc. bot. de France, T. 33, 1886, S. 151.

65. Рн. Van Tieghem. Sur l'appareil sécréteur et les affinités de structure des Nymphéacées. Bull. de la Soc. bot. de France, T. 33, 1886, S. 72 .

66. Ph. Van Treghem. Structure de la tige des Primevères nouvelles du Yun-Nan. Bull. de la Soc. bot. de France, T. 33, 1886 , S. 95.

67. Ph. Van Tieghem et H. Douliot. Sur les tiges à plusieurs cylindres centraux. Bull. de la Soc. bot. de France, T. 33 , 1886 , S. 213. 
68. Ph. Van Tieghem et H. Douliot. Sur la polystélie. Ann. des Sc. nat., Bot., 7ième Sér., T. 3, 1886, S. 275.

69. P. Vuillemin. L'exoderme. Bull. de la Soc. bot. de France, T. 33,1886 , S. 80 .

70. P. Vuildemin. L'endoderme de Senecio Cineraria. Bull. de la Soc. bot. de France, T. 33, 1886.

71. M. W. Beyerinck. Beobachtungen und Betrachtungen über Wurzelknospen und Nebenwurzeln. Verh. der Kon. Akad. van Wetensch. te Amsterdam, Dl. 25, 1887.

72. Dangeard et BarbÉ. La polystélie dans le genre Pinguicula. Bull. de la Soc. bot. de France, T. 34, 1887.

73. A. Dumont. Recherches sur l'anatomie comparée des Malvacées, Bombacées, Tiliacées, Sterculiacées. Ann. des Sc. nat., Bot., 7ième Sér., T. 6, 1887, S. 129.

74. Lignier. Recherches sur l'anatomie comparée des Calycancanthacées, des Melastomacées et des Myrtacées. Paris, 1887.

75. Ph. Van Tieghem. Structure de la racine et disposition des radicelles dans les Centrolepidées, Ériocaulées, Joncées, Mayacées et Xyridées. Journ. de Bot., 1, 1887, S. 305.

76. Ph. Van Tieghem. Sur la limite du cylindre central et de l'écorce dans les Cryptogames vasculaires. Journal de Bot., 2, 1888 , S. 369.

77. Ph. Van Tifghem. Sur le dédoublement de l'endoderme dans les Cryptogames vasculaires. Journ. de Bot., 2, 1888, S. 404.

78. Ph. Van Tieghem et H. Douliot. Recherches comparatives sur l'origine des membres endogènes dans les plantes vasculaires. Ann. des Sc. nat., Bot., 7ième Ser., T. 8, 1888, S. 1.

79. Ph. Van Tieghem et H. Douliot. Origine, structure et nature morphologique des tubercules radicaux des légumineuses. Bull. de la Soc. bot. de France, T. 35, 1888, S. 105.

80. Leclerc du Sablon. Sur l'endoderme de la tige des Sélaginelles. Journ. de Bot., 3, 1889, S. 207.

81. A. Tschirch. Angewandte Pflanzenanatomie. Wien und Leipzig, 1889. 
82. J. H. WAKRER. Bau und Dickenwachsthum des Stengels von Abrus precatorius. Bot. Zg., 47. Jahrgang, 1889, S. 629.

83. H. Douliot, Recherches sur la croissance terminale de la tige des Phanérogames. Ann. des Sc. nat. Bot., 7ième Sér., T. 11, 1890 , S. 283.

84. M. Thouvenin. Recherches sur la structure des Saxifragacées. Ann. des Sc. nat., Bot., 7ième Sér., T. 12, 1890, S. 1.

85. Ph. VAN Tieghem. Remarques sur la structure de la tige des prêles. Journ. de Bot., 4, 1890, S. 365.

86. Ph. Van Tieghem. Remarques sur la structure de la tige des Ophioglossées. Journ. de Bot., 4, 1890, S. 405.

87. Ph. Van Tieghem. Péricycle et péridesme. Journ. de Bot., 4, 1890, S. 433.

88. E. Warming. Handbuch der systematischen Botanik. Deutsch von E. Knoblauch, Berlin, 1890.

92. D. H. Sсотт. On some points in the Anatomy of Ipomoea versicolor, Meissn. Ann. of Botany, Vol. 5, 1890-'91, S. 173.

93. D. H. Sсотт. On the origin of Polystely in Dicotyledons. Ann. of Botany, Vol. 5, 1890-91, S. 5̃14.

94. H. DоuLiot. Recherches sur la croissance terminale de la tige et de la feuille chez les Graminées. Ann. des Sc. nat., Bot., 7 ième Sér., T. 13, 1891, S. 93.

95. L. Косн. Ueber Bau und Wachsthum der Sprossspitze der Phanerogamen, I. Die Gymnospermen. Pringsheims Jahrbücher 22. Bd., 1891, S. 491.

96. C. Sauvageau. Sur la tige des Zostera. Journ. de Bot., 5, 1891, S. 33.

97. C. Sauvageau. Sur la tige des Cymodocées Aschs. Journ. de Bot., 5, 1891, S. 205.

98. E. Strasburger. Ueber den Bau und die Verrichtungen der Leitungsbahnen in den Pflanzen. Histologische Beiträge, Heft 3, 1891. 
99. Рн. Van Tieghem. Un nouvel exemple de tissu plissé. Journ. de Bot., 5, 1891, S. 165.

100. Ph. Van Tieghem. Sur la structure et affinités des Mémécylées. Ann. des Sc. nat., Bot., 7ième Sér., 'T. 13, 1891, S. 23.

101. Ph. Van Tieghem. Traité de Botanique. Paris, $2^{i e ̀ m e ~ E ́ d ., ~}$ 1891.

102. A. Drerer. Beitrag zur Kenntniss der Funktion der Schutzscheide. Inaug. Diss., Jena, 1892.

103. A. B. Frank. Lehrbuch der Botanik. Leipzig, 1892.

104. J. W. Moll. Das Mikrotom Reinhold-Giltay. Zeitschr. für wiss. Mikroskopie, 9, 1892 , S. 445.

105. Briquet. Monographie du genre Galeopsis. Bruxelles, 1893.

106. A. Bolles Lee. The Microtomist's Vade-mecum. London, 1893.

107. O. G. Petersen. Bemaerkninger om den monokotyledone Staengels Tykkelsevaext og anatomiske Regioner. Botanisk Tidskrift, 18. Bind, 3. Haefte, 1893.

108. Ph. Van Tieghem. Recherches sur la structure et les affinités des Thyméléacées et des Pénéacées. Ann. des Sc. nat., Bot., 2 e Sér., T. 17, 1893, S. 185.

109. L. Frot. Recherches sur la zone périmédullaire de la tige. Ann. des Sc. nat., Bot., 7ième Sér., T. 18, 1893, S. 37.

110. L. A. Boodle and W. C. Worsdell. On the Comparative Anatomy of the Casuarinae, with special reference to the Gnetaceae and Cupuliferae. Ann. of Botany, vol. 8, 1894, S. 231.

111. L. Косн. Ueber Bau und Wachsthum der Wurzelspitze von Angiopteris evecta Hoffm. Pringsheims Jahrbücher, Bd. 27, 1895 , S. 369.

112. S. BeLLI. Endoderma e periciclo nel G. Trifolium in rapporta colla teoria della stelia di V. Tieghem e Douliot. Memorie della Reale Accademia delle Scienze di Torino, Serie seconda, T. 46,1896 , S. 35:3. 
113. D. T. Gwynne-Vaughan. A new Case of Polystely in Dicotyledons. Ann. of Botany, vol, 10, 1896, S. 289.

114. D. T. Gwrnne-Vaughan. The Arrangement of the vascular bundles in certain Nympheaceae. Ann. of Botany, vol. 10, 1896 , S. 624.

115. G. HaberLandt. Physiologische Pflanzenanatomie, 2. Aufl., Leipzig, 1896.

116. I. Baranetziky. Sur le développement des points végétatifs des tiges chez les Monocotylédones. Ann. des Sc. nat., Bot., 8ième Sér., T. 3, 1897, S. 311.

117. D. T. Gwrnne-Vaughan. On Polystely in the Genus Primula. Ann. of Botany, vol 11, 1897, S. 307.

118. E. C. Jefrerey. The Morphology of the Central Cylinder in Vascular Plants. Report British Association, 1897, Toronto, S. 869.

119. E. Strasburger. Das botanische Practicum, 3. Aufl., Jena, 1897.

120. J. W. MoLL. Einige Verbesserungen am Mikrotom Reinhold-Giltay. Zeitschr. für wiss. Mikroskopie, 15, 1898, S. 23.

121. E. Perrot. Anatomie comparée des Gentianacées. Ann. des Sc. nat., Bot., 8ième Sér., T. 7, 1898, S. 105.

122. Strasburger, Noll, Schenck und Schjmper. Lehrbuch der Botanik, 3. Auflage, Jena, 1898.

123. Рh. Van Tieghem. Eléments de Botanique, zième Edition, Paris, 1898.

124. M. Westermater. Ueber die ersten morphologischen Differenzirungen am Phanerogamen-Keimling. Compte-Rendu du quatrième Congrès Scientifique international des Catholiques tenu à Fribourg, 1897; Fribourg, 1898.

125. G. Fron. Recherches anatomiques sur la racine et la tige des Chénopodiacées. Ann. des Sc. nat., Bot., 8ième Sér., T. 9, 1899, S. 157. 
126. E. C. Jefremey. The Development, Structure, and Affinities of the Genus Equisetum. Memoirs of the Boston Society of natural History, vol 5, No. 5, 1899, S. 155.

12\%. E. C. Jeffrex. The Morphology of the Central Cylinder in the Angiosperms. Trans. of the Canad. Inst., vol 6, 1899, S. 599 .

128. H. SOLEREDER. Vergleichende Anatomie der Dicotyledonen, Stuttgart, 1899.

129. I. Baranetsky. Recherches sur les faisceaux bicollatéraux. Ann. des Sc. nat., Bot., 8ième Sér. T. 12, 1900, S. 261.

130. C. Brunotte. Recherches embryogéniques et anatomiques sur quelques espèces d'Impatiens et de Tropaeolum. Thèse Sciences nat., Paris, No. 1039, 1900.

131. H. Fischer. Der Pericykel in den freien Stengelorganen. Pringsheims Jahrbücher, 35. Bd., 1900, S. 1.

132. L. Fцот. Sur l'origine commune des tissus dans la feuille et dans la tige des Phanérogames. Comptes rendus, 81, 1900, 2, p. 1319.

133. L. Hering. Zur Anatomie der monopodialen Orchideen. Inaug. Diss., Heidelberg 1900 (und Bot. Centralbl., Bd. 84, 1900).

134. E. Pritzel. Lycopodiaceae, in Engler und Prantl, Die natürlichen Pflanzenfamilien I, 4. Abt 1900, S. 563.

135. C. DAvid. Étude anatomique du genre Bupleurum. Thèse Pharm, Paris, No. 7, 1900-'01.

136. M. Mirande. Recherches physiologiques et anatomiques sur les Cuscutacées. Thèse Sciences nat., Paris, No. 1044, 1900-'01.

137. F. Rouanet. Étude botanique et chimique du Cynanchum monspeliacum. Thèse Pharm., Montpellier, No. 11, 1900-'01.

138. E. Decrock. Anatomie des Primulacées. Ann. des Sc. nat., Bot., 8ième Sér. T. 13, 1901., S. 1.

139. J. H. FAULL. The Anatomy of the Osmundaceae. Bot. Gazette, Dec. 1901, vol. 32, S. 381.

140. D. T. GWYnne-Vaughan. Observations on the Anatomy of Solenostelic Ferns. Ann. of Botany, 1901, vol. 15, S. 71. 
141. T. Holm. Eriocaulon decangulare. An anatomical Study. Bot. Gazette, vol. 31, 1901, S. 17.

142. F. X. LANG. Untersuchungen über Morphologie, Anatomie und Samenentwickelung von Polypompholyx und Byblis gigantea. Inaug. Diss., München, 1901, (und Flora 1901, Bd. 88).

143. J. C. M. Pitard. Recherches sur l'évolution et la valeur. anatomique et taxinomique du péricycle des Angiospermes. Thèse. Pharm, Bordeaux No. 14, 1901.

144. E. Warming. Den almindelige Botanik. Fjerde udgave, Kjöbenhavn, 1901.

145. G. Brebner. On the Anatomy of Danaea and other Marattiaceae. Ann. of Botany, vol. 16, 1902, S. 517.

146. J. Bretland Farmer and T. G. Hill. On the Arrangement and Structure of the Vascular Strands in Angiopteris evecta, and some other Marattiaceae. Ann. of Botany, vol. 16, 1902, S. 371.

147. S. O. Ford. The Anatomy of Ceratopteris thalictroides. Ann. of Botany, vol. 16, 1902, S. 95 .

148. E. C. Jefrrey. The Structure and Development of the Stem in the Pteridophyta and Gymnosperms. Philos. Transactions, vol. 195, 1902, S. 119.

149. F. Joesting. Beiträge zur Anatomie der Sperguleen, Polycarpeen, Paronychieen, Sclerantheen und Pterantheen. Beih. zum Bot. Centralbl., Bd. 12, 1902, s. 139.

150. J. C. Schoute. Über Zellteilungsvorgänge im Cambium. Verh. Kon. Akad. v. Wetenschappen te Amsterdam, Dl. 9, 1902, No. 4.

151. A. G. Tansley and R. B. Lulham. On a new Type of Fernstele, and its probable phylogenetic Relations. Ann. of Bot., vol. 16, 1902 , S. 157.

152. W. C. Worsdell. The Evolution of the Vascular Tissue of Plants. Bot. Gazette, vol. 34, 1902, S. 216.

153. J. C. Schoute. Die Stammesbildung der Monokotylen. Flora, 92, 1903, S. 32. 
N A C H T A G.

154. J. SAchs. Ueber das Auftreten der Stärke bei der Keimung ölhaltiger Saamen. Bot. Zg., 17. Jahrgang, 1859, S. 177.

155. Ph. van Tieghem. Anatomie de la Moschatelline (Adoxa moschatellina L.). Bull. de la Soc. bot. de France, T. 27, 1880.

156. E. C. Jeffrex. A Theory of the Morphology of Stelar Structures. Proc. of the Royal Society of Canada, 1896, S. 106.

157. G. Haberlandt. Ueber die Perception des geotropischen Reizes. Ber. der d. Bot. Ges., 18. Jahrgang, 1900, S. 261.

158. L. A. Boodue. Comparative Anatomy of the Hymenophyllaceae, Schizaeaceae and Gleicheniaceae: I. On the Anatomy of the Hymenophyllaceae. Ann. of Botany, Vol 14, 1900 , S. 455.

159. Id. II. On the Anatomy of the Schizaeaceae, vol. 15, 1901, S. 359 .

160. Id. III. On the Anatomy of the Gleicheniaceae, vol. 15, 1901 , S. 703. 



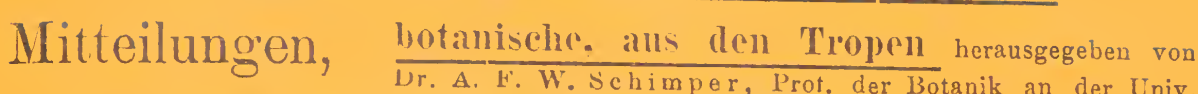
Bonn. 9 Hefte. 1888-1901. Lex.-Form. Preis: 109 Mark.

Heft I: Schimper, A. F. W., Die Wechselbeziehungen zwischen Pllanzen und Ameisen im trop. Amerikia. 1888, 97 s. mit 3 Tafelu. Preis: 4 IIark $50 \mathrm{Pf}$. (Vergriffen.)

Heft II: Sch imper, A. F. W., Die epiphytische Vegetation Amerikas. Mit 6 Tafeln, 1888. Preis: 7 Mark 50 Pf.

Heft III: Schimper, A. F. W., Die indo-malayische Strandflora. Mit 7 Textfiguren. 1 Karte und 7 Tafeln. 1891. Preis: 10 Mark.

Heft IV: Schenck. H., Dr., Privatdocent a. d. Univ. Bonn, Beiträige zur Biologie und Anatomie der Lianen, im besonderen der in Brasilien einheimischen Arten. I. Teil: Beiträge zur Biologie der Liauen. Mit 7 Tafeln. 1892. Preis: 15 Mark.

Heft $V$ : Schenck, H., Beitrage zur Biologie und Anatomie der Lianen, im besonderen der in Brasilien einheimischen Arten. Il. Teil: Beiträge zur Anatomie der Lianen. Mit 12 Tafeln u. 2 Text-Zinkograph. 1893. Preis: 20 Mark.

Heft VI: Möller, Alfred, Die Pilzgiirten einiger amerikaniseher Ameisen. Mit 7 Tafeln u. 4 Holzschnitten. 1893, Preis: 7 Mark. (Vergriffen.)

Heft YIl: Iöller, Alfred, Brasilische Pilzblumen. Mit 8 Tafeln. 1895. Preis : 11 Mark.

Heft VIII: Müller, Alfred, Protobasidiomyceten. Untersuchungen aus Brasilien. Mit 6 Tafeln. 1895. Preis: 10 Mark.

Heft IX: Möller, A Ifred, Phycomyceten und Ascomyceten. Untersuchungen aus Brasilien. Nit 11 Tafeln und 2 Textabbildungen. 1901. Preis: 24 Mark.

Möbius, Prof. Dr. M., in Frankfurt a. M., Beitråge zur Lehre ron der Fortpflanzung der Genächse. Nit 36 Abbildungen im Text. 1897. Preis: 4 Mark 50 Pf.

Molisch Dr. Hans, Prof. d. Botanik und Vorstand des pflanzenphysiolog. Instituts , der Univ. Prag, Studien iiber den Milchsatt und Schleimsaft der Pflanzen. Mit 33 Holzschnitten im Text. 1901. Preis: 4 Mark.

Grundriss einer IIstochemie der planzlichen Genussmittel. Mit

15 Holzschnitten. 1891. Preis: 2 Mark.

- Untersuchungen iiber das Erfrieren der Pflanzen. Mit 11 Holzschnitten im Text. 1897. Preis: 2 Mark 50 Pf.

Die Planze in ihren Bezichungen zum Eisen. Eine physiologische Studie. Mlit 1 Tatel. 1892. Preis: 3 Mark.

Néme Dr. B., Privatdozent der Botanik an der k. k. böhmischen Univ. in Prag, Nemec, Die Reizleitung und die reizleitenden Strukturen bei den Pflanzen. Mlit 3 Tafeln u. 10 Abbildungen im Text. 1901. Preis: 7 Mark.

Orelton, Dr., Privatdozent der Biologie und Assistent der Botanik an der Universität $Z$ ürich, Studien iiber die Yarkose, zugleich ein Beitrag zur allgemeinen Pharmakologie. 1901. Preis: 4 Mark 50 Pf.

Potoní́, Dr. H., Kgl. preuss. Landesgeolog und Professor, bezw. Privatdozent der Eilla Palabotanik an der Kgl. Bergakademie und der Universität zu Berlin, Elin Blick an Geschichte der Worphologie und die Pericaulom.Theovie. Erweiterter Abdruck aus der naturwissenschaftlichen Wochenschrift. Neue Folge. II. Band, der ganzen Reibe XVIII. Band. Mit 9 Abbildungen. Preis: 1 Mark. 
Pringsheim, N., Gesammelte Abhandlungell. Herausgegeben von and Systematik der Ilgen. Mit einem Bildnis des Verfassers und 28 lithographischen Tofeln. Preis: 20 Mark.

Zweiter Band: Phycomyceten, Charen, Moose, Furne. Mit 32 lithographischen Tafeln. Preis: 15 Mark.

Dritter Band: Zellenbau, Morphologisches, Ilistorisches. Mit 13 lithographischen Tafeln. Preis: 12 Mark.

Vierter Band: Chlorophyll, Assimilation, Lichtwirkung, Sanerstoffabgabe, 0smotische Versuche. Mit 22 lithographischen Taleln und 7 Abbildungen im Text. Preis: 13 Mark.

Schimper, Dr. A. F. W., a. o. Professor an der Universität Bonn, Pflanzen502 als Tufeln oder $m$ den Text gedruckten Abbudungen in Autotypie, 5 in Lichtdruck und 4 geographischen Karten. 1898. Preis: brosch. 27 Mark, elegant in Halbfranz geb. 30 Mark.

\section{Schniewind-Thies, s, Die Redulition der Chromosomenzahl}

Emhryosaclimutterzellen. Nit 5 lithographischen Tafeln, 1901. Preis: 7 Mark.

Schulz, Dr. Fr. N., a. o. Professor an der Universität Jena, Praktikum der dungen im Text. 1901. Preis: brusch. 2 Mark, gebunden 2 Mark 50 Pf.

Studien zur Chemie der Eiweissstoffe. Erstes II eft: Die Krrstallisation ron Eiweisstollen und ihre Bedentung fiir die Eiweisschemie. 1901. Preis: 1 Mark $20 \% \mathrm{f}$. $Z \mathrm{w}$ e it e s $\mathrm{H}$ ef $\mathrm{t}$ : Die Grösse des Eiweissmolekiils. 1902. Preis: 2 Mark 50 Pf.

Strashuro Dr. Eduard, o. ö. Professor der Botanik an der Universität Bonn, Strasbulgo'el, Histologische Beitriac. Heft 1-6. 1888-1900.

Heft 1: Ueber Kern- und Zellteilung im Planzenreiche nebst einem Anhang über Befruchtung. Mit 3 lithographischen Tafeln. Preis: 7 Mark.

Heft 2: Ueber das Wachstum regetabilischer Zellhinte. Mit 4 lithographischen Tafeln. Preis: 7 Mlark.

Heft 3: Ceber den Ban und die Yerrichtungen der Leitungsbahnen in den Pflanzell. Nit 5 lithographischen Tafeln und 17 Abbildungen im Text. Preis: 24 Nark.

Heft 4: Leber das Yerhalten des Polleus und die Befruchtungstorginge bei den Gymospermen. - Schwämsporen, Gameten, pflambliche spermatozoiden und das Wesen der Befruchtung. Mit 3 lithogr. Tateln. Preis: 7 Mark.

Heft 5: Ueber das Saltsteigen. - Ueber die Wirkungssphaire der Kerne und die Zellgrösse. Preis: 2 Mark 50 Pt.

Heft 6: Ueber Reduktionsteilung, Spindelbildung, Centrosomen und Cilienbildner im Pflanzenreich. Mit 4 lithograph. Tafeln, 1900. Preis: 10 Mark 50 Pf,

Das botanische Praktikum. Anleitung zum Selbststudium der mikroskopischen Butanik. Fiur Antäuger und Geübtere. Zugleich ein Handbuch der mikroskopischen Technik. Vierte Auflage. Mit 230 Holzschnitten. Preis: 20 Mark, geb. 22 Mark 50 Pf. 






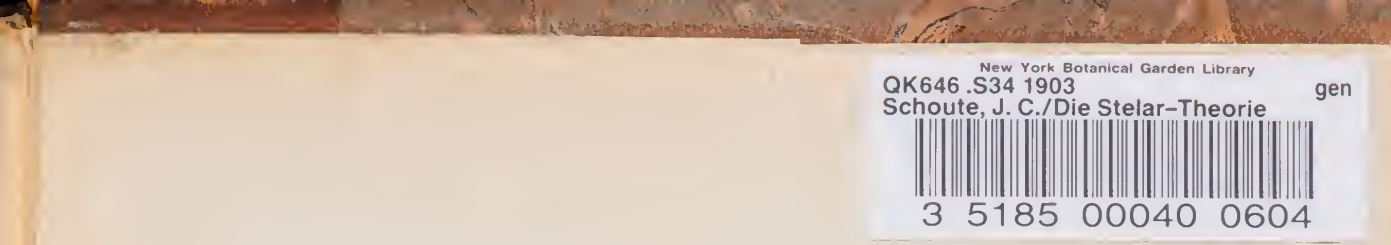




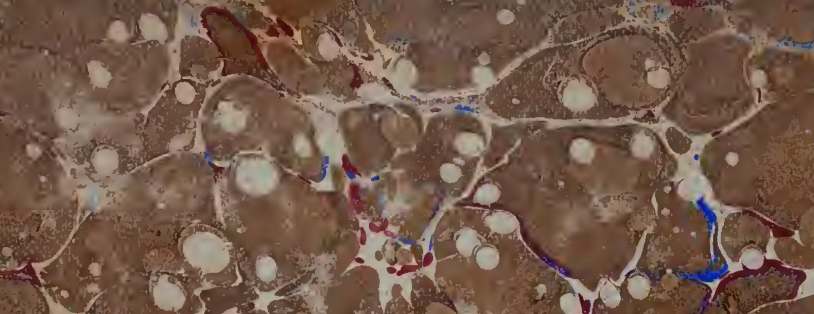

40 1.

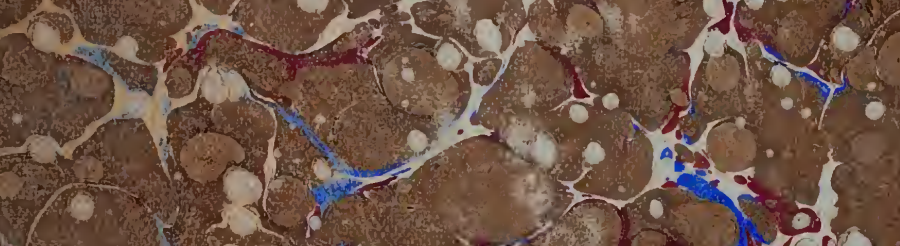
ol

Q

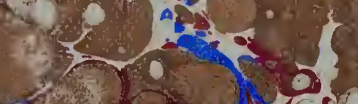

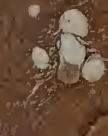
20

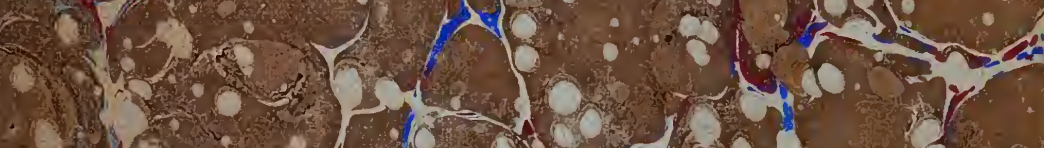

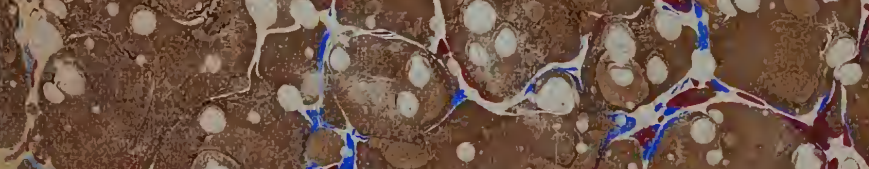

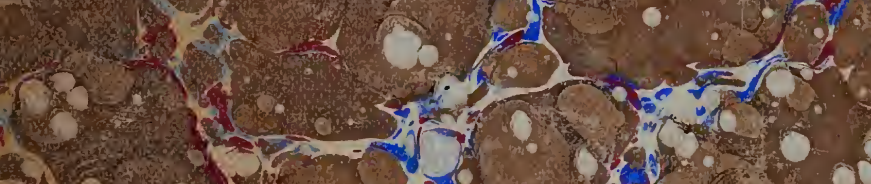

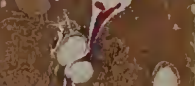

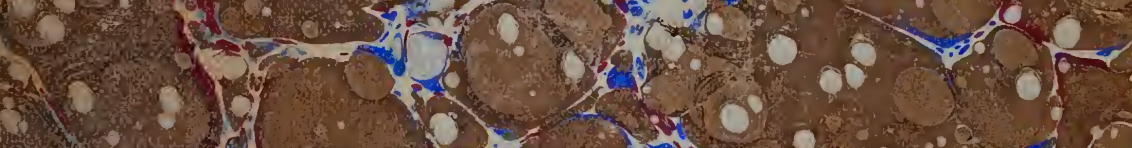
S.

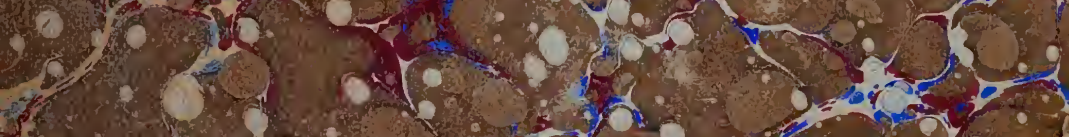
(3.

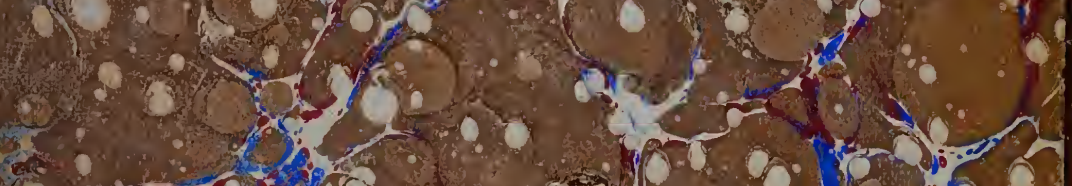

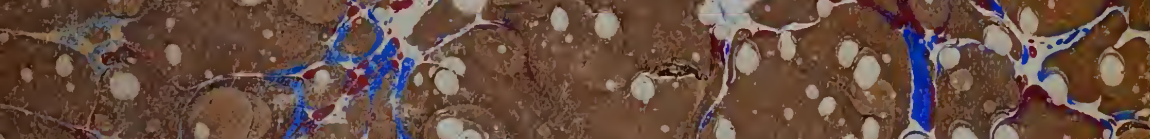

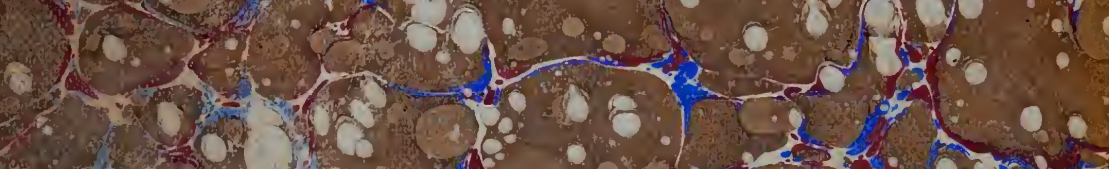

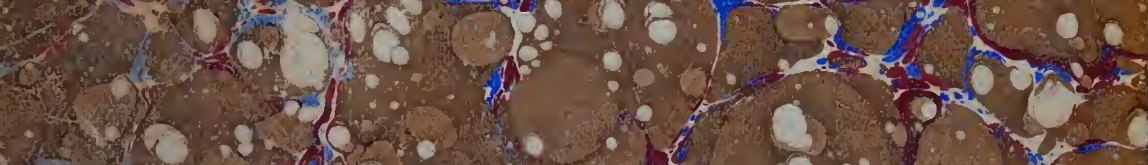

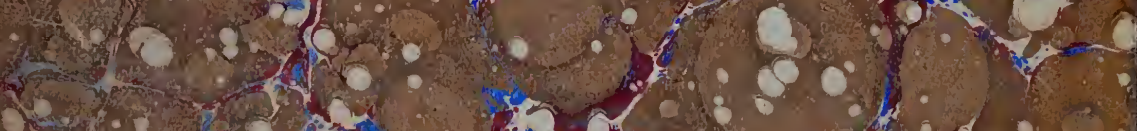

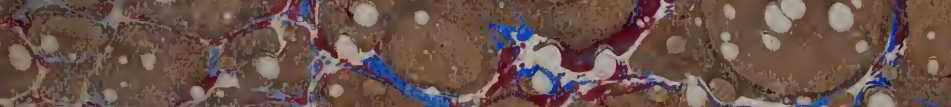

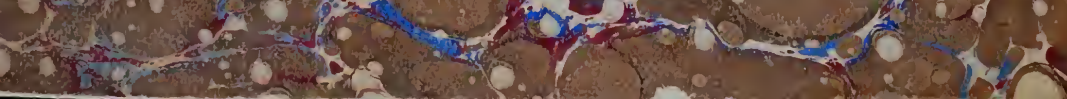

